\title{
MAPEAMENTO DA VARIAÇÃO REGIONAL DA RESISTÊNCIA ADESIVA EM SUPERFÍCIES PLANAS DE DENTINA
}

RAQUEL SANO SUGA TERADA

Tese apresentada à Faculdade de Odontologia de Bauru, da Universidade de São Paulo, como parte dos requisitos para obtenção do título de Doutor em Odontologia, na Área de Dentística.

(Edição Revisada) 


\section{MAPEAMENTO DA VARIAÇÃO REGIONAL DA RESISTÊNCIA ADESIVA EM SUPERFÍCIES PLANAS DE DENTINA}

RAQUEL SANO SUGA TERADA

Tese apresentada à Faculdade de Odontologia de Bauru, da Universidade de São Paulo, como parte dos requisitos para obtenção do título de Doutor em Odontologia, na Área de Dentística.

Orientador: Prof. Dr. Ricardo Marins de Carvalho

\section{BAURU}

2001 
T391a Mapeamento da variação regional da resistência adesiva em superfícies planas de dentina. / Raquel Sano Suga Terada.

Bauru, 2001.

176p.:il. : $30 \mathrm{~cm}$.

Tese (Doutorado) Faculdade de Odontologia de Bauru. USP.

Orientador: Prof. Dr. Ricardo Marins de Carvalho

Autorizo, exclusivamente para fins acadêmicos e científicos, a reprodução total ou parcial desta Tese, por processos fotocopiadores e/ou meios eletrônicos.

Assinatura do autor:

Data: 


\section{RAQUEL SANO SUGA TERADA}

17 DE DEZEMBRO DE 1967 - Nascimento - Tupã/São Paulo

Filiação : Júlio Suga

Suzuye Sano Suga

\begin{tabular}{|l|l|}
\hline $1986 / 1989$ & $\begin{array}{l}\text { Curso de Graduação em Odontologia na Faculdade de } \\
\text { Odontologia de Bauru da Universidade de São Paulo }\end{array}$ \\
\hline $1991 / 1993$ & $\begin{array}{l}\text { Curso de Pós-Graduação em Odontologia, ao Nível de } \\
\text { Mestrado, na Área de Dentística - Faculdade de Odontologia } \\
\text { de Bauru da Universidade de São Paulo }\end{array}$ \\
\hline 1995 & $\begin{array}{l}\text { Dissertação: "Avaliação In Vitro da Liberação de Flúor de } \\
\text { Cimentos de lonômero de Vidro e Outros Materiais que } \\
\text { Contêm Flúor", (Orientadora: Prof }{ }^{a} \text { Dra Maria Fidela de Lima } \\
\text { Navarro). }\end{array}$ \\
\hline 1993 & $\begin{array}{l}\text { Professora Auxiliar durante o 1 }{ }^{\circ} \text { semestre na área de } \\
\text { Dentística, da Universidade de Marília }\end{array}$ \\
\hline $1993 / 1995$ & $\begin{array}{l}\text { Professora Auxiliar junto ao Departamento de Odontologia } \\
\text { da Universidade Estadual de Maringá }\end{array}$ \\
\hline $1996 /$ & $\begin{array}{l}\text { Professora Assistente junto ao Departamento de } \\
\text { Odontologia da Universidade Estadual de Maringá }\end{array}$ \\
\hline $1997 / 1999$ & $\begin{array}{l}\text { Curso de Pós-Graduação em Odontologia, ao Nível de } \\
\text { Doutorado, na Área de Dentística - Faculdade de Odontologia } \\
\text { de Bauru da Universidade de São Paulo }\end{array}$ \\
\hline
\end{tabular}




\section{ASSOCIAÇÕES DE CLASSE E SOCIEDADES CIENTÍFICAS}

Associação Paulista de Cirurgiões-Dentistas (Sede Central de S. Paulo) APCD

Associação Maringaense de Odontologia - AMO

Grupo Brasileiro de Professores de Dentística - GBPD

International Association for Dental Research - IADR 
Dedico este trabalho ao Hélio, meu esposo. 


\section{Agradecimentos}

Á Faculdade de Odontologia de Bauru - USP e à Universidade Estadual de Maringá, à coordenação do Curso de Pós-Graduação em Dentística, a todos os professores do

Curso de Pós-Graduação em Dentística - Doutorado, aos funcionários da biblioteca e da secretaria de Pós-Graduação da FOB, aos professores e funcionários do Departamento de Odontologia da Universidade Estadual de Maringá, meus agradecimentos por permitirem desenvolver este curso.

A todos os professores e funcionários do Departamento de Dentística da FOB, aos funcionários do setor de Pós-Graduação da UEM, à Fundação CAPES, aos professores David Pashley e Edna Pashley e funcionários do Departamento de Biologia Oral da Medical College of Georgia, meus sinceros agradecimentos pela contribuição significativa na elaboração deste trabalho.

Á Dental Press, ao Laurindo Z. Furquim, à Tereza D'Áurea Furquim, ao Anderson Marotti, à Andréa Miriam Laurindo e ao Maycon Patrick de O. Martins, pela amizade e pelo suporte na diagramação e impressão deste trabalho, meu agradecimento especial.

Aos colegas de curso, Margareth Nunes, Marina Fracasso, Lúcia Pereira, Luíza Esmeral, Mônica Yamauti, Nelson Silva, Narumi Pavan, Luciana Azevedo e Sérgio Santiago, obrigada por ajudarem a tornar alguns dias longe de casa mais leves.

Á Dra Maria Tereza Atta A. Bastos, agradeço sinceramente por ter contribuído muito com o meu aprendizado do que é ser mestre e doutor.

Á Dra Maria Fidela de Lima Navarro, sou grata por tudo que me ensinou e por sempre me apoiar.

Ao Dr. Ricardo Marins de Carvalho, meu orientador, muito obrigada por todas as oportunidades de crescimento.

Carlos Augusto Fernandes e Alaíde Aguiar, obrigada por estarem sempre presentes. Agradeço a amizade que nasceu em Bauru.

Aos meus pais, Julio Suga e Suzuye Sano Suga, às minhas irmãs, Marise Sano Suga e Selma Sano Suga, à toda minha família, meu muito, muito obrigada.

Hélio Hissashi Terada, sempre, por tudo, muito, muito obrigada. 


\section{SUMÁRIO}

LISTA DE ABREVIATURAS E SÍMBOLOS ............................................................ vii

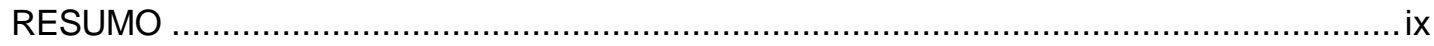

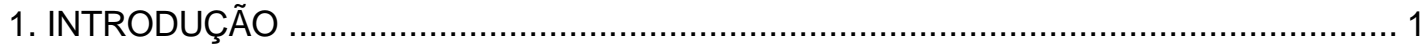

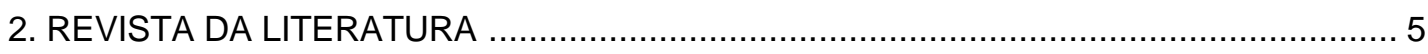

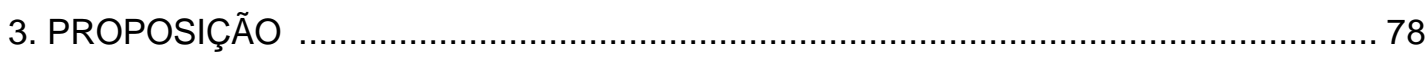

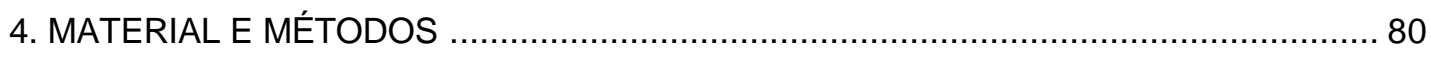

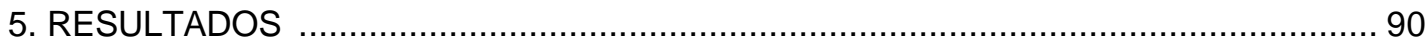

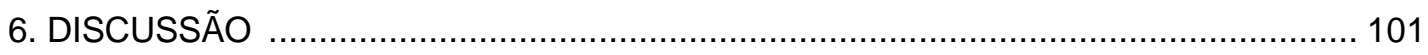

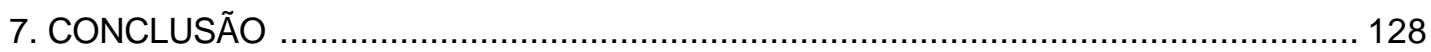

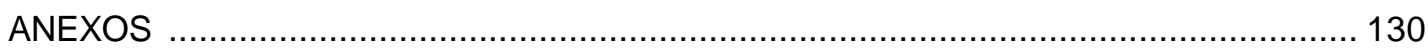

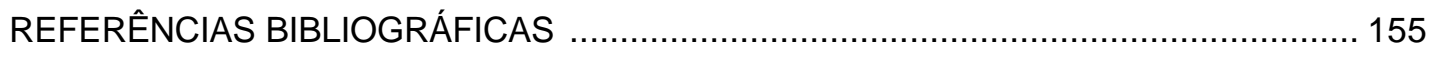

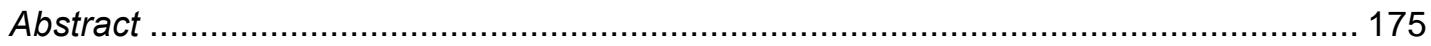




\section{LISTA DE ABREVIATURAS E SÍMBOLOS}

$\begin{array}{ll}\# & \text { Número } \\ \% & \text { Porcentagem } \\ \pm & \text { Mais ou menos } \\ \mu \mathrm{L} & \text { Microlitro } \\ \mu \mathrm{m} & \text { Micrômetro } \\ < & \text { Menor que... (para significância estatística) } \\ > & \text { Maior que... (para significância estatística) } \\ \text { 4-META } & \text { 4-Metacriloxietil trimetilato anidro } \\ \text { ANOVA } & \text { Análise de variância } \\ \text { APF } & \text { Flúor fosfato acidulado } \\ \text { Bis-GMA } & \text { Bisfenol-glicidil-metacrilato } \\ \mathrm{CLB2V} & \text { Clearfil Liner Bond 2V } \\ \mathrm{cm}^{2} & \text { Centímetro } \\ \mathrm{cm}^{2} & \text { Centímetro ao quadrado } \\ \mathrm{cm}^{3} \mathrm{~m}^{-1} & \text { Centímetro ao cubo por metro } \\ \mathrm{Cu} & \text { Cobre } \\ \text { EDTA } & \text { Ácido etileno diamino tetra-acético } \\ \mathrm{F} & \text { Flúor } \\ \mathrm{Fe} & \text { Ferro }\end{array}$

Fig. Figura

Figs. Figuras

$\mathrm{H}_{2} \mathrm{O} \quad$ Água

HEMA 2-hidroxi-etil-metacrilato

HF Ácido hidrofluorídrico

JEC Junção esmalte-cemento

$\mathrm{Kg} \quad$ Quilograma

$\mathrm{Kg} / \mathrm{cm}^{2} \quad$ Quilograma por centímetro ao quadrado

Kgm Quilograma

M Molar (notação química)

MET Microscopia eletrônica de transmissão 


\begin{tabular}{ll} 
MEV & Microscopia eletrônica de varredura \\
$\mathrm{mL}$ & Mililitro \\
$\mathrm{mm}$ & Milímetro \\
$\mathrm{mm} / \mathrm{min}$ & Milímetros por minuto \\
$\mathrm{mm}{ }^{2}$ & Milímetro ao quadrado \\
$\mathrm{MOD}$ & Mésio-ocluso-distal \\
$\mathrm{mol} / \mathrm{L}$ & Mol por litro (notação química) \\
$\mathrm{MPa}$ & Mega Pascal \\
$\mathrm{NaOCl}$ & Hipoclorito de sódio \\
$\mathrm{nm}$ & Nanômetro \\
$\mathrm{N}$ No & Número \\
$\mathrm{NPG}$ & N-fenil-glicidil \\
${ }^{\circ} \mathrm{C}$ & Graus Celsius \\
OS & One-Step \\
$\mathrm{PBS}$ & Solução saliva tamponada com fosfato \\
$\mathrm{PENTA}$ & Ácido dipenta-eritritol-pentacrilato \\
pH & Potencial hidrogeniônico \\
$\mathrm{PTFE}$ & Poli-tetraflúor-etileno \\
SB & Single Bond \\
SMPP & Scotchbond Multi-Purpose Plus \\
SNK & Student-Newman-Keuls \\
vol. & Volume \\
X & Indica número de vezes. Ex.: 20X (de aumento) \\
Zn & Zinco \\
\hline
\end{tabular}




\section{Resumo}

"semel emissum volat irreparabile verbum..." 


\section{RESUMO}

O presente trabalho avaliou a influência das variações morfológicas do substrato dentinário na resistência de união à microtração de três sistemas adesivos resinosos: Clearfil Liner Bond 2V, One-Step e Single Bond, empregando como substrato superfícies planas de dentina. Para o preparo e exposição da superfície de dentina, o esmalte oclusal foi desgastado com lixas de carbureto de silício de granulação 320 e 600. Doze dentes foram tratados com um dos sistemas adesivos e foi aplicada uma camada de 1 centímetro de altura em resina composta Z100, pela técnica incremental. Após armazenagem em água destilada em estufa a 37으 por 24 horas, os espécimes foram preparados para serem submetidos ao teste de microtração. Utilizando-se uma máquina de cortes seriados, os dentes foram fatiados em espessuras de aproximadamente $0,8 \mathrm{~mm}$ nos sentidos mésiodistal e vestíbulo-lingual, obtendo-se médias de áreas de adesão de 0,7 $\mathrm{mm}^{2}$. Foram obtidos, em média, 23 espécimes por dente. Identificando-se cada espécime através de um código de cores, a superfície de cada dente foi mapeada. Para a leitura da resistência de união, cada espécime em forma de "palito" foi afixado individualmente em um dispositivo de microtração, Bencor Multi-T, de modo a posicionar a área de adesão perpendicularmente ao longo eixo do espécime. Após o teste, o modo de fratura da interface adesiva foi avaliado. Os resultados obtidos permitiram concluir que existe uma variação regional da resistência de união em superfícies planas de dentina. Independentemente do sistema adesivo empregado, a variação da resistência de união encontrada em superfícies planas de dentina foi determinada por variações no substrato dentinário. 
Comparando-se a resistência de união entre os materiais, os sistemas OneStep (53,97 $\pm 12,58 \mathrm{MPa})$ e Single Bond (52,59 \pm 17,67 MPa) apresentaram uma resistência semelhante e estatisticamente superior ao sistema Clearfil Liner Bond 2V (32,90 \pm 12,43 MPa). Comparando-se a resistência de união à dentina central e à dentina periférica, os três materiais não apresentaram uma diferença estatisticamente significante. 
"verba volant, scripta manent..." 


\section{1 - INTRODUÇÃO}

Há 35 anos, quando Buonocore ${ }^{6}$ realizou pela primeira vez o condicionamento ácido do substrato de esmalte como tentativa para melhorar a adesão da resina ao dente, certamente, a comunidade odontológica não podia prever que o avanço conseguido iria alcançar resultados restauradores e estéticos tão rápidos e satisfatórios nos anos atuais. Uma gama de materais restauradores - resinas compostas, cerâmicas, cerômeros - são ferramentas de rotina empregadas dentro de um novo campo de atuação conhecido como Odontologia Estética.

Um paradoxo para os profissionais que trabalham com a Dentística Restauradora e Estética, recai, de um lado, pelo fato de a Odontologia Estética ter evoluído com a possibilidade de unir os materiais recémdescobertos à estrutura dentária e, de outro, em função das limitações ainda hoje encontradas no que se refere a um selamento permanente. Evoluimos sim, mas ainda procuramos um material restaurador que se adira à superfície dentária promovendo um vedamento ideal. Uma boa resistência de união, por si só, não implica em um bom selamento marginal, o que pode comprometer o resultado final da restauração.

Dentro deste cenário, a adesão ao substrato dentinário sempre foi mais crítica quando comparada ao esmalte. Isso se deve, em parte, à sua própria heterogeneidade, à composição aquosa e permeabilidade variáveis, às características hidrofóbicas dos monômeros resinosos, e às alterações fisiológicas a que esse substrato está sujeito. Antes mesmo de tentar-se unir 
as resinas ao esmalte, a união à dentina também já fora aventada. Os resultados, entretanto, foram frustantes. Os estudos não pararam, os sistemas adesivos evoluíram, e a formação da camada híbrida como meio de adesão está bem estabelecida. Entretanto, a efetividade dos sistemas adesivos disponíveis atualmente, ainda depende de sua estabilidade e sensibilidade frente a essas variações regionais de morfologia e fisiologia dentinária.

Muitos trabalhos já foram realizados para demonstrar a variação da resistência de união em função das diferentes características do substrato $^{2,3,8,10,17,19,21,23,26,28,30,31,34,38,41,43,45,46,49,51,52,54,55,63,73,83,88,93,95,96,99,100,102}$ ,103,118,119,120,121,125,127,129,131,133,152,154,156,157,158. A influência de fatores como a quantidade de umidade superficial, conteúdo de cálcio, densidade tubular, profundidade, orientação dos túbulos, tipo etc, na qualidade de adesão à dentina já foi demonstrada. Entretanto, dentre esses inúmeros estudos, não encontramos uma metodologia que tenha sido capaz de investigar os valores de união em várias regiões de um mesmo dente, ou ainda, que permitisse um mapeamento dessa união em áreas diminutas de uma mesma superfície. Com o desenvolvimento da técnica de microtração por Carvalho et al. ${ }^{13}$ e Sano et al. ${ }^{110}$ tornou-se possível a determinação da resistência de união de sistemas adesivos à áreas diminutas da superfície dentária. A principal vantagem da técnica de microtração consiste em oferecer uma versatilidade de modos de avaliação da resistência de união, o que não era possível com os métodos convencionais ${ }^{86}$. Assim, esta técnica tem sido empregada com sucesso para testar a resistência adesiva em situações que simulam as restaurações in vivo, sobre diferentes tipos substratos dentinários, ou ainda, em qualquer região do dente.

Com o constante desenvolvimento dos sistemas adesivos e a introdução no mercado de sistemas adesivos ditos autocondicionantes, parece que os problemas de sensibilidade técnica e sensibilidade às variações frente ao substrato dentinário têm diminuído. A grande vantagem dos sistemas adesivos autocondicionantes é que a desmineralização da 
superfície e conseqüente infiltração dos monômeros resinosos ocorrem simultaneamente, eliminando a subjetividade da umidade dentinária ideal, necessária para a aplicação dos sistemas adesivos que fazem uso do condicionamento ácido prévio da superfície com ácido fosfórico.

Com a possibilidade de avaliar a uniformidade ou não da adesão em um mesmo dente empregando-se sistemas adesivos convencionais e autocondicionantes através da técnica de microtração; com a possibilidade de mapear os valores de resistência de união em uma superfície dentária ou em um preparo cavitário, o presente trabalho foi conduzido em laboratório empregando dois sistemas adesivos convencionais, o One-Step e o Single Bond, e um sistema autocondicionamente, o Clearfil Liner Bond 2V, com o objetivo de responder a essas hipóteses. 


\section{Revista da Literatura}

"Verbum proverbo..." 


\section{2 - REVISTA DA LITERATURA}

BUONOCORE ${ }^{6}$, em 1955, em um trabalho clássico, com o objetivo de encontrar um método que aumentasse a adesão dos materiais restauradores à superfície do esmalte, propôs o emprego de algumas substâncias ácidas ao esmalte, previamente a aplicação da resina, substâncias estas que promoveriam uma alteração física e química, favorecendo a união. Após alguns resultados laboratoriais e clínicos, o autor recomendou a utilização do ácido fosfórico a $85 \%$ aplicado por 30 segundos na superfície do esmalte para propiciar uma maior retenção da resina, naquela época, uma resina acrílica, às custas de irregularidades criadas pela desmineralização seletiva do esmalte após a atuação do ácido.

Em 1956, BUONOCORE; WILEMAN; BRUDEVOLD7 , descreveram a primeira tentativa de adesão à dentina, condicionando-a com um ácido e restaurando-a com resina acrílica. Utilizando dentes extraídos e trabalhando em uma superfície plana de dentina, aplicou-se uma solução de ácido clorídrico a 7\% por um minuto e em seguida, aplicou-se a resina numa área isolada, circular, com diâmetro de $5 \mathrm{~mm}$. Os resultados demonstraram que o valor da resistência de união à tração foi praticamente duplicado quando realizou-se este tratamento. Por outro lado, quando os espécimes foram armazenados em água, houve uma diminuição significante neste valor. Para as superfícies não tratadas com ácido, a resistência de união inicial foi de 28 $\mathrm{Kg} / \mathrm{cm}^{2}$, sendo reduzida para $15 \mathrm{Kg} / \mathrm{cm}^{2}$ após três meses de armazenagem 
em água. Para as superfícies tratadas com ácido, o valor inicial da resistência de união foi de $53 \mathrm{Kg} / \mathrm{cm}^{2}$, diminuindo para $28 \mathrm{Kg} / \mathrm{cm}^{2}$ após cinco meses de imersão em água. A partir destes resultados, foi sugerido que a adesão era devida à possibilidade de combinação química entre um dos constituintes da resina e a matriz orgânica da dentina.

Em um trabalho clássico realizado em 1976 por GARBEROGLIO; BRÄNNSTRÖM ${ }^{33}$, os autores buscaram avaliar através de MEV os túbulos dentinários em dentina humana fraturada, a várias distâncias em relação à polpa. Foram utilizados para o estudo diferentes grupos de dentes (24 pré-molares, 5 molares e 1 incisivo), tanto de pessoas jovens quanto de adultos. As coroas de 23 dentes foram fraturadas através de sulcos nas faces vestibular, lingual ou proximal, ao nível dos cornos pulpares, com os túbulos dentinários sendo expostos transversalmente. Treze dos 23 dentes foram fraturados transversalmente, no centro da superfície oclusal, e os 7 dentes restantes, fraturados longitudinalmente, ao centro da polpa, para avaliar-se o diâmetro dos túbulos. Para determinar a diferença entre o diâmetro e o número de túbulos em dentina descalcificada e não descalcificada, 9 dentes com dupla fratura foram examinados. A análise das fotomicrografias mostrou que não houve diferença significante quanto ao diâmetro e número dos túbulos dentinários em relação ao fator idade. O número de túbulos próximos à polpa foi de $45.000 / \mathrm{mm}^{2}$ e o diâmetro médio destes, foi de $2,5 \mu \mathrm{m}$; na dentina média, esse valores foram de $29.500 / \mathrm{mm}^{2}$ e $1,2 \mu \mathrm{m}$; na periferia, próxima à junção amelodentinária, os números foram, respectivamente, de $20.000 / \mathrm{mm}^{2}$ e $0,9 \mu \mathrm{m}$. A média do valor do volume total dos túbulos na dentina coronária foi calculada em $10 \%$ do volume total de dentina. Este valor foi de $28 \%$ na dentina próxima à polpa e de $4 \%$ na dentina próxima ao esmalte. O diâmetro dos túbulos aumentou consideravelmente na superfície fraturada descalcificada em função da remoção total da dentina peritubular. Além destes resultados, observou-se a 
presença de processos odontoblásticos apenas nas áreas dos túbulos próximas à polpa.

NAKABAYASHI; KOJIMA; MASUHARA ${ }^{69}$, em 1982, realizaram um estudo verificando a efetividade da solução 4-META na adesão de um cilindro de acrílico ao esmalte e à dentina (bovina e humana) condicionadas com uma solução formada pela mistura de ácido cítrico a $10 \%$ e cloreto férrico a 3\%. Observaram que monômeros resinosos com grupos hidrofóbicos e hidrofílicos como o 4-META, infiltravam-se por entre as fibras colágenas expostas pelo tratamento ácido e, após polimerização, formavam uma zona mista, ácido resistente, de dentina desmineralizada permeada pela resina, denominada camada híbrida. Tal camada promovia um aumento na resistência de união da resina composta à dentina. Este trabalho foi considerado um marco no estudo dos adesivos dentinários por ter demonstrado que a obtenção de uma ótima adesão não se deve exclusivamente pela formação de tags no interior dos túbulos dentinários como se acreditava até então, mas principalmente, pela retenção micromecânica dos agentes resinosos com as fibras colágenas da dentina intertubular.

Para testar a hipótese de que a variabilidade regional da dentina tem influência na resistência adesiva de materiais restauradores, CAUSTON ${ }^{19}$, em 1984, preparou superfícies em dentina superficial e dentina profunda que foram tratadas com o sistema adesivo Scotchbond. Em metade dos grupos, representada por cada um dos tipos de superfície de dentina, foi utilizada uma solução com potencial mineralizador (ITS) antes da aplicação do sistema adesivo. Os resultados demonstrataram que a aplicação do Scotchbond não aumentou significantemente a resistência adesiva em relação aos resultados relatados anteriormente e que a sua efetividade dependeu do nível de cálcio no substrato. Os valores das resistências adesivas foram significantemente menores em dentina profunda do que em 
dentina superficial; no entanto, quando foi feito o tratamento com a solução mineralizadora, houve um aumento significante na resistência adesiva em dentina profunda.

Com o objetivo de avaliar os efeitos do tempo após a extração dos dentes e da espessura da dentina remanescente nos valores de resistência de união, MITCHEM; GRONAS ${ }^{63}$, em 1986, utilizando terceiros molares humanos extraídos, prepararam espécimes que foram submetidos a um ensaio de cisalhamento. A avaliação das resistências de união foi feita em uma máquina de testes universal Instron e mensuradas em $\mathrm{Kgm}$. As resistências adesivas de cinco sistemas adesivos, Bondlite, Dentin Adhesit, Durafil Dentin Adhesive, J \& J Dentin Adhesive e Scotchbond, foram avaliadas. Os autores obtiveram como resultados para a adesão que não houve diferença significante para o efeito do tempo após a extração; variando o período de 1 dia a vinte e seis dias, o valor de resistência de união média foi de aproximadamente 4,85 Kgm. Para o efeito da espessura remanescente de dentina, houve uma diferença significante na resistência: entre $2 \mathrm{~mm}, 1,5 \mathrm{~mm}$ e 0,75 mm de distância da superfície de dentina em relação à polpa, os valores variaram de 4,90, 4,17 e 2,77 Kgm, respectivamente.

Frente às consideráveis diferenças de valores de adesão à dentina encontrados na literatura, em 1988, SUZUKI; FINGER ${ }^{120}$ propuseram-se a avaliar o efeito do local da adesão na resistência adesiva à dentina de três sistemas adesivos: Clearfil New Bond, Gluma Dentin Bond e Scotchbond. Os autores testaram a adesão dos materiais em dentina à diferentes distâncias da polpa. Após os testes, mediram a quantidade de dentina remanescente entre a superfície adesiva e a câmara pulpar e, através da tomada de imagens de microscopia eletrônica, calcularam a densidade de túbulos por área do respectivo sítio de adesão. Seus resultados confirmaram outros estudos, demonstrando que os valores de resistência adesiva, para os três 
materiais, foram em torno de 30 a $40 \%$ inferiores para a dentina próxima à polpa do que na dentina periférica. Traçando uma correlação entre quantidade de dentina remanescente, área de dentina sólida (representada pela área de dentina intertubular no sítio de adesão) e resistência adesiva, concluíram que os valores de adesão eram diretamente proporcionais à área de dentina sólida na superfície.

TAO; PASHLEY ${ }^{125}$, em 1988, realizaram um trabalho com o objetivo de comparar a resistência adesiva do sistema adesivo Scotchbond à dentina após esta ser submetida a tratamentos com discos de lixa granulação \#320 ou com broca cone-invertida \#37, em baixa-rotação, para criar diferentes tipos de smear layer. Foi comparada também a diferença nos valores de resistência adesiva encontrados na dentina superficial, média e profunda, antes e após diferentes tratamentos empregados para remover a smear layer, e a variação da resistência adesiva encontrada na dentina localizada mais ao centro da coroa e a dentina sobre os cornos pulpares. Para o experimento, foram utilizados somente terceiros molares humanos nãoerupcionados e com o auxílio de uma máquina de cortes seriados, a porção coronária dos dentes foi removida a fim de permitir a obtenção de uma superfície plana de dentina, seja ela na região mais superficial, média ou profunda. Para a análise do efeito dos diferentes tratamentos superficiais da smear layer na resistência adesiva, utilizou-se como controle, lavagem com água durante 1 minuto, e, como grupos experimentais, ultra-som por 1 hora, Tubulicid (EDTA $0.2 \% \mathrm{pH} 7,1$ ) por 1 minuto, ácido cítrico $6 \%$ por 1 minuto ou ácido fosfórico 37\% por 15 segundos. Desta forma, o trabalho pôde ser dividido em 3 etapas: o efeito do tratamento da smear layer com relação a sua obtenção e remoção; o efeito do tratamento da smear layer com relação a profundidade de dentina; e o efeito do tratamento da smear layer com relação a localização da dentina: central ou sobre os cornos pulpares. Para a análise da resistência adesiva, os espécimes foram confeccionados de forma que o diâmetro da área circular adesiva era de $3 \mathrm{~mm}$ e o tipo de força aplicada foi de cisalhamento. Assim, a smear layer criada com discos de lixa 
permitiu que a resistência adesiva fosse ligeiramente superior quando comparada com a smear layer criada com brocas. Todos os tratamentos empregados sobre a smear layer, antes da aplicação do sistema adesivo, prejudicaram a adesão, exceto o ultra-som quando aplicado sobre a smear layer produzida por broca. Com relação ao tratamento da smear layer e a profundidade de dentina, no grupo controle não houve diferença significante na resistência adesiva extraída da dentina superficial, média ou profunda; porém, em geral, todos os tratamentos diminuíram a resistência com algumas variações dependendo do tipo de substrato dentinário. 0 tratamento com ácidos, cítrico ou fosfórico, levou a produção de uma menor resistência adesiva na dentina profunda com relação a dentina superficial. Por fim, com relação ao tratamento da smear layer e a localização da dentina, central ou sobre os cornos pulpares, verificou-se que a resistência adesiva não diferiu significantemente; ou seja, independentemente da área adesiva localizar-se central ou mais perifericamente, os valores foram semelhantes, variando apenas em função do tratamento dado à smear layer.

Em 1989, VAN NOORT et al. ${ }^{147}$ procuraram examinar os métodos usuais de avaliação da resistência adesiva e discutir a necessidade do controle e da padronização dos testes, realizando um trabalho empregando a análise do elemento finito. Para tanto, partiram de uma configuração básica onde um corpo-de-prova de resina medindo $6 \mathrm{~mm}$ de altura por $6 \mathrm{~mm}$ de largura foi aderido à uma superfície plana de dentina e assim, acoplado a um programa de computador. Analisou-se o efeito das diferentes propriedades dos materiais, da geometria (tamanho) dos corpos-de-prova e das condições de carregamento da força, bem como o efeito do carregamento sob cisalhamento na distribuição dos estresses. Mesmo aplicando-se uma carga uniforme, verificou-se que a distribuição de estresses na interface dente/restauração não é uniforme. Existe uma maior concentração de estresses nos cantos da interface e quanto maior o módulo de elasticidade do material restaurador, maior é a concentração de estresses. Além disso, verificou-se que as forças de tração máximas são 
geradas ao longo da superfície da restauração e não na interface dente/restauração, o que dificulta predizer com certeza o local onde a falha adesiva começa. Com relação ao tamanho do corpo-de-prova, verificou-se que ao diminuir aproximadamente $3 \mathrm{~mm}$ em altura, não houve uma alteração significante da distribuição de forças na interface; entretanto, reduzindo-se o corpo-de-prova para $2 \mathrm{~mm}$ ou menos, as forças diminuíram no canto da restauração e aumentaram no centro, no interior do volume do material, e, desta forma, a falha muda da superfície para um lugar imprevisível, onde existe um defeito interno, por exemplo. Isto também foi evidente quando a carga foi concentrada ao invés de uniforme, variando-se o tamanho do corpo-de-prova. Em outras palavras, verificou-se que existe uma altura mínima do corpo-de-prova para se conduzir os testes de resistência de união. Com relação ao teste de cisalhamento, verificou-se que as forças de tração/compressão na interface aumentam quando a distância entre o ponto de aplicação da carga e a superfície dentinária aumenta, devido ao aumeto nos momentos de dobramento. Neste caso, salientaram, provavelmente a falha adesiva comece também na superfície do material e não na interface dente/restauração. Os autores concluíram que uma força de tração ou cisalhamento uniforme não é conseguida na interface dente/restauração e que mesmo para testes semelhantes realizados no mesmo laboratório, existe a possibilidade de aparecerem muitas variações. Além disso, comentaram que a resistência adesiva pode ser usada somente para uma comparação da efetividade dos agentes de união e que a mesma não pode ser relacionada diretamente ao que acontece clinicamente. Finalmente, os autores recomendaram que seja realmente implantado um teste padronizado para avaliar a resistência adesiva, mesmo que este não proporcione uma falha verdadeira.

No livro-texto publicado em 1990 por MJÖR; FEJERSKOV ${ }^{66}$, lê-se que a composição da dentina é geralmente estimada em cerca de $70 \%$ de material inorgânico, 18\% de material orgânico e 12\% de água; entretanto, por causa da mineralização normal e progressiva que ocorre depois que o 
dente está completamente formado, esta composição varia, dependendo da idade do dente. A porção inorgânica da dentina constitui-se principalmente de cristais de hidroxiapatita, alguns fosfatos de cálcio amorfos, sais inorgânicos como carbonatos, fosfato de cálcio diferentes da hidroxiapatita e sulfatos, bem como elementos como o $\mathrm{F}, \mathrm{Cu}, \mathrm{Zn}, \mathrm{Fe}$ e outros. A porção orgânica consiste principalmente de colágeno, que representa $93 \%$ de todo material orgânico, frações de lipídeos, glicosaminoglicanas e compostos não identificados de proteína e, além disso, ácido cítrico. As entidades estruturais básicas da dentina seriam o odontoblasto com o processo odontoblástico, o túbulo dentinário, o espaço periodontoblástico, a dentina peritubular e a dentina intertubular. Também foi demonstrada a existência de uma estrutura orgânica em forma de folha, denominada lâmina limitante, que reveste o túbulo dentinário ao longo de toda a sua extensão. No mesmo capítulo, os autores comentam que não se sabe ainda 0 quanto os processos odontoblásticos se estendem para a periferia da dentina mas está bem documentada a presença de extensões citoplasmáticas do odontoblasto no terço pulpar da dentina, pelo menos até $200 \mu \mathrm{m}$ no interior da dentina de dentes recém-erupcionados.

Com o objetivo de investigar a correlação entre permeabilidade dentinária, profundidade de dentina e resistência de união ao cisalhamento, TAGAMI; TAO; PASHLEY ${ }^{121}$, em 1990, utilizaram os sistemas adesivos Scotchbond, Clearfil New Bond e Superbond C\&B, aplicados em dentina de incisivos bovinos. A permeabilidade foi determinada utilizando-se um dispositivo para medir conductância hidráulica, sendo executada sempre antes da aplicação dos sistemas adesivos. A smear layer criada com papel abrasivo de carbureto de silício de granulação 320 , não foi tratada quando o Scotchbond foi utilizado. Nos espécimes em que foi aplicado o Clearfil New Bond, foi feito o condicionamento com ácido fosfórico a 37\% por 60 segundos e para o grupo do Superbond C\&B, a dentina foi pré-tratada com a solução 10-3 (ácido cítrico a 10\%, cloreto férrico a 3\%). Após ter sido medida 
a permeabilidade dentinária, as superfícies foram lavadas, secas e os sistemas adesivos, aplicados. Não houve aplicação de pressão de fluido durante o procedimento adesivo e estocagem. Os autores encontraram como resultados que, a relação entre permeabilidade dentinária e profundidade de dentina dependeu da presença ou ausência da smear layer. $\mathrm{Na}$ relação entre a resistência de união ao cisalhamento e a espessura de dentina, a mais baixa resistência foi encontrada quando foi utilizado o Clearfil New Bond (0-4,5 MPa). Houve uma relação inversa, estatisticamente significante, entre a resistência de união e a espessura de dentina, na qual a resistência de união na dentina superficial foi mais alta do que em dentina profunda. O Scotchbond produziu valores de resistência de união ligeiramente superiores (0-6,6 MPa). A relação entre a resistência de união do Scotchbond e a profundidade da dentina foi baixa, mas estatiticamente significante. O Superbond C\&B demonstrou a mais alta resistência de união (0-25 MPa). Houve muitas falhas coesivas de resina ou dentina na união acima de $15 \mathrm{MPa}$. Todas as outras falhas de união foram adesivas. Na relação entre a profundidade de dentina e a resistência de união para o Scotchbond e Clearfil New Bond, as resistências de união na dentina superficial foram similares, mas a resistência de união do Scotchbond em todas as outras profundidades restantes foi mais alta do que a do Clearfil New Bond, cujos valores diminuíram com o aumento da profundidade de dentina. Para a relação entre a resistência de união e permeabilidade dentinária, não houve nenhuma relação significante entre as variáveis do grupo do Scotchbond. No entanto, houve uma relação inversa estatisticamente significante entre a resistência de união e a permeabilidade nos grupos do Superbond C\&B e Clearfil New Bond.

DUKE; LINDEMUTH ${ }^{26}$, em 1991, publicaram um trabalho de revisão cujo conteúdo é de significância clínica pois discorre que as experiências têm sugerido que as variações da composição e da morfologia da dentina influenciam diretamente o comportamento dos sistemas adesivos à dentina, e assim, à medida que a dentina permanece por mais tempo na cavidade 
bucal tornando-se mais transparente e esclerótica, mais difícil torna-se a porcentagem de sucesso da união das restaurações. Nestes casos, salientaram os autores, deveria-se, portanto, considerar a necessidade de execução de artifícios retentivos nos preparos, até que se alcance um avanço melhor neste aspecto. A variabilidade da dentina seria o único fator que poderia explicar as enormes variações dos resultados das avaliações clínicas.

Para avaliar os efeitos da posição e profundidade da dentina, como também a presença ou ausência da pressão pulpar sobre a resistência ao cisalhamento, TAO; TAGAMI; PASHLEY ${ }^{127}$, em 1991, realizaram um trabalho empregando dois sistemas adesivos, SuperBond e Gluma, em dentina humana. Utilizando uma máquina de cortes seriados, os dentes foram recortados removendo-se as raízes e o esmalte oclusal. Definiu-se como dentina superficial aquela corespondente a $0,5 \mathrm{~mm}$ abaixo da junção amelodentinária no centro da superfície oclusal. Como dentina profunda, aquela $0,5 \mathrm{~mm}$ acima do corno pulpar. Para cada situação, ou seja, dentina superficial ou profunda, central ou acima dos cornos pulpares, presença ou ausência de pressão pulpar igual a $32 \mathrm{~cm} \mathrm{H}_{2} \mathrm{O}$, foram preparados 10 corposde-prova de cada material cuja área de adesão foi definida em $3 \mathrm{~mm}$. Após 24 horas de armazenamento, fez-se a leitura da resistência de união frente a uma força de cisalhamento. Desta forma, observou-se que não houve diferença significante nos valores de resistência adesiva entre dentina superficial ou profunda e central ou acima dos cornos pulpares quando empregou-se o sistema adesivo SuperBond. Estes valores variaram de 16,319,1 MPa e não foram afetados pela presença ou não de pressão pulpar. Com relação aos valores obtidos com o sistema Gluma, estes foram bem menores do que os obtidos com o outro material. Na dentina superficial, a resistência deste variou de 8,1-8,8 MPa e não foi diferente estatisticamente daquela encontrada na dentina profunda. Embora a posição não tenha afetado os resultados, na presença de pressão pulpar, houve uma queda nos valores obtidos em dentina profunda, especialmente acima dos cornos 
pulpares. Assim, pela análise de variância, notou-se que a profundidade e a posição da dentina afetam a resistência adesiva do sistema Gluma, mas não do sistema SuperBond.

Questionando que a geometria da interface adesiva pode ter um efeito significante sobre a mensuração da resistência adesiva e que esta, também pode ser um fator que contribui para as discrepâncias dos dados da literatura, VAN NOORT et al. ${ }^{148}$, em 1991, procuraram avaliar as modificações na distribuição de forças na interface dente/restauração através de uma análise do elemento finito e mensurar a resistência de união à tração de espécimes com ou sem o esparrame de uma camada de adesivo. Foram utilizados 24 molares humanos hígidos, os quais tiveram suas coroas seccionadas a fim de expor a superfície dentinária. Os materiais restauradores empregados foram o sistema adesivo Scotchbond 2 e a resina composta P-50. Os dentes foram divididos em dois grupos, sendo que no primeiro, o adesivo foi aplicado uniformemente sobre toda a superfície dentinária, e, no segundo, o adesivo foi aplicado somente na área efetivamente isolada para o procedimento restaurador, feito com um molde de PTFE. Desta forma, os espécimes foram armazenados durante 24 horas em água destilada para a execução posterior dos testes de tração. Para a mensuração da distribuição das forças na interface, foi empregado um programa TOMECH para análise do elemento finito. Os resultados indicaram que a resistência de união à tração alterou significantemente em função do modo de aplicação do adesivo, onde: para o grupo onde o adesivo foi aplicado somente na área a ser restaurada, a resistência foi duas vezes menor. Em números, o valor da resistência para o primeiro grupo foi de aproximadamente 6,90 MPa e, para o segundo grupo, 3,10 MPa. Esta diferença foi explicada pela forma como os estresses distribuem-se na região próxima à interface, vista pela análise de elemento finito. 
Em 1992, GWINNETT ${ }^{38}$ realizou um trabalho com o objetivo de determinar se a umidade superficial da dentina previamente à aplicação do sistema adesivo, influencia a resistência de união ao cisalhamento, particularmente empregando-se primers hidrofílicos e que contêm acetona. Os sistemas adesivos utilizados foram : All Bond, Amalgambond, Gluma, Mirage Bond e Tenure; sendo que o All Bond, o Mirage Bond e o Tenure, são sistemas com primer à base de acetona. Para cada material, realizou-se restaurações com a dentina na condição seca e úmida. Os resultados obtidos foram, respectivamente, em dentina seca e úmida para os sistemas testados: All Bond, 20,01 e 28,91 MPa; Amalgambond, 19,77 e 26,02 MPa; Gluma, 9,39 e 0,00 MPa; Mirage Bond, 5,53 e 24,09 MPa e Tenure, 18,10 e 28,53 MPa. Não houve diferença estatisticamente significante para todos os sistemas adesivos testados em dentina úmida, com exceção do Gluma, que foi totalmente comprometido pela presença de umidade e os valores não foram obtidos. Em dentina seca, não houve diferença significante entre os sistemas All Bond, Amalgambond e Tenure e entre o Mirage Bond e o Gluma, com os seus respectivos valores. Os sistemas que contêm acetona tiveram um aumento estatisticamente significante no valor de resistência de união ao cisalhamento quando foram aplicados em dentina úmida, sendo que com o Mirage Bond, os valores foram quadruplicados. Analisando-se os espécimes em MEV, verificou-se que na condição de dentina seca, as fraturas ocorreram predominantemente na interface entre a dentina e o primer, enquanto que para a condição úmida, um número significante (40$60 \%$ ), resultou em falhas coesivas profundas em dentina.

KANCA III ${ }^{49}$, em 1992, realizou um estudo para avaliar a capacidade de união de um sistema adesivo hidrofílico, para esmalte e dentina, simultaneamente ao substrato dentinário seco e úmido, em dentes humanos extraídos. O sistema empregado (All-Etch/All-Bond) utilizava o ácido fosfórico a 10 e 37\%. Após a montagem dos dentes em resina acrílica autopolimerizável, as superfícies dentinárias foram expostas e então armazenadas em água a $4^{0} \mathrm{C}$ por 24 horas para assegurar total hidratação, 
sendo posteriormente aquecidos até a temperatura corpórea. As superfícies dentinárias foram tratadas com uma das diferentes concentrações do ácido, que, após a lavagem, foram secas com ar comprimido ou deixadas úmidas através da remoção do excesso de água com lenço de papel absorvente. As gotas, uma de cada um dos primers, foram devidamente misturadas e imediatamente aplicadas em quatro camadas consecutivas. Após 10 segundos de repouso, foram totalmente secas com jatos de ar por 5 segundos para remover qualquer remanescente do solvente volátil. Uma camada uniforme de resina sem carga foi aplicada e polimerizada por 20 segundos. Sobre essas superfícies, foram construídos pequenos cilindros de resina composta fotopolimerizável Bisfil de $4 \mathrm{~mm}$ de diâmetro e 2,5 $\mathrm{mm}$ de espessura, fotopolimerizados por 40 segundos. Em seguida, os dentes foram armazenados em água a $37^{\circ} \mathrm{C}$ por 24 horas, antes de serem submetidos ao teste de resistência de união ao cisalhamento. Os grupos onde a superfície foi mantida úmida, para ambas as concentrações de ácido, apresentaram os maiores valores de resistência adesiva. $O$ autor considerou que para sistemas que apresentam um primer a base de acetona e com características hidrofílicas, a umidade superficial da dentina deixa de ser inconveniente, mas sim desejável para obenção de uma adesão ótima.

Para analisar a relação entre a resistência a tração e três características da dentina, isto é, espessura de dentina remanescente, concentração de cálcio e dureza, em 1992, PERINKA; SANO; HOSODA ${ }^{96}$ realizaram um estudo empregando 62 incisivos bovinos divididos em quatro grupos, pois foram testados quatro sistemas adesivos diferentes. A superfície vestibular de cada dente foi desgastada com disco de lixa granulação 600 de forma que o esmalte fosse removido para obter-se uma superfície plana de dentina, adequada para adesão. A área de adesão, correspondente a um diâmetro de $5,5 \mathrm{~mm}$, foi isolada com uma fita e o procedimento adesivo foi realizado, para cada grupo, seguindo-se as recomendações dos fabricantes. Os sistemas adesivos empregados foram: Clearfil New Bond, Clearfil Photo Bond, Scotchbond 2 e um sistema adesivo 
experimental onde a superfície dentinária deveria ser condicionada com uma solução aquosa de ácido cítrico $10 \%$ e cloreto de cálcio $20 \%$ e em seguida tratada com um primer a base de NMSA 3\% em álcool. Estes sistemas adesivos corresponderam, respectivamente, ao tratamento dado para os grupos 1, 2, 3 e 4. Nos grupos 1 e 2, a dentina foi condicionada com ácido fosfórico $37 \%$ e no grupo 3, foi aplicado somente o primer. Preparados os espécimes, realizou-se o teste de resistência adesiva à tração e em seguida, para avaliar a correlação, foi feita a análise da microdureza e também a mensuração da espessura de dentina remanescente e da concentração de cálcio. Os valores de resistência adesiva foram: 2,5 $\mathrm{MPa}, 5,2 \mathrm{MPa}, 7,7 \mathrm{MPa}$ e 9,2 MPa, respetivamente para os grupos 1, 2, 3 e 4. Os valores dos dois últimos grupos não diferiram estatisticamente. Com relação a correlação entre resistência e tração e as características da dentina analisadas, verificou-se que o grupo 1 apresentou uma correlação significante com a concentração de cálcio; o grupo 2, correlação com a espessura de dentina e a concentração de cálcio; o grupo 3, não apresentou correlação com nenhuma característica e, o grupo 4, sofreu a influência com relação a espessura de dentina e a dureza.

PRATI; PASHLEY ${ }^{100}$, em 1992, realizaram um estudo com o objetivo de avaliar a correlação entre permeabilidade, umidade e espessura de dentina com a resistência adesiva de quatro sistemas adesivos e um cimento de ionômero de vidro modificado por resina: All Bond, Clearfil Photobond, Scotchbond 2, Tenure, e Vitrabond, respectivamente. Utilizandose terceiros molares humanos, os espécimes foram obtidos removendo-se a raiz e o esmalte oclusal e em seguida, a espessura de dentina remanescente foi mensurada com um compasso. Desta forma, os espécimes foram adaptados a um aparato empregado para simular a presença de pressão hidráulica e mensurar a permeabilidade dentinária. Para a mensuração da umidade superficial, empregou-se o dispositivo de Periotron. Após a utilização dos materiais adesivos seguindo-se as recomendações dos fabricantes, aplicou-se uma camada de resina sobre a 
área de trabalho, exceto quando foi empregado o cimento ionomérico. Para todos os procedimentos restauradores, a área adesiva limitou-se a $3 \mathrm{~mm}$ de diâmetro. Para avaliar a resistência adesiva, empregou-se um teste de cisalhamento após um período de armazenamento dos espécimes de 24 horas, sob pressão hidrostática. Analisando-se os resultados da resistência adesiva, o Vitrabond e o Tenure apresentaram valores semelhantes $(2,31 \mathrm{e}$ $3,26 \mathrm{MPa}$, respectivamente), os quais foram significantemente inferiores aos demais materiais. Pela análise de regressão, observou-se que não houve correlação significante entre a resistência adesiva e permeabilidade, pressão pulpar ou espessura de dentina remanescente para o All Bond empregando a técnica de condicionamento total, para o Clearfil Photobond e para o Vitrabond. Entretanto, para os demais materiais e para o All Bond sem condicionamento, foram encontradas várias correlações significantes.

Em 1992, VAN MEERBEEK et al. ${ }^{142}$, conduziram um experimento para avaliar a interface dente/resina de diferentes sistemas adesivos, após esta ter sido tratada com um feixe de íons de argônio. Este tratamento permite uma melhor visualização da interface através de MEV. Baseados nas observações das fotomicrografias, os autores procuraram classificar os diferentes sistemas adesivos morfologicamente como também, esclarecer o mecanismo de adesão envolvido. No total, foram analisados 25 sistemas adesivos e para cada material, foram preparados 5 espécimes. Quanto a morfologia, foram observados três grupos diferentes. Em um primeiro grupo, a smear layer foi totalmente removida e foi possível observar claramente a presença da camada híbrida, provavelmente devido ao fato de que o condicionamento com ácidos ou agentes quelantes desmineralizaram a camada mais superficial de dentina a uma certa profundidade, expondo uma rede de colágenos que facilitou a penetração do adesivo, levando à formação de um entrelaçamento mecânico entre colágeno e adesivo. No segundo grupo, a smear layer foi preservada e os túbulos dentinários permaneceram obliterados. Neste caso, a intenção dos sistemas adesivos seria incorporar a smear layer juntamente com os monômeros hidrofílicos, os 
quais apresentam uma afinidade aos componentes orgânicos e inorgânicos da dentina subjacente. No terceiro grupo, composto por um número pequeno de materiais, a smear layer foi dissolvida parcialmente, levando à formação de uma camada híbrida bem fina e smear plugs impregnados com resina. Assim, o trabalho mostrou que a aplicação dos sistemas adesivos provocam alterações estruturais na morfologia da superfície da dentina, criando uma interface retentiva denominada zona de interdifusão entre a dentina mais profunda e intacta e o material restaurador. Essa zona de interdifusão fornece, portanto, sítios para adesão e, concomitantemente, deve apresentar uma propriedade protetora aos tecidos pulpares.

Com o propósito de quantificar a contribuição da penetração de resina no substrato dentinário para a resistência de união ao cisalhamento, GWINNETT $^{39}$, em 1993, realizou um trabalho empregando o sistema adesivo All-Bond 2 em quatro situações diferentes, realizadas em terceiros molares humanos extraídos, a saber: Grupo 1) sobre uma smear layer intacta; Grupo 2) após a remoção da smear layer com um jato de bicarbonato de sódio; Grupo 3) após condicionamento ácido da superfície dentinária com ácido fosfórico a 10\% por 20 segundos; e Grupo 4) sobre dentina fraturada. Para cada grupo, foram confeccionados 10 espécimes, sendo que alguns espécimes adicionais foram avaliados em MEV. A média da resistência obtida respectivamente para os grupos 1, 2, 3 e 4 foram: $10,24 \pm 2,98 \mathrm{MPa}, 20,37 \pm 4,62 \mathrm{MPa}, 26,77 \pm 4,85$ e 32,68 \pm 7,12 MPa. Baseados nos resultados obtidos e na análise das fotomicrografias, os autores concluíram que aproximadamente um terço da resistência de união ao cisalhamento à dentina, com o sistema All-Bond 2, é devida a infiltração da resina e, metade deste valor decorrrente da infiltração da resina, pode ser atribuída a penetração da resina nos túbulos dentinários, sendo a metade restante, decorrente da hibridização ou da infiltração da resina na matriz de dentina intertubular. 
Um trabalho realizado por PASHLEY et al. ${ }^{88}$, em 1993, avaliou a resistência adesiva à dentina superficial, intermediária e profunda in vivo, considerando que a pressão intrapulpar positiva e a smer layer criada com as brocas são fatores que diferem certamente das condições laboratoriais. Para tanto, foram utilizados dentes de cachorro, caninos e molares, e quatro sistemas adesivos: Clearfil Liner Bond System, Scotchbond 2, Superbond C\&B e Tenure. Definiu-se a área de adesão realizando-se um desgaste com pontas diamantadas em alta rotação, sendo que a espessura do dente foi mensurada antes e durante os desgastes, pois o mesmo dente serviu de espécime para avaliar a resistência adesiva em diferentes profundidades. $A$ área adesiva era circular, com 3,0 mm de diâmetro. Decorridos 30-45 minutos após a adesão, a resistência adesiva frente a uma força de cisalhamento foi testada. Comparando os resultados obtidos em caninos e molares, a resistência adesiva foi maior nos caninos do que em molares e ainda, a maioria dos sistemas adesivos comportou-se melhor na dentina mais superficial do que profunda. Em ordem decrescente de maior resistência adesiva, teve-se: Clearfil Liner Bond, Superbond C\&B, Scotchbond e Tenure. Os dois primeiros apresentaram valores de resistência em caninos acima de $10 \mathrm{MPa}$, independentemente da profundidade de dentina enquanto que os dois últimos, Scotchbond 2 e Tenure, os valores foram menores que $10 \mathrm{MPa}$.

A permeabilidade da dentina aos agentes adesivos é de crucial importância para a obtenção de uma boa adesão. Baseados neste fato, PASHLEY et al. ${ }^{81}$, em 1993, compararam em um trabalho as características subestruturais da dentina fraturada com a da dentina recoberta com smear layer, antes e após o condicionamento ácido com ácido fosfórico a $37 \%$ durante 30 segundos, através de MEV, procurando identificar a presença de porosidades superficiais que permitiriam a infiltração da resina durante os procedimentos adesivos. Pelas fotomicrografias, verificou-se que não houve diferença aparente entre a superfície de dentina fraturada que foi seca com um jato de ar, com a que foi mantida úmida. Os túbulos dentinários 
apareceram abertos, com um diâmetro aproximado de $1 \mu \mathrm{m}$, circundados por uma matriz de dentina peritubular de cerca de $1 \mu \mathrm{m}$ de espessura. $\mathrm{O}$ condicionamento ácido produziu algumas alterações significantes na dentina, alargando o diâmetro dos túbulos para $3 \mu \mathrm{m}$, em função da perda da dentina peritubular. Houve um aumento na porosidade, tanto da dentina intertubular quanto da matriz de dentina desmineralizada do interior dos túbulos, e a dentina abaixo da superfície pareceu ser mais porosa do que a da superfície. A profundidade da desmineralização da matriz de dentina foi de aproximadamente $5 \mu \mathrm{m}$ e as fibras colágenas observáveis abaixo da superfície, apresentaram um diâmetro aproximado de 100 nm. Pôde-se observar também que nos espécimes secos com ar, havia uma camada mais espessa de colágenos condensados ou colapsados. Quando o ácido foi aplicado sobre a dentina recoberta por smear layer e a superfície foi mantida úmida, a smear layer foi totalmente removida juntamente com a maioria dos smear plugs. Os oríficios dos túbulos apresentaram um diâmetro de 2 a 3 $\mu \mathrm{m}$. Além disto, observou-se a presença de uma grande quantidade de pequenos poros (cerca de $0,05 \mu \mathrm{m}$ ) na dentina intertubular, e a profundidade da desmineralização foi de 5 a $7 \mu \mathrm{m}$. Nos espécimes cuja smear layer estava presente inicialmente e após o condicionamento a superfície foi seca, pôde-se verificar a presença de algumas fendas superficiais e uma alternância de zonas mais ou menos porosas. Muitas fibras colágenas ficaram ligadas e colapsadas, e, no topo da matriz de dentina desmineralizada, verificou-se uma camada amorfa, relativamente não porosa. A profundidade de desmineralização estendeu-se de 5 a $10 \mu \mathrm{m}$.

Em 1993, RUBEN; ARENDS ${ }^{105}$ realizaram um trabalho apresentando um método para mensurar a contração da dentina desmineralizada através do uso de um perfilômetro e de análises microrradiográficas. Primeiramente, a contração da dentina foi mensurada, perpendicularmente à superfície mais externa, durante um período de secagem superior a 30 minutos. Posteriormente, os espécimes de dentina foram submetidos à 
desmineralização durante 1,2 ou 3 semanas e, decorrido cada período, a contração pelo contato com o ar, foi mensurada. Os espécimes de dentina apresentavam as seguintes medidas: $4 \times 5 \mathrm{~mm}^{2}$ de área e espessura de aproximadamente 1-1,5 $\mathrm{mm}$. Os resultados do trabalho mostraram que a contração da dentina desmineralizada varia linearmente com o tempo de secagem e aumenta com o aumento do tempo de desmineralização. Nas amostras de dentina que não foram submetidas à desmineralização, a contração foi pequena, de aproximadamente 0,3\%. Além dessas considerações, observou-se que a dentina desmineralizada e seca, quando reidratada, restabelece as dimensões iniciais.

$\mathrm{Na}$ mesma linha de pesquisa, RUBEN; ARENDS ${ }^{104}$, em 1993, realizaram um trabalho com o propósito de apresentar um método para prevenir a contração da matriz de dentina desmineralizada e avaliar o efeito da contração em função do período de secagem das amostras. Assim, na primeira parte do estudo, empregando-se espécimes de dentina desmineralizados obtidos a partir de terceiros molares humanos extraídos, a amostra foi microrradiografada imediatamente após a obtenção dos espécimes, secas durante 3-4 segundos ou durante um período superior a 24 horas, e, novamente microrradiografadas. Na segunda parte, a amostra, constituída da mesma forma de espécimes de dentina desmineralizada, foi microrradiografada após a obtenção dos espécimes e após ser seca durante 10, 30, 60 minutos e 24 horas. Em seguida, a mesma amostra foi submersa em água durante 8 horas e subsequentemente colocada em $100 \mathrm{~mL}$ de etanodiol por 24 horas. Assim, todos os espécimes foram secos e microrradiografados após os mesmos períodos acima mencionados. Os resultados obtidos, resumidamente mostraram que o uso de etanodiol previne a contração da dentina desmineralizada durante 1 hora e que, na ausência deste tratamento, o efeito de contração na dentina é de aproximadamente $20 \%$ em profundidade e de $30 \%$ em perda mineral, após secagem com ar durante 120 segundos. 
TAM; PILLIAR ${ }^{122}$, em 1993, empregaram um tipo de teste conhecido como "fracture toughness", para avaliar a interface de união resina/dente pela primeira vez medindo-se o valor da energia de fratura (Kic). Considerando que o Kic reflete a capacidade de um material ou de uma interface, de resistir ao início e à propagação da ruptura, para a realização do experimento foram confeccionados espécimes para avaliar a união dos sistemas adesivos All Bond 2, Scotchbond 2 e Scotchbond Multi Purpose em combinação com as resinas compostas Bis-Fil e P-50 à dentina, através dos testes de tração convencional e de "fracture toughness". Os resultados do trabalho mostraram que embora os números relativos para os materiais em ambos os testes tenham sido semelhantes, não foi possível correlacionar os achados dos dois testes e, portanto, os autores ressaltaram que o teste de "fracture toughness" e o teste de tração são dois parâmetros distintos de avaliação da interface adesiva e necessariamente não seguem os mesmos critérios de fratura.

BURROW et al. ${ }^{8}$, em 1994, investigaram qual a influência que duas variáveis, profundidade e idade da dentina humana, poderiam ter na resistência adesiva à tração de três sistemas adesivos: Scotchbond MultiPurpose, Superbond D-Liner e Liner Bond II. Os dentes foram divididos em dois grupos: o primeiro, de dentes extraídos de pacientes com idade em torno de trinta anos e o segundo com pacientes acima de cinqüenta anos de idade. Foram preparados discos de dentina a partir da porção oclusal, abaixo da junção esmalte-dentina e acima da polpa, com aproximadamente $3 \mathrm{~mm}$ de espessura. Essas duas superfícies foram classificadas como dentinas superficial e profunda, respectivamente. Os adesivos seguidos da resina Photo Clearfil Anterior foram aplicados nas superfícies em uma área de $3 \mathrm{~mm}$ de diâmetro e submetidos aos testes após 24 ou 48 horas. Seis espécimes foram testados para cada variável (dentina jovem ou adulta e dentina superficial ou profunda). Os autores encontraram como resultados de resistência adesiva que não houve diferença quando os espécimes foram testados nos períodos de 24 ou 48 horas e todos os valores foram maiores 
que $10 \mathrm{MPa}$ para todos os materiais. Para os grupos do Scotchbond MP e Liner Bond II, houve uma uniformidade nos resultados, o mesmo não ocorrendo quando o Superbond D-Liner foi utilizado em dentina jovem profunda (10,8 MPa) e dentina adulta superficial (17,4 MPa). No entanto, para os espécimes aderidos em dentina profunda, na sua totalidade, os valores foram levemente mais baixos.

CARVALHO et al. ${ }^{13}$, em 1994, realizaram um estudo com a finalidade de apresentar e avaliar a resistência de união à microtração de um sistema adesivo e de um cimento de ionômero de vidro à dentina, comercialmente conhecidos como Scotchbond Multi-Purpose e Variglass, respectivamente. Para tanto, a superfície oclusal da dentina de terceiros molares não irrompidos e extraídos foi tratada com um dos materiais, e, em seguida, uma restauração da porção coronária removida, de aproximadamente 3-5 mm de altura foi construída pela técnica incremental, utilizando-se resina composta Z100 ou o próprio cimento de ionômero de vidro. As áreas das superfícies adesivas foram desgastadas em forma de ampulheta, com a porção mais estreita coincidente com a área adesiva e, posteriormente, foram calculadas antes dos testes pela medida da largura e espessura de cada espécime, as quais variaram de aproximadamente $0,5 \times 0,5 \mathrm{~mm}$ a $2 \times 3 \mathrm{~mm}$. Os espécimes foram afixados a um dispositivo de testes Bencor-Multi-T e submetidos ao ensaio de tração em uma máquina Instron. Após a realização dos testes, a natureza da fratura de cada espécime foi observada sob microscópio de dissecção em aumento de 10X. Como resultados, os autores encontraram uma relação inversa entre a resistência de união à tração e a área de superfície adesiva para ambos os materiais testados e que, o Scotchbond Multi-Purpose apresentou uma maior força de união do que o Variglass. A área de superfície adesiva para o Scotchbond variou de 0,45$4,95 \mathrm{~mm}^{2}$ e nenhuma fratura coesiva de dentina foi observada; todas as falhas foram de natureza adesiva. Para o Variglass, a área de adesão variou de 0,42-4,01 $\mathrm{mm}^{2}$ e nenhuma falha coesiva em dentina também foi observada; entretanto, várias falhas coesivas ocorreram no material. 
Em 1994, CHAPPELL et al. ${ }^{20}$, realizaram um estudo para avaliar a existência de um mecanismo micromecânico de união à dentina, promovido pela anastomose dos prolongamentos de resina nos canais laterais dos túbulos dentinários. Para tanto, realizaram uma investigação da interface adesiva em dentina desmineralizada através de MEV, a partir da obtenção de espécimes preparados em terceiros molares humanos extraídos. As coroas dos dentes foram seccionadas, horizontal e perpendicularmente ao longo eixo do dente, a aproximadamente $2 \mathrm{~mm}$ da polpa. A superfície foi desgastada com lixa de carbureto de silício de granulação 320 para padronizar a smear layer. Utilizou-se os sistemas adesivos All-Bond 2, C\&B Metabond, Scotchbond Multipurpose, Tenure Solution e XR-Bond e como material restaurador, a resina P-50. Após a realização das restaurações, os espécimes foram desmineralizados e preparados para serem avaliados em MEV, em aumentos que variaram de 10 a 2.500X. Os resultados obtidos indicaram que, à exceção do XR-Bond e do All-Bond 2 sem o uso do condicionamento, os quais formaram poucos prolongamentos transversais na superfície de dentina, todos os sistemas empregados demonstraram uma alta densidade de prolongamentos de resina nos túbulos e canais laterais. $A$ densidade de penetração em canal lateral foi substancialmente maior com o adesivo Soctchbond Multipurpose e cada prolongamento caracterizava uma rede interconectada de adesivo polimerizado. Os autores concluíram que a penetração do adesivo nas anastomoses dos canais laterais em dentina desmineralizada, é um fator que contribui para o aumento da retenção mecânica dos sistemas adesivos à dentina.

GWINNETT $^{41}$, em 1994, realizou um trabalho com o objetivo de avaliar o efeito da secagem com ar e do reumedecimento da dentina condicionada ou não com ácido fosfórico a 10\% sobre a resistência de união ao cisalhamento e, também, com o objetivo de determinar o fator que mais contribui para esta resistência de união; se a rede de colágenos ou se a área superficial da dentina desmineralizada remanescente. Para a primeira parte do estudo, empregou-se 120 molares humanos extraídos, os quais foram 
dividos em 12 grupos e restaurados com o sistema adesivo All-Bond 2 e a resina composta BisFil. Os seguintes valores foram obtidos quando realizouse o condicionamento ácido da dentina: Grupo 1) controle com dentina úmida: 24,20 \pm 2,03 MPa; Grupo 2) secagem durante 10 segundos: 19,83 \pm 5,42 MPa; Grupo 3) secagem durante 30 segundos: 11,56 \pm 4,93 MPa; Grupo 4) secagem durante 10 segundos e reumedecimento por 5 segundos: 25,38 \pm 3,89 MPa; Grupo 5) secagem durante 30 segundos e reumedecimento por 5 segundos: 24,66 \pm 4,54 MPa; Grupo 6: aplicação de $\mathrm{NaOCl}$ a $5 \%$ durante 2 minutos, lavagem com água por 30 segundos e secagem: $25,97 \pm 3,61 \mathrm{MPa}$. Para os grupos que não sofreram condicionamento ácido, os valores foram: Grupo 7) controle com dentina úmida: 21,54 \pm 4,07 MPa; Grupo 8) secagem durante 10 segundos: 14,62 \pm 3,55; Grupo 9) secagem durante 10 segundos e reumedecimento por 5 segundos: 16,95 \pm 4,04 MPa; Grupo 10) aplicação de $\mathrm{NaOCl}$ a 5\% durante 2 minutos, lavagem com água por 30 segundos e secagem: 13,67 \pm 4,39 MPa; Grupo 11) aplicação de um jato de ar abrasivo de bicarbonato de sódio: 18,78 \pm 3,62 MPa; Grupo 12) jato abrasivo seguido de $\mathrm{NaOCl}$ a 5\%: 19,87 \pm 2,03 MPa. Para a segunda parte do estudo, através de fotomicrografias obtidas por MEV e através de uma análise profilométrica, verificou-se que parece existir uma relação entre a área superficial e a resistência de união, ou seja, a camada mais superficial da zona de colágeno da dentina desmineralizada não contribui, per se, com a resistência de união. Por outro lado, sua integridade morfológica e o estado de umidade em que se encontra, permitem concluir que têm um papel significante quando se deseja uma resistência de união ótima.

Em 1994, SANO et al. ${ }^{110}$ levantaram a hipótese de que não existe uma relação entre área de superfície dentinária disponível para adesão e resistência de união à tração dos materiais adesivos. Para testarem esta hipótese, o esmalte da superfície oclusal de 20 terceiros molares humanos extraídos foi removido, expondo uma superfície plana de dentina 
posteriormente recoberta com resina composta ou cimento de ionômero de vidro, reconstruindo-se a porção coronária dos dentes que fora removida. Dividiu-se os dentes em 3 grupos, dependendo do sistema adesivo ou do material empregado para realizar a reconstrução: Clearfil Liner Bond 2, Scotchbond Multi-Purpose e Vitremer. Após 24 horas, cada dente reconstruído recebeu vários cortes longitudinais com espessuras variáveis de $0,5 \mathrm{~mm}$ a $3,0 \mathrm{~mm}$. Cada fatia assim obtida foi trabalhada para obter um corpo-de-prova em forma de ampulheta, sendo a porção mais estreita coincidente com a área da interface adesiva. Mensurou-se a área de superfície aderida, a quantidade de dentina remanescente com relação à polpa e, em seguida, cada corpo-de-prova foi submetido à força de tração. Como resultado, os autores observaram que há uma relação inversa entre a resistência de união à tração e a área de superfície aderida para os três sistemas adesivos testados. Com relação à espessura de dentina remanescente, não houve uma relação estatisticamente significante entre a resistência de união à tração e proximidade com a polpa. Em uma área de adesão menor que $0,4 \mathrm{~mm}^{2}$, a resistência de união por tração foi cerca de 55 MPa para o Clearfil Liner Bond 2, $38 \mathrm{MPa}$ para o Scotchbond MP e $20 \mathrm{MPa}$ para o Vitremer. Além destes valores quantitativamente mais elevados do que os encontrados em áreas de adesão maiores, todas as fraturas foram de natureza adesiva na união. $\mathrm{O}$ método empregado para realizar este teste foi denominado "microtração" e, além de permitir a mensuração de resistências de união elevadas sem fratura coesiva da dentina, o mesmo possibilita a realização de mensurações múltiplas em um único dente, citaram os autores.

Em 1994, SANO et al. ${ }^{108}$, realizaram um trabalho com o objetivo de examinar e localizar a presença de um canal de microinfiltração na camada híbrida, diferente daquele visto comumente via gap, analisando-se a interface dente/resina através de crio-MEV e MEV convencional após empregar o método de impregnação com íons de prata. Assim, 10 dentes bovinos anteriores foram empregados para o estudo, os quais receberam 
individualmente um preparo classe $\mathrm{V}$ em forma de píres, condicionamento ácido da superfície dentinária com ácido fosfórico a 37\%, aplicação do sistema adesivo Clearfil PhotoBond e restauração com Photo Clearfil Brigth. Metade dessa amostra foi preparada para a análise através de crio-MEV e a outra metade, para o método convencional de MEV, com impregnação de prata. A análise das fotomicrografias obtidas por crio-MEV permitiu observar que houve uma adaptação marginal muito boa do material restaurador às paredes cavitárias do preparo e uma ausência de gap, visto que este método de microscopia não danifica o espécime. Entretanto, independentemente da ausência de gap, analisando-se as fotomicrografias obtidas pelo método convencional, verificou-se que os íons de prata estavam presentes na porção mais basal da camada híbrida, indicando uma infiltração entre a resina e a estrutura dentária descalcificada. Este fato levou os autores a concluírem que os monômeros adesivos do Clearfil PhotoBond não foram capazes de penetrar completamente a área de dentina desmineralizada após o condicionamento ácido, deixando uma zona porosa disponível como canal de microinfiltração, bem abaixo da camada híbrida. Em outras palavras, existe um novo canal para a microinfiltração, não descrito previamente.

O colágeno, sem o suporte mineral de dentina ou mesmo de resina, pode atuar como uma área de transição fraca da interface dente/resina, e assim, permitir a instalação de uma eventual falha de união. Entretanto, a localização exata da falha de união ainda não foi claramente mostrada. Com estas colocações, TAM; PILLIAR ${ }^{123}$, em 1994, realizaram um estudo com o objetivo de caracterizar o modo de fratura da interface dente/resina, obtida a partir de espécimes preparados em dentes bovinos e submetidos ao teste de "fracture toughness", como descrito em um trabalho anterior publicado em 1993 ${ }^{122}$. Os sistemas adesivos utilizados foram: All-Bond 2 com e sem condicionamento ácido, Scotchbond 2 e Scotchbond Multi-Purpose. Assim, observou-se quatro tipos diferentes de formas de falha na união: 1) fratura coesiva da smear layer; 2) no interior de uma camada modificada de resina, 
entre a zona de interdifusão e o adesivo; 3) na camada híbrida e 4) na camada de colágeno que não foi infiltrada por resina. Os autores mencionaram que a interface apresenta uma arquitetura complexa que varia com a natureza do substrato dentinário, com o tratamento superficial dado à dentina e com o sistema adesivo empregado. Além disto, os tipos de falha na união parecem correlacionar-se com o teste empregado e com a extensão com que a resina é infiltrada e polimerizada, salientam.

TAY et al. ${ }^{134}$, em 1994, realizaram um estudo in vivo para investigar a interface dente/resina obtida com o sistema adesivo All-Bond 2, após condicionamento ácido total da dentina com ácido fosfórico $10 \%$. As características ultraestruturais desta camada foram examinadas 21 a 28 dias após a realização das restaurações, através de MEV e MET, em espécimes preparados a partir de restaurações classe $\mathrm{V}$ profundas, executadas em 20 pré-molares indicados para extração por razões ortodônticas. A partir da obtenção das fotomicrografias, cuja excelência das imagens deixa bem evidente, pôde-se sugerir que a obtenção de um selamento efetivo dos túbulos dentinários é conseguida pela: 1) formação de uma zona mais externa constituída pelo plug de resina, circunscrita por uma bainha de dentina impregnada por resina; e 2) pela formação de uma zona mais interna que aloja um revestimento de resina ao longo das paredes internas dos túbulos e que adapta bem próximo ao seu lúmen, os processos odontoblásticos.

O ponto de vista pessoal de VAN NOORT ${ }^{145}$ sobre a relevância clínica dos trabalhos laboratoriais que abordam a determinação da resistência dos materiais foi publicado em um artigo da revista Journal of Dentistry, em 1994. O autor considera que a mensuração da resistência dos materiais é realizada em laboratório primeiramente para determinar a sua relação com as características microestruturais do material, visto que, compreendo-se a microestrutura, é possível produzir materiais mais 
resistentes. Entretanto, salientou, começam a aparecer problemas quando se tenta relacionar esses dados com algum significado clínico, sem se levar em conta os aspectos funcionais do mecanismo através do qual o material é construído, como por exemplo: que a resistência, embora desejável, pode não ser necessariamente a questão mais importante e assim, consequentemente, deve-se tomar muito cuidado ao interpretar dados sobre resistência; deve-se dizer também que a maioria das propriedades são consideradas individualmente, para cada aplicação clínica, resumiu.

Questionando a validade dos testes de resistência adesiva que empregam uma força de cisalhamento, DELLA BONA; VAN NOORT ${ }^{25}$, em 1995, realizaram um trabalho para testar a hipótese de que esse teste é impróprio e inadequado para testar a adesão in vitro da resina composta à materiais cerâmicos, visto que, o sítio de fratura normalmente encontrado, ocorre na base cerâmica dos espécimes e não na área da interface adesiva. Para tanto, os autores conduziram o experimento em duas etapas; uma para avaliar a resistência ao cisalhamento e a distribução das forças através da análise do elemento finito, e outra, para avaliar a resistência à tração como forma alternativa mais favorável. Para a avaliação do efeito do cisalhamento, foram empregadas três configurações de espécimes diferentes, todas elas, porém, com interfaces adesivas iguais: grupo A) base cilíndrica de cerâmica medindo $10 \mathrm{~mm}$ de diâmetro por $3 \mathrm{~mm}$ de altura, onde foi aderida uma sobrebase de resina composta de $3 \mathrm{~mm}$ de diâmetro por $4 \mathrm{~mm}$ de altura; grupo B) base de resina com sobrebase de cerâmica; grupo C) cilindro único de resina. Para o teste de tração, foram confeccionadas 40 hastes cilíndricas cerâmicas em um dispositivo metálico próprio, adaptável a um mecanismo de encaixes de peças que permitiam a realização do teste na máquina de ensaios. Os espécimes foram divididos em dois grupos, sendo que em um deles, a superfície exposta da cerâmica foi tratada com HF 9,6\% durante dois minutos e no outro, com APF 4\%, seguindo-se a aplicação de um silano, uma fina camada de adesivo e em seguida, uma camada de resina composta, unindo duas hastes. Assim, para cada grupo, foram 
confeccionados 10 corpos-de-prova. Com relação à resistência ao cisalhamento, o valor encontrado para o grupo $A$ foi significativamente menor (10,37 MPa) do que os dos grupos B (18,02 MPa) e C (21,82 MPa). Destacou-se, porém, que no grupo B, $80 \%$ das falhas foram coesivas na base de resina e, no grupo $\mathrm{C}$, todas as fraturas foram coesivas na base. Com relação ao teste de resistência à tração, não houve diferença em realizar-se o tratamento cerâmico com HF ou APF (13,46 e 13,43 MPa, respectivamente) e todos os corpos-de-prova fraturaram-se na área da interface adesiva. Pela análise do elemento finito, verificou-se que o padrão de distribuição dos estresses nos espécimes submetidos à força de cisalhamento é altamente desuniforme, fora da área adesiva. Como conclusão, os autores relataram que o teste de resistência adesiva à tração é mais apropriado para avaliar a capacidade de união das resinas às cerâmicas.

Com o objetivo de comparar a morfologia da camada híbrida e o molhamento e a penetração do adesivo em relação à superfície dentinária submetida a diferentes pré-tratamentos, EICK et al. ${ }^{27}$, em 1995, conduziram um estudo empregando quatro sistemas adesivos, MEV, MET e espectroscopia de energia dispersiva. Para tanto, realizaram uma pequena alteração na molécula do HEMA, substituindo o átomo de oxigênio por enxofre, produzindo um análogo - HETMA - com parâmetros de solubilidade e outras propriedades físicas e de molhamento muito semelhantes. Assim, quatro grupos de três dentes cada foram tratados com diferentes tipos de primer ou condicionamento e, em seguida, aplicou-se uma solução de HETMA a $10 \%$ (vol./vol.) em acetona. Quando foi empregado como tratamento prévio o ácido nítrico, o ácido maleico e a solução ácido cítrico/cloreto férrico, houve a formação de uma zona desmineralizada de aproximadamente 1 a $3 \mu \mathrm{m}$ de espessura. Analisando-se as fotomicrografias obtidas, o HETMA penetrou perfeitamente nesta área desmineralizada produzida pelo ácido maleico e a solução 10/3; entretanto, com o uso do ácido nítrico, a permeação do HETMA não foi possível. O último grupo de 
dentes foi tratado com uma solução a base de álcool mais PENTA e HEMA, a qual, aparentemente, modificou a smear layer ligeiramente mas não desmineralizou a dentina subjacente, e assim, o HETMA aplicado nesses espécimes estava visivelmente em contato com a dentina ou a smear layer modificada, sem contudo, difundir-se nessas áreas. Concluindo o trabalho, os autores consideraram que o pré-tratamento ácido da dentina influencia o comportamento de molhamento do adesivo e portanto, pode afetar substancialmente o resultado da resistência adesiva.

JACOBSEN; SÖDERHOLM ${ }^{47}$, em 1995, realizaram um trabalho com o objetivo de determinar se a resistência de união obtida com primers a base de HEMA é afetada pelo tipo de solvente empregado, água ou acetona, se o tempo de aplicação destes primers afeta da mesma forma a resistência de união e a taxa de conversão de adesivos contaminados por água. Empregando-se 32 incisivos centrais bovinos divididos em quatro grupos com oito espécimes cada, foram realizadas restaurações em dentina aplicando-se como primer uma solução de HEMA/acetona ou HEMA/água, por 30 ou 120 segundos, as quais posteriormente foram testadas quanto à resistência de união ao cisalhamento. Para avaliar-se a taxa de conversão dos adesivos, preparou-se um adesivo misturando-se $37,1 \%$ por peso de HEMA com $61,9 \%$ por peso de água, 0,3\% por peso de canforoquinona, 0,025\% por peso de buthylated hydroxytoluene (BHT) e $0,675 \%$ por peso de dimethylaminoethylmethacrylate. $1 \mathrm{~mL}$ de adesivo foi gotejado em vários recipientes e em seguida, foi adicionada água em quantidades variáveis individualmente; 0,05, 0,10,0,20, 0,40 e 0,80 mL. Para cada variação da quantidade de água adicionada, foram confeccionados 6 espécimes. Estes, após serem misturados em ultra-som, foram analisados em espectrofotometria infravermelha transformada de Fourier (FTIR). Os dois grupos (30 ou 120 segundos, respectivamente) tratados com primer à base de acetona apresentaram valores de resistência de união maiores (22,2 \pm 2,1 MPa e 21,5 $\pm 3,2 \mathrm{MPa}$ ) do que os grupos tratados com primer à base de 
água (7,0 \pm 3,3 MPa e 16,2 \pm 4,8 MPa). Nestes últimos, observou-se que a resistência aumentou quando o primer foi aplicado em um tempo maior; porém, este valor não chegou a ser o mesmo que o observado para os grupos que empregaram primers à base de acetona. Com relação à taxa de conversão do adesivo, esta foi de $53,5 \%$, diminuindo para aproximadamente $25 \%$ quando $0,2 \mathrm{~mL}$ ou mais de água foi aplicado por $\mathrm{mL}$ de resina. Como conclusão, os autores defenderam que: comparando-se a acetona e a água, como solventes de primers à base de HEMA, a água confere uma resistência de união menor do que a acetona e requer um tempo de atuação do primer mais prolongado. Isto poderia ser explicado, segundo eles, pela capacidade da água em interferir com a polimerização dos adesivos.

PASHLEY et al. ${ }^{82}$, em 1995, apresentaram uma revisão da literatura sobre os tipos de testes de resistência adesiva e a validade dos valores obtidos com os mesmos, enfocando diversos aspectos: os substratos para a adesão, as variáveis envolvidas no condicionamento, na aplicação dos primers e dos adesivos, as variáveis de armazenamento e as variáveis dos testes em si. Considerando que muitos dos sistemas adesivos atuais apresentam capacidade de desenvolver resistências adesivas da ordem de 20 a $30 \mathrm{MPa}$ e que, como conseqüência destes altos valores muitas das falhas de união ocorrem coesivamente na dentina, os autores enfatizaram a importância em se desenvolver novos tipos de testes para avaliar a resistência de união. Dentre esses, destacam o método de microtração como uma possível solução pois, segundo eles, este método permite analisar adesões sob condições clinicamente relevantes, valores de união de até $70 \mathrm{MPa}$ e uma maior porcentagem de falhas adesivas. São citadas as seguintes vantagens do teste de microtração: maior porcentagem de falhas adesivas do que coesivas; possibilidade de mensuração de valores de resistência de união bem mais elevados; possibilidade de mensuração de resistências de união regionais; possibilidade de cálculo da média e do desvio-padrão em um único dente; possibilidade de testar a resistência de 
união em superfícies irregulares; possibilidade de testar áreas muito pequenas; facilidade de exame em MEV da área de fratura, visto que a superfície a ser avaliada é de aproximadamente $1 \mathrm{~mm}^{2}$. Como desvantagens, são citadas: a dificuldade em preparar os espécimes, o que demanda cuidados técnicos; a dificuldade em se mensurar valores de resistência de união inferiores à $5 \mathrm{MPa}$; a necessidade de equipamento especial; e a tendência dos espécimes de se desidratarem rapidamente por serem muito pequenos.

Considerando que até então, pouco se sabia a respeito da capacidade dos sistemas adesivos em restaurar as propriedades físicas da dentina desmineralizada e que os sistemas adesivos sem carga que são usados para a adesão apresentam um módulo de elasticidade relativamente baixo e uma capacidade limitada de aumentar a rigidez da dentina, embora possam aumentar a resistência à tração, SANO et al. ${ }^{112}$ (1995) realizaram um trabalho para testar a hipótese de que a infiltração de resina na dentina desmineralizada pode restaurar sua propriedade de resistência à tração de forma semelhante à da dentina mineralizada. Para tanto, foram preparados pequenos espécimes de dentina humana desmineralizada em forma de " cuja porção central media $0,5 \times 0,5 \mathrm{~mm}$. Em seguida, os espécimes, num total de 50 , foram divididos em 5 grupos para receberem aleatoriamente, o tratamento com um dos sistemas adesivos: All-Bond 2, Scotchbond MultiPurpose, Clearfil Liner Bond 2, Superbond C\&B e Clearfil Photobond. Desta forma, procurou-se determinar o quanto a infiltração do sistema adesivo na matriz de dentina desmineralizada poderia alterar a sua propriedade de resistência à tração. A esses cinco grupos, foram também adicionados dois grupos controle de 10 espécimes cada: um grupo com a matriz de dentina mineralizada, e outro, de dentina desmineralizada com EDTA mas que não recebeu nenhum outro tratamento adicional. Assim, após serem submetidos ao teste de microtração, os resultados mostraram que alguns sistemas adesivos, após serem infiltrados na dentina desimineralizada, podem restabelecer ou mesmo exceder a resistência à tração máxima da dentina 
mineralizada. Além disso, esses sistemas adesivos aumentaram o módulo de elasticidade da dentina infiltrada com os adesivos até alcançarem valores semelhantes ou até mesmo superiores àqueles dos sistemas adesivos somente; porém, não aumentaram a ponto de se igualarem ao módulo de elasticidade da dentina mineralizada.

Considerando que muito embora a maioria dos estudos sobre microinfiltração baseia-se em quantificar a penetração ou a "movimentação" de uma molécula traçadora através da interface entre o material restaurador e a parede do preparo, SANO et al. ${ }^{111}$, em 1995, realizaram um trabalho para examinar a possível migração do nitrato de prata no interior da interface dentina/sistema adesivo, na ausência de gap, com cinco diferentes sistemas adesivos. Para tanto, foram utilizados 35 molares humanos, os quais receberam individualmente um preparo classe $\mathrm{V}$ em forma de pires. Realizados o tratamento da superfície dentinária e a restauração, os espécimes foram armazenados em água durante 24 horas e, em seguida, após recobrimento de toda superfície dentária exposta $1 \mathrm{~mm}$ além da restauração, os mesmos foram imersos em uma solução de nitrato de prata $3 \mathrm{~mol} / \mathrm{L}$ por mais 24 horas. Desta forma, os espécimes foram seccionados e preparados para serem avaliados em MEV. As fotomicrografias revelaram vários padrões de infiltração; porém, todos eles indicavam a presença de infiltração no interior da camada híbrida. A taxa de infiltração em ordem decrescente para os diferentes sistemas adesivos foi respectivamente: AllBond 2, Superbond C\&B, Scotchbond Multi Purpose, Clearfil Liner Bond System e, por fim, KB-200. Para distinguir esse tipo de microinfiltração no interior da região basal e mais porosa da camada híbrida na ausência de formação de gap da infiltração convencional, os autores propuseram o termo "nanoinfiltração".

No mesmo ano, novamente SANO et al. ${ }^{113}$ realizaram um trabalho na mesma linha de pesquisa na tentativa de localizar as porosidades 
nanométricas ou submicrométricas encontradas no interior da camada híbrida formada por dois sistemas adesivos diferentes, através de MEV e MET. Assim, para avaliar a qualidade da camada híbrida, consideraram a possibilidade da utilização de moléculas traçadoras como o nitrato de prata de serem detectadas tanto por MEV quanto por MET, e auxiliarem a encontrar a localização destas porosidades que podem permitir a hidrólise das fibras colágenas e a degradação dos monômeros resinosos. Desta forma, o estudo procurou também comparar os resultados das fotomicrografias obtidas através dos dois métodos. Para tanto, foram preparados dez espécimes (cinco para cada material) em forma de "sanduíches de discos de dentina", empregando-se como sistemas adesivos o Clearfil Liner Bond e o All-Bond 2. Após 24 horas de armazenamento, os espécimes foram seccionados ao meio e uma metade serviu para ser avaliada em MEV e a outra em MET. Para cada grupo de material, três espécimes foram submersos em nitrato de prata e os outros dois remanescentes serviram de controle. As fotomicrografias revelaram que com o sistema adesivo Clearfil Liner Bond, as partículas de prata apareceram dispersas nos dois terços inferiores da camada híbrida, tanto em MEV quanto em MET. Por outro lado, o sistema All-Bond 2 mostrou uma impregnação completa de prata em toda a extensão da camada híbrida, também em ambos métodos de avaliação. Os espécimes que serviram de controle não apresentaram qualquer indicação de depósitos elétron-densos na base da camada híbrida, tanto em MEV quanto em MET. Os autores concluíram que a MEV permite detectar facilmente a penetração do nitrato de prata no interior da camada híbrida, mas a MET é também necessária porque permite determinar a distribuição exata da prata dentro da camada híbrida.

Considerando que nos últimos anos tem-se observado um número significativo de trabalhos na literatura abordando criticamente o papel da rede de colágenos de dentina exposta após o condicionamento ácido, e que, a dissolução do colágeno pela desproteinização previamente ao processo 
adesivo, produz uma melhora nos resultados de resistência adesiva, UNO; FINGER ${ }^{141}$, em 1995, conduziram um estudo com o objetivo de investigar o efeito, portanto, da dissolução do colágeno após o condicionamento ácido na resistência de união e na micromorfologia e adaptação marginal de restaurações de resina composta. Utilizando-se dentes molares humanos, o preparo dos espécimes para o teste de resistência de união ao cisalhamento foi dividido em três grupos com cinco dentes cada. No grupo 1, que serviu de controle, empregou-se como condicionador uma solução de ácido fosfórico a $20 \%$ seguida da aplicação do sistema adesivo Gluma e restauração com a resina Pekafill, numa área circular de adesão com diâmetro de 3,5 mm. Para o grupo 2, empregou-se como condicionador um gel de ácido fosfórico a $20 \%$ contendo $5 \%$ de dióxido de silicone como um agente espessante, seguindo-se da aplicação de $\mathrm{NaOCl} 10 \%$ durante 60 segundos e todo procedimento restaurador descrito para o grupo anterior. No último grupo, grupo 3, as restaurações foram feitas da mesma forma que no grupo anterior, porém, ao invés de um gel, foi aplicada uma solução de ácido fosfórico a $20 \%$. Para a análise micromorfológica, foram preparados alguns espécimes para MEV. Os valores de resistência de união ao cisalhamento foram: grupo 1: 12,7 \pm 2,0 MPa; grupo 2: 16,6 \pm 3,2 MPa; e, grupo 3: 15,4 \pm 4,4 MPa. Nenhuma diferença estatística foi encontrada entre os grupos, embora quando foi feita a desproteinização do colágeno (grupos 2 e 3), a resistência tenha mostrado, tendenciosamente, valores mais altos. Por outro lado, analisandose as fotomicrografias obtidas, verificou-se que a qualidade marginal das restaurações foi nitidamente superior no grupo controle, ou seja, quando a camada híbrida encontrava-se presente. Os autores consideraram que a camada híbrida apresenta um módulo de elasticidade mais baixo que o do material restaurador e, portanto, ela poderia atuar como um camada elástica que absorveria as forças de contração da resina, o que poderia explicar 0 melhor comportamento dos espécimes do grupo 1. 
YOSHIYAMA et al. ${ }^{155}$, em 1995, realizaram um trabalho com o objetivo de avaliar a morfologia interfacial por MEV de dois sistemas adesivos, All Bond 2 e Imperva Bond, empregados sobre uma superfície de dentina mais superficial e outra mais profunda através da técnica do sanduíche reverso, e também, avaliar a resistência adesiva pela técnica de microtração. Para a análise em MEV, foram preparados discos com dentina mais superficial e discos com dentina mais profunda sendo que um par de disco de diferente profundidade foi obtido de um mesmo dente. Utilizou-se apenas terceiros molares humanos não erupcionados. Após a aplicação do sistema adesivo, os dois discos obtidos do mesmo dente foram unidos, formando um espécime cuja configuração foi denominada "sanduíche reverso". No total, foram preparados dois espécimes para cada sistema adesivo. Adicionalmente, dois espécimes de cada material foram preparados sem o condicionamento prévio. Desta forma, os espécimes receberam um tratamento adequado para análise em MEV. Para a análise da resistência adesiva, utilizou-se 16 dentes no total; metade para avaliar a resistência na camada de dentina mais superficial, e a outra metade, a resistência na camada mais profunda. Da mesma forma, metade dos dentes a serem avaliados também receberam condicionamento ácido prévio e a outra metade não, formando 4 subgrupos. E assim, os dentes foram trabalhados a fim de permitir a obtenção de espécimes para serem avaliados quanto a resistência à microtração, cuja área de secção transversa no local de leitura variou de 0,95-1,05 $\mathrm{mm}^{2}$. Os resultados das fotomicrografias revelaram que ambos materiais quando aplicados após o condicionamento ácido formaram uma camada híbrida mais espessa $(4-8 \mu \mathrm{m})$ na dentina profunda do que na dentina superficial (2-4 $\mu \mathrm{m})$. Quando não foi feito o condicionamento, houve a formação de uma camada híbrida muito fina (menos do que 0,5 $\mu \mathrm{m}$ ), independentemente do substrato dentinário. Os resultados dos testes de microtração mostraram que a resistência adesiva dos dois materiais foi maior do que $20 \mathrm{MPa}$, independentemente da profundidade de dentina quando foi feito o condicionamento ácido prévio. Também não houve diferença estatística significante entre eles. Quando não foi feito o 
condicionamento prévio, a resistência adesiva para ambos sistemas à dentina profunda foi significantemente menor do que da dentina superficial. Assim, os autores relataram que para os sistemas que fazem uso do condicionamento total, a profundidade da dentina afeta a espessura da camada híbrida, porém, a espessura da camada híbrida não apresenta uma relação significante com a resistência adesiva. Os autores ainda comentaram que os dados indicam que a técnica de condicionamento ácido poderia prevenir a diminuição da resistência adesiva vista na dentina profunda, quando esta não foi executada.

Em 1996, BURROW et al. ${ }^{9}$ avaliaram a resistência à tração de quatro sistemas adesivos à dentina coronária e radicular de dentes bovinos e a estrutura da camada híbrida nesses diferentes substratos através de MEV. Para o preparo dos espécimes, os dentes foram seccionados na junção amelocementária e desgastados com disco de lixa granulação 600 até atingir uma superfície plana, adequada para adesão, paralela ao longo eixo do dente. A área disponível para adesão foi isolada com fita adesiva, expondo um orifício de $3 \mathrm{~mm}$ de diâmetro. Os sistemas adesivos testados foram: All Bond 2, Clearfil Liner Bond II, ProBond e Super-Bond D-Liner Plus e, para restauração, utilizou-se a resina Photo Clearfil Bright. No total, foram confeccionados 10 corpos de prova de cada substrato para cada material e assim, os mesmos foram submetidos ao teste de resistência adesiva frente a uma forca de tração. Para a análise de MEV preparou-se 5 espécimes de cada substrato para cada material e os mesmos foram avaliados após polimento, após imersão em ácido fosfórico 10\% por 3-5 segundos, seguida pela imersão em hipoclorito de sódio $5 \%$ durante 10 minutos. Os resultados obtidos da resistência adesiva mostraram que não houve diferença estatística entre a dentina coronária e radicular quando empregou-se 0 ProBond e o Super-Bond D-Liner Plus. Com o All Bond 2, observou-se uma resistência significantemente menor na dentina coronária, enquanto que com o Clearfil Liner Bond II, observou-se o oposto, ou seja, uma maior resistência na dentina radicular. As análises das fotomicrografias revelaram que a 
camada híbrida pode ser observada com o All Bond 2, Liner Bond II e SuperBond D-Liner Plus, sem diferenças aparentes entre a camada híbrida formada na dentina radicular e coronária. No caso do ProBond, onde a smear layer não foi removida durante a etapa de aplicação do primer, parece que este infiltrou-se e hibridizou a smear layer. Assim, os autores relatam que provavelmente as diferenças nos valores de resistência adesiva parecem estar relacionadas com as diferenças no mecanismo de união de cada material, assim como com a presença de possíveis variações nos substratos coronal ou radicular.

CARVALHO et al. ${ }^{14}$, em 1996, realizaram um trabalho de revisão abordando o problema da contração de polimerização, discorrendo sobre a relação dos estresses gerados durante a polimerização e os estresses de relaxamento que ocorrem nas restaurações adesivas com materiais resinosos. Os autores comentaram que essa competição de forças de contração de polimerização e a força de união pode até certo ponto ser controlada através da configuração cavitária (fator $\mathrm{C}$ ), do uso de bases, pelo tamanho, forma e posição dos incrementos de resina composta inseridos na cavidade, como também pelo tipo de polimerização da resina, química ou fotoativada. $\mathrm{O}$ fator $\mathrm{C}$, em outras palavras, poderia ser expresso como 0 resultado da fração do total das faces aderidas da restauração sobre o total de faces não aderidas. Assim, os estresses de relaxamento poderiam ser conseguidos pela manutenção de um fator $C$ menor possível, pelo uso de resinas quimicamente ativadas, pela aplicação de forramentos de baixo módulo de elasticidade, e, com o decorrer do tempo, pela absorção de água. Concluindo, destaca-se que a compreensão destes princípios, permite que o clínico exerça um maior controle destas variáveis e, consequentemente, consiga melhorar a qualidade de suas restaurações adesivas.

Considerando que existe pouca informação concernente aos efeitos dos vários tipos de tratamento e de condicionadores sobre a estrutura de 
dentina desmineralizada, CARVALHO et al. ${ }^{15}$, em 1996, realizaram um trabalho com o objetivo de mensurar as alterações dimensionais na área de dentina desmineralizada quando esta é sujeita aos procedimentos seqüenciais empregados na técnica de aplicação do sistema adesivo, através do uso de macromodelos. O presente trabalho também testou a hipótese de que a infiltração da dentina desmineralizada com HEMA, pode prevenir sua contração quando exposta ao ar. Para tanto, foram confeccionados 40 espécimes de dentina medindo aproximadamente 0,7 $\mathrm{x}$ 0,7 x 5,0 mm, obtidos a partir de terceiros molares humanos extraídos e armazenados em solução salina contendo 0,5\% de azido de sódio. Os espécimes foram desmineralizados em solução de ácido cítrico 10\% e cloreto férrico $3 \%$ durante 8 horas e posteriormente divididos em quatro grupos $(A, B, C$ e $D)$ de 10 espécimes cada. Os espécimes dos grupos $A$ e $B$ serviram para avaliar as alterações volumétricas após a secagem e posterior imersão em água ou numa solução aquosa de 50\% água/50\% HEMA ou $100 \%$ HEMA. Na seqüência, os espécimes do grupo A foram secos, imersos em água, em seguida imersos em 100\% HEMA e novamente secos. Os do grupo $B$, foram secos, imersos em 100\% HEMA, imersos em água, imersos em 50\% HEMA e, finalmente, deixados para secar espontaneamente, de forma que as alterações volumétricas foram monitoradas em função do tempo. Os espécimes dos grupos $\mathrm{C}$ e D serviram para avaliar a capacidade do $100 \%$ HEMA ou do $100 \%$ etilenoglicol em prevenir o colapso da dentina desmineralizada quando exposta ao ar. Os tratamentos, na seqüência, no grupo C foram: imersão gradual em diferentes soluções de HEMA (50, 75 e $100 \%$ ) e secagem espontânea e monitorada. No grupo D, os tratamentos foram os mesmos que os do grupo $\mathrm{C}$, porém as soluções empregadas eram a base de etilenoglicol. Em todos os grupos, após cada tratamento, foi feita a análise da alteração dimensional com o auxílio de um microscópio de dissecção, sendo que para isso, os espécimes quando mensurados, ficavam submersos na solução apropriada. Os resultados do trabalho mostraram que: 1) a desmineralização causou uma pequena redução no volume da dentina (1,9\%), porém, não significante; 2) a posterior secagem com ar 
reduziu $65,6 \%$ do volume original; 3) após a secagem, quando os espécimes foram imersos em água, eles restabeleceram o seu volume original; 4) a imersão dos espécimes em 100\% HEMA não permitiu uma reexpansão da dentina desmineralizada colapsada; 5) os espécimes imersos na solução de $50 \%$ HEMA contraíram $50 \%$ em volume quando expostos ao ar; 6) ambas as soluções, 100\% HEMA e 100\% etilenoglicol foram capazes de prevenir o colapso da dentina desmineralizada; 7) a técnica empregada foi efetiva para avaliar as alterações dimensionais que devem ocorrer em nível microscópico durante os procedimentos adesivos.

CARVALHO et al. ${ }^{16}$, em 1996, realizaram um estudo com o objetivo de avaliar os efeitos da secagem com ar, da acetona e do HEMA sobre o módulo de elasticidade da dentina humana desmineralizada e, para tanto, barras retangulares de dentina foram obtidas da coroa de terceiros molares humanos e desmineralizadas em sua porção central por 72 horas em 0,5 M de EDTA. Alguns espécimes foram desidratados em acetona, outros em HEMA e outros expostos ao ar. Os espécimes foram testados em tração e os dados de esforço e deformação calculados em função das dimensões originais da área transversal e do comprimento da área desmineralizada. $\mathrm{O}$ módulo de elasticidade foi calculado para os espécimes desidratados e comparado com espécimes testados em água. Todos os métodos de desidratação causaram um aumento significante no módulo de elasticidade da dentina desmineralizada. Os espécimes secos em ar sofreram o maior aumento de módulo, seguidos do espécimes desidratados em acetona e, finalmente, espécimes desidratados em HEMA. A mudança das propriedades mecânicas da dentina desmineralizada, causada pelos solventes orgânicos tais como acetona e HEMA, pode alterar a permeabilidade da área condicionada aos agentes adesivos, comentam os autores. Isso pode influenciar a qualidade do processo adesivo à dentina, finalizam. 
KANCA $\| I^{52}$, em 1996, realizou um trabalho com o objetivo de examinar o efeito do tempo e da distância de secagem sobre a resistência de união ao cisalhamento proporcionada pelo uso de um sistema adesivo que faz uso da técnica úmida de adesão, o One-Step. Empregou-se 70 molares humanos extraídos, os quais foram divididos em 7 grupos, variandose o tempo e a distância de secagem. A superfície vestibular dos dentes foi removida, expondo uma superfície plana de dentina que foi tratada com ácido fosfórico a 37\% durante 10 segundos, lavada, e em seguida restaurada seguindo-se as variações de cada grupo no que se refere à secagem da superfície, para receber uma restauração de resina Bis-Fil compreendendo uma área adesiva de $4 \mathrm{~mm}$ de diâmetro. Os valores obtidos foram: Grupo 1) secagem durante 5 segundos, deixando-se a superfície visivelmente com uma camada de água: 30,0 \pm 4,3 MPa; Grupo 2) secagem por 1 segundo a uma distância de $1 \mathrm{~cm}$ : 25,7 \pm 5,4 MPa; Grupo 3) secagem por 3 segundos a uma distância de $1 \mathrm{~cm}$ : 11,0 \pm 4,3; Grupo 4) secagem por 5 segundos a uma distância de $1 \mathrm{~cm}: 8,6 \pm$ 2,3 MPa; Grupo 5) secagem por 1 segundo a uma distância de $10 \mathrm{~cm}$ : 31,7 \pm 2,9 MPa; Grupo 6) secagem por 3 segundos a uma distância de 10 cm: 24,3 \pm 5,2 MPa; Grupo 7) secagem por 5 segundos a uma distância de $10 \mathrm{~cm}$ : 15,8 \pm 4,7 MPa. Analisando-se os resultados, verificou-se que o tempo e a distância de secagem tiveram uma influência significante sobre os valores de resistência de união; ou seja, quanto maior o tempo de secagem e menor a distância, pior foi a resistência encontrada. Os autores comentam que o balanço de água necessário para uma boa adesão é um assunto que requer uma melhor compreensão e maiores investigações.

Durante os procedimentos adesivos, a superfície dentinária usualmente é tratada com um agente condicionador que remove a smear layer e desmineraliza a camada mais superficial, expondo uma rede de colágenos. Esta superfície descalcificada é seca com um jato de ar ou então, tratada com solventes orgânicos; procedimentos esses, que podem 
modificar as propriedades físicas da matriz dentinária. Baseados nessas observações, MACIEL et al. ${ }^{58}$, em 1996, realizaram um trabalho para avaliar os efeitos da desidratação sobre a rigidez da matriz de dentina descalcificada. Para tanto, pequenos espécimes de dentina medindo $8 \times 1,7$ x 0,9 mm foram preparados a partir do terço médio-coronário de molares humanos extraídos. As extremidades desses espécimes foram recobertas com um verniz de proteção, e, em seguida, os mesmos foram colocados em 0,5 M de EDTA por cinco dias para sofrerem descalcificação completa. A rigidez dos espécimes foi mensurada tanto pela técnica de cantilever como pelo teste de força/deformação convencional. Para o grupo dos espécimes testados pela técnica de cantilever, estes foram expostos seqüencialmente em água, acetona, álcool, HEMA e glutaraldeído. Pelo teste de força/deformação convencional, os espécimes foram expostos à água, à acetona ou ao HEMA, ou então, foram deixados expostos ao ar, para que secassem espontaneamente. Os resultados obtidos indicaram que a rigidez da matriz de dentina humana descalcificada é muito baixa (aproximadamente $7 \mathrm{MPa}$ ) quando os espécimes foram submersos em água. Desidratando-os, quimicamente em solventes orgânicos ou fisicamente com o ar, a rigidez aumentou cerca de 20 a 38 vezes com um carregamento de força baixo, e cerca de 3 a 6 vezes, ao empregar-se forças mais altas. Entretanto, o aumento no módulo de elasticidade foi rapidamente perdido quando colocou-se os espécimes em água, o que provocou uma reidratação das fibras colágenas expostas. Com a aplicação do glutaraldeído, houve da mesma forma um aumento na rigidez; porém, esta não foi reversível quando os espécimes foram recolocados em água.

Considerando que para o sucesso observado com a técnica úmida de adesão o estado de hidratação das fibras colágenas que permite a preservação da integridade morfológica é uma condição fundamental, TAY et al. ${ }^{136}$, em 1996, realizaram um estudo com o objetivo de avaliar as diferenças micromorfológicas entre as técnicas de adesão úmida e seca empregando um sistema adesivo cujo primer consiste de apenas um 
componente, à base de álcool e não apresenta água na sua composição (Aelitebond) e um sistema adesivo experimental cujo primer apresenta-se na forma de dois componentes, à base de acetona e também não possui água na sua composição. Para o experimento, utilizou-se 24 dentes humanos, terceiros molares, a partir dos quais foram preparados 24 discos de dentina de 1-1,5 mm de espessura. Os discos foram divididos em quatro grupos e condicionados com ácido fosfórico $10 \%$ na forma de gel durante 20 segundos e em seguida lavados com água por mais 20 segundos. Dois grupos de dentes serviram para testar a condição seca da dentina e os outros dois, para condição úmida, e neste caso, somente o excesso de água sobre a dentina foi eliminada com papel absorvente de forma que a superfície permanecesse visivelmente úmida antes do procedimento adesivo. Nos grupos para avaliar a condição seca, as superfícies foram desidratadas com jato de ar durante 30 segundos, previamente ao procedimento adesivo. Após realizar o procedimento adesivo, os discos de dentina de cada grupo foram unidos com resina, formando três pares de disco por grupo. Cada disco foi posteriormente seccionado ao meio e metade foi preparada para ser analisada em MEV e a outra metade para MET. Nos grupos que serviram para avaliar a condição úmida, observou-se a presença de fibras colágenas e dos espaços interfibrilares e um completo molhamento dessa rede de colágenos pela resina, resultando na formação de uma camada híbrida de aproximadamente $5 \mu \mathrm{m}$. Nos outros grupos, verificou-se a presença de uma camada híbrida muito fina sobre a superfície dentinária, ao longo das paredes dos túbulos e ao longo dos prolongamentos laterais dos túbulos. A ausência das fibras colágenas e dos espaços interfibrilares nestas áreas sugeriu que existe uma matriz de dentina colapsada que restringiu a penetração da resina na matriz intertubular subsuperficial, produzindo uma camada não infiltrada completamente, denominada pelos autores de "região hibridóide". 
TAY; GWINNETT; WEI ${ }^{128}$, em 1996, relataram que para se conseguir uma boa adesão e um bom selamento, é necessária uma quantidade suficiente de água; se a quantidade de água for excessiva, ela pode prejudicar esse resultado. Assim, considerando que a umidade superficial da dentina é, portanto, um assunto que precisa ser melhor compreendido, os autores realizaram um trabalho para testar a hipótese nula de que o grau de umidade superficial da dentina não é um fator importante para que os sistemas adesivos apresentem um bom comportamento. Para tanto, foram utilizados 24 dentes humanos, terceiros molares, e confeccionados 24 discos de dentina de aproximadamente 1,0 a 1,5 mm de espessura. Em seguida, os espécimes foram divididos em 3 grupos. Em todos os grupos, os espécimes receberam condicionamento ácido com ácido fosfórico a 10\% durante 20 segundos, foram lavados com água e restaurados com All-Bond 2. A diferença entre os grupos era que no grupo 1, a superfície dentinária foi seca com ar por 3 segundos a uma distância de $20 \mathrm{~cm}$, sem deixar sinais visíveis de água; no grupo 2, o excesso de água foi removido com pequenos pedaços de papel absorvente e a superfície dentinária apresentava-se visivelmente úmida; e, no grupo 3, para simular um supermolhamento, foram gotejados $40 \mu \mathrm{L}$ de água destilada sobre a superfície dentinária. Os discos foram tratados com o sistema adesivo de forma que um par de discos foi aderido um contra o outro. Desta forma, os espécimes foram preparados para serem analisados em microscópio óptico. Os resultados apresentados revelaram que quando foi deixado um excesso de umidade sobre a superfície da dentina, formaram-se espaços semelhantes a uma bolha na interface dentina/primer. Abaixo desses espaços, existiam túbulos que não estavam completamente selados. Além disso, havia a formação de glóbulos de primer sobre a superfície dentinária. Ou seja, a presença de bolhas microscópicas na interface dentina/primer pode servir de resposta às observações de uma menor resitência adesiva quando o sistema adesivo All-Bond 2 é aplicado com excesso de umidade superficial. A relevância do trabalho é que provavelmente, deve existir uma quantidade de água limite necessária para deixar a rede de colágeno desmineralizada estável de forma 
que se possa usufruir dos benefícios da "técnica úmida". Particularmente com o All-Bond 2, os autores comentam que a quantidade de água presente no material ou em sistemas semelhantes, pode ser um fator negativo para aqueles que já têm praticado a técnica úmida.

Seguindo a mesma linha de estudo, como parte de uma investigação micromorfológica do efeito da umidade superficial sobre a interface dente/resina, TAY, GWINNETT; WEI ${ }^{129}$, em 1996, realizaram um trabalho conduzido de forma semelhante ao acima referido, empregando-se 24 terceiros molares humanos extraídos divididos em 3 grupos tratados da mesma forma, porém, preparados para serem avaliados através de MEV. Pela análise das fotomicrografias, observou-se que embora a camada híbrida tenha sido observada nos três grupos, houve uma deterioração seqüencial da interface e uma perda completa do selamento tubular à medida que a quantidade de umidade superficial aumentava. Observou-se também a presença de glóbulos de resina intratubulares, abaixo de plugs curtos de resina, no grupo onde foi feita a secagem durante 3 segundos da superfície dentinária condicionada. No segundo grupo, onde o excesso de água foi removido com papel absorvente e a superfície dentinária apresentava-se visivelmente úmida, havia pequenos espaços em forma de bolha, isolados, confinados no interior da camada de resina. Estas bolhas também encontraram-se presentes nos espécimes do grupo 3 , onde 0 sistema adesivo foi aplicado sobre uma dentina excessivamente úmida; porém, neste caso, os espaços eram bem maiores. No interior destas bolhas, frequentemente contínuas à túbulos parcialmente selados, normalmente havia glóbulos de primer, dispersos em uma matriz amorfa. Os autores comentam que a relevância clínica desses achados seriam que a presença de falhas microscópicas ao longo da interface dente/resina propiciam uma explicação morfológica da diminuição da resistência de união relatada na presença de uma umidade superficial excessiva e que o selamento incompleto dos túbulos associado com a presença de espaços em forma de bolha, poderiam formar um canal para a movimentação 
hidrodinâmica de fluidos, o que poderia explicar alguns casos de sensibilidade pós-operatória relatados com o uso de sistemas adesivos à base de acetona.

Em 1996, considerando que a dentina tem uma estrutura orientada pela presença dos túbulos dentinários e que o número e a densidade tubular variam dependendo da proximidade com a polpa, WATANABE; MARSHALL JR.; MARSHALL ${ }^{152}$ realizaram um trabalho com o objetivo de testar a hipótese de que a resistência ao cisalhamento da dentina varia com a localização e a orientação dos túbulos dentinários. Para tanto, o estudo foi dividido em duas etapas. Na primeira parte, foram preparados 24 espécimes de dentina com medidas de $1 \times 1 \times 5 \mathrm{~mm}$, obtidos a partir de terceiros molares humanos extraídos e de uma única localização, entre o centro do dente e a área abaixo das cúspides, que permitia a avaliação da resistência ao cisalhamento em duas orientações tubulares diferentes: paralela a orientação dos túbulos dentinários (a) ou perpendicular à orientação dos túbulos (b), de forma que a área de secção transversa da região da fratura expusesse o longo eixo dos túbulos. Na segunda parte, os espécimes foram preparados a partir de duas localizações diferentes: do centro do dente ou de uma área abaixo das cúspides. A resistência ao cisalhamento foi avaliada da mesma forma descrita para a primeira parte do estudo e, adicionalmente, foram confeccionados alguns espécimes que permitiam que a força exigida para a fratura por cisalhamento fosse aplicada perpendicularmente à orientação dos túbulos dentinários (c), expondo uma área de secção transversa da região de fratura também perpendicular ao longo eixo dos túbulos. Os resultados da primeira parte do experimento demonstraram que a resistência à fratura quando a força foi aplicada paralela ou perpendicularmente à orientação dos túbulos foi estatisticamente a mesma; respectivamente, de 72,4 MPa e 78,4 MPa. Da mesma forma, na segunda parte do experimento, para os espécimes localizados no centro do dente, a resistência à força aplicada paralela ou perpendicularmente à orientação dos túbulos foi semelhante; aproximadamente 53,5 MPa. 
Entretanto, para os espécimes cujos túbulos estavam orientados paralelos aos seus longos eixos, a resistência foi significantemente maior; 78,0 MPa. Para os espécimes retirados das áreas cuspídeas, não houve diferença de valores de acordo com a orientação dos túbulos em nenhuma das três situações avalidas: (a) 83,6 MPa, (b) 85,2 MPa, (c) 91,8 MPa. Comparandose os resultados dos espécimes obtidos da área central com os da área cuspídea, verificou-se que os da área cúspidea apresentaram uma resistência significativamente superior nas situações (a) e (b). Assim, os autores concluíram que a resistência ao cisalhamento difere de região pra região, se central ou cuspídea, e ainda, que na área central do dente, ela também depende da orientação dos túbulos dentinários. E também, a resistência ao cisalhamento da dentina é superior à resistência adesiva observada na literatura.

YOSHIYAMA et al. ${ }^{156}$, em 1996, procuraram comparar a diferença nos valores de resistência adesiva e de MEV entre a parede oclusal e gengival de lesões cervicais, em forma de cunha, com dentina esclerosada, presentes em dentes naturais, com aquela de cavidades preparadas artificialmente. Desta forma, a hipótese nula testada foi que não existe diferença nos valores de resistência adesiva entre as duas regiões, oclusal e gengival, ou entre dentina esclerosada e normal. Para o experimento, foram utilizados 30 caninos; metade com lesões naturais (grupo I), metade hígidos (grupo II). Os dentes do grupo II receberam um preparo com dimensões semelhantes ao grupo I. Assim, para cada grupo, os dentes foram subdivididos em três grupos diferentes, dependendo do sistema adesivo empregado para a restauração: All Bond 2, Clearfil Liner Bond 2 ou Scotchbond Multi-Purpose. Após um dia de armazenamento em água, os dentes foram trabalhados de forma que permitissem a obtenção de espécimes para leitura da resistência adesiva pela técnica de microtração. $A$ análise de MEV foi feita em todos os espécimes, após serem submetidos ao teste de microtração. Os resultados obtidos permitiram verificar que não houve diferença nos valores de resistência adesiva entre a parede oclusal e gengival nos preparos, porém, 
com relação ao tipo de dentina, as lesões naturais apresentaram valores de resistência adesiva 20-45\% menores. Na parede oclusal, os valores de resistência adesiva para o All Bond 2, Clearfil Liner Bond 2 e Scotchbond Multi-Purpose, em lesões naturais, foram: 16,5, 16,6 e 17,8 MPa, respectivamente. Nas lesões preparadas artificialmente, foram: 25.6, 29.9 e 21,5 MPa. Com relação às fotomicrografias, verificou-se que o Clearfil Liner Bond 2 formou a camada híbrida mais fina, a qual não foi possível ser mensurada nas lesões naturais.

Considerando que ainda existe pouca informação a respeito da performance dos sistemas adesivos na dentina radicular, YOSHIYAMA et al. ${ }^{157}$, em 1996, realizaram um trabalho com o objetivo de mensurar a resistência a tração da resina composta a dentina radicular e coronária através da técnica de microtração, e analisar a interface através de MEV. A hipótese nula a ser testada foi que a resistência adesiva, na dentina radicular ou coronária, não varia. Para o experimento, foram utilizados 16 caninos humanos. Por vestibular, foi removido o esmalte e o cemento de cada dente de forma que fosse obtido um preparo longo, com $1 \mathrm{~mm}$ de profundidade em dentina, do terço coronário até o ápice radicular. Aleatoriamente, metade dos espécimes foi tratada com All Bond 2 e a outra metade com Imperva Bond. Em seguida, todos os espécimes foram seccionados transversalmente em 16 fatias de 4 porções diferentes: dentina coronária, dentina cervical, dentina da porção mediana da raiz e dentina apical. Assim, cada fatia foi desgastada de forma que a área de adesão fosse reduzida a aproximadamente $1 \mathrm{~mm}^{2}$ e posteriormente, foi feita a análise da resistência adesiva frente a técnica de microtração. Os demais dentes, foram preparados para análise em MEV. Os espécimes tratados com All Bond 2 apresentaram valores de resistência bem elevados (23,5 MPa) na dentina coronária e apical, o que levou a rejeitar a hipótese testada para este sistema adesivo. Porém, na dentina cervical e mediana da raiz, a resistência foi significativamente menor. Já os espécimes tratados com Imperva Bond apresentaram um resultado relativamente alto em todas as áreas, não 
havendo diferença entre elas. As fotomicrografias revelaram que a espessura da camada híbrida formada pelo sistema adesivo All Bond 2 na dentina radicular $(1,9 \mu \mathrm{m})$ foi menor do que na dentina coronária $(3,7 \mu \mathrm{m})$. Já com o Imperva Bond, a espessura foi sempre constante, menor que 0,5 $\mu \mathrm{m}$. Desta forma, os autores assumem que os resultados sugerem que valores altos de resistência adesiva podem ser obtidos, mesmo com uma infiltração mínima de resina na dentina radicular. Em outras palavras, não existe uma correlação entre espessura da camada híbrida e resistência adesiva.

FERNANDES ${ }^{28}$ em 1997, determinou a resistência adesiva através de ensaios de microtração, de dois novos sistemas adesivos resinosos, OneStep e Clearfil Liner Bond 2, empregando como substrato superfícies planas de dentina superficial e profunda, em faces oclusais de terceiros molares humanos extraídos. Para a obtenção da superfície de dentina superficial, o esmalte oclusal foi desgastado com lixa de carbureto de silício de granulação 320, expondo uma superfície plana de dentina. A superfície de dentina profunda foi obtida por meio de um corte perpendicular ao longo eixo dos dentes na altura da JEC, obtendo-se assim uma superfície plana de dentina, imediatamente acima dos cornos pulpares. As superfícies foram tratadas com um dos sistemas adesivos e foi aplicada a resina composta Z100 de acordo com as recomendações dos fabricantes. Após armazenagem a $37^{\circ} \mathrm{C}$ por 24 horas, os espécimes foram preparados para serem submetidos ao teste de microtração. Utilizando-se uma máquina de cortes seriados, os dentes foram fatiados em espessuras de 0,8 $\mathrm{mm}$ nos sentidos mésio-distal e vestíbulo-lingual, obtendo-se áreas de adesão de 0,6 $\mathrm{mm}^{2}$ na área de teste. Os espécimes em forma de "palitos" foram afixados individualmente em um dispositivo de microtração pelas suas extremidades, de modo a posicionar a área de adesão perpendicular ao longo eixo da força de tração. Após o teste, as duas porções fraturadas foram removidas e a área transversal correspondente à fratura foi medida utilizando-se um paquímetro universal com leitura digital eletrônica. Os valores de 
resistências adesivas foram calculados e expressos em $\mathrm{MPa}$. $\mathrm{O}$ modo de fratura da interface adesiva foi avaliado em microscopia óptica com 40X de aumento. A análise estatística aplicada demonstrou não haver diferenças nos valores de resistência de união quando a variável foi o substrato. Diferenças significantes foram observadas na variável material, com o sistema adesivo One-Step fornecendo valores de resistência de união mais elevados.

MARSHALL JR et al. ${ }^{61}$ em 1997, publicaram um trabalho revisando as variações estruturais e as propriedades do substrato dentinário relacionadas à adesão, baseados nas alterações fisiológicas e patológicas que permitem a classificação da dentina em diferentes formas. Mencionou-se que embora seja certo que tenha ocorrido um grande avanço no que se refere à compreensão da estrutura e da morfologia da dentina, muitos assuntos ainda necessitam ser melhor esclarecidos. É evidente, portanto, que as variações estruturais da dentina normal e as conseqüências que elas implicam sobre as propriedades da própria dentina e sobre os tratamentos preventivos e restauradores, estejam levantando um maior interesse de estudo. Por outro lado, algumas variações encontradas nas propriedades da dentina através destes estudos podem ser provenientes não somente das diferenças nos métodos de estudo empregados, além das diferenças inerentes das propriedades da dentina e sua sensibilidade à umidade ou à desmineralização, por exemplo. As descobertas tecnológicas mais recentes têm trazido a promessa de desvendar muitas das inconsistências do conhecimento e da compreensão do que é a dentina, comentam. Destacouse também que, no entanto, dentro deste contexto, a dentina ainda altera-se no decorrer do tempo e essas alterações de envelhecimento introduzem outras modificações na sua estrutura e nas suas propriedades clinicamente significantes e também, o conhecimento dessas alterações atualmente ainda está em fase inicial. 
Com o objetivo de testar duas hipóteses, primeiro, de que existe uma relação inversa entre a resistência de união da resina ao esmalte e a área de secção transversal e, segundo, de que existe uma variação regional nos valores de resistência de união também da resina ao esmalte, SHONO et al. ${ }^{117}$ em 1997, conduziram um trabalho empregando a técnica de microtração. Para tanto, as superfícies vestibular e lingual de terceiros molares humanos extraídos foram desgastadas com tiras de lixa granulação 240 a uma profundidade de $0,3 \mathrm{~mm}$, em esmalte, de modo a formar uma superfície plana. Numa primeira parte do experimento, foi realizado o procedimento de desgaste das superfícies vestibular e lingual nos terços oclusal, médio e cervical para avaliar-se as variações regionais. Na segunda parte do experimento, o procedimento restaurador foi executado somente no terço oclusal da porção coronária do dente para avaliar-se a relação da resistência de união com a área de secção transvesa. Os sistemas adesivos empregados foram o Clearfil Liner Bond 2 e o Scotchbond Multi-Purpose Plus. Realizadas as restaurações e decorrido um período de armazenagem em água de 24 horas, os dentes foram seccionados longitudinalmente em fatias de $1 \mathrm{~mm}$ de espessura, sendo que, para a segunda parte do experimento, a área de superfície adesiva preparada variou de 0,5 a 3,0 $\mathrm{mm}^{2}$. Para ambos materiais, houve uma relação inversa altamente significante entre resistência de união e área de secção transversa aderida. Pela análise de regressão, os valores máximos de resistência no ponto de intersecção com o eixo y foram de 51 e $59 \mathrm{MPa}$, respectivamente para o sistema Clearfil Liner Bond 2 e Scotchbond Multi-Purpose Plus. Com relação à variação regional, não houve diferença estatística entre os valores encontrados nas superfícies vestibular e lingual. Entretanto, para os dois materiais, a resistência de união foi significantemente maior no terço oclusal do esmalte. Uma análise do modo de fratura dos espécimes revelou que para o sistema Clearfil, as fraturas foram principalmente do tipo adesiva (cinco a seis espécimes num total de nove), nos terços oclusal, médio e cervical, não havendo nenhuma fratura coesiva em resina e nem em esmalte. Já com o sistema Scotchbond, não houve nenhuma fratura 
puramente adesiva, tampouco houve fratura coesiva em esmalte. A maioria das fraturas foram coesivas em resina no terço oclusal e cervical e, no terço médio, todas as fraturas foram mistas.

TAY; GWINNETT; WEI, ${ }^{132}$ em 1997, considerando que a manutenção da integridade estrutural das fibras colágenas e dos microcanais interfibrilares facilita a infiltração dos monômeros e que a umidade tem um papel fundamental em prevenir o colapso da rede de colágeno desmineralizada, fundamentos esses que justificam o emprego da técnica úmida de adesão, realizaram um estudo com o objetivo de investigar o efeito do reumedecimento sobre a matriz de colágeno desmineralizada e também sobre uma matriz de colágeno estruturalmente alterada pela aplicação de glutaraldeído, através de MET. Preparou-se 30 discos de dentina a partir de terceiros molares humanos extraídos, os quais foram condicionados com ácido fosfórico a 10\% e em seguida divididos em cinco grupos, de acordo com a condição da dentina previamente à aplicação do sistema adesivo One-Step: Grupo 1) controle positivo - dentina visivelmente úmida; Grupo 2) dentina seca durante 3 segundos com ar; Grupo 3) dentina seca durante 3 segundos e reumedecida com água; Grupo 4) controle negativo - dentina seca durante 3 segundos, armazenada em glutaraldeído a 8\% durante 15 minutos, lavada com água e seca por 3 segundos; Grupo 5) dentina seca durante 3 segundos, armazenada em glutaraldeído por 15 minutos, lavada com água e mantida úmida. Para cada grupo, foram preparados 3 espécimes, unindo-se dois discos com uma resina quimicamente ativada, os quais, em seguida, foram submetidos aos tratamentos necessários para análise em MET. Pelas fotomicrografias, observou-se uma completa infiltração da resina na zona de dentina desmineralizada nos grupos 1 e 3 . No grupo 2, a infiltração limitou-se à superfície e à base da rede desmineralizada, aparentemente ao longo dos canais laterais dos túbulos dentinários. Nos grupos 4 e 5, houve uma infiltração mínima de resina, ao longo da base da rede desmineralizada colapsada e fixada pelo glutaraldeído de forma irreversível. Como conclusão, os autores ressaltam 
que quando o colágeno não é desnaturado irreversivelmente em dentina condicionada com ácido, a água ajuda a restaurar a plasticidade e a permeabilidade da rede fibrilar de colágeno desmineralizada durante 0 reumedecimento, o que é crucial para que ocorra uma máxima hibridização.

ARMSTRONG; BOYER; KELLER ${ }^{3}$, em 1998, conduziram um estudo com o objetivo de determinar a resistência de união à tração de dois sistemas adesivos à dentina empregando o método de microtração e também analisar o modo de fratura de cada espécime através de MEV. Para tanto, utilizou-se seis molares humanos extraídos, livres de cárie. A superfície oclusal em esmalte de cada dente foi removida e em seguida, sobre a superfície plana de dentina obtida, foi realizada a restauração com resina composta da porção coronária removida, sendo que em três dentes, utilizou-se o sistema adesivo All-Bond 2 e nos demais, o sistema Optibond FL, sempre de acordo com as recomendações do fabricante. Após um período de armazenamento de 24 horas a $37^{\circ} \mathrm{C}$ em cloramina $\mathrm{T}$ a $0,5 \%$, os dentes foram seccionados perpendicularmente à área de união, de forma a permitir a obtenção de seis a sete fatias por dente, posteriormente preparados na conformação preconizada pelo teste de microtração, ou seja, no formato de ampulheta. Esses espécimes permaneceram por mais seis dias armazenados na mesma solução, e assim, foram em seguida testados quanto a resistência de união. Analisando-se os espécimes em MEV, as fraturas foram classificadas em: interfaciais (adesivas ou mistas), ou em substrato (dentina ou resina composta). Os resultados de resistência de união dos dois materias não foram estatisticamente diferentes: 40,7 \pm 9,0 MPa para o All-Bond 2 e 34,0 \pm 7,7 MPa para o Optibond. Quanto ao modo de fratura, para o sistema All-Bond 2 verificou-se que doze dos vinte espécimes apresentaram fraturas interfaciais, sendo que dessas, sete foram fraturas estritamente adesivas; quanto aos demais espécimes (8/20), a fratura foi em subtrato, sendo que destes, 5 foram em resina. Com 0 Optibond FL, a maioria das fraturas foi em substrato (13/20), particularmente 
na resina (12/20); dos demais espécimes (7/20) que apresentaram fraturas do tipo interfaciais, quatro delas foram fraturas adesivas.

IWAMI et al. ${ }^{46}$ em 1998, realizaram um trabalho com o objetivo de investigar o efeito da umidade superficial da dentina e do esmalte sobre a resistência de união ao cisalhamento empregando sete diferentes sistemas adesivos: All-Bond 2, Clearfil Liner Bond II, Imperva Fluoro Bond, One Step, ProBond, Scotchbond Multi-Purpose e Super Bond D-Liner II. Utilizou-se um total de 210 molares superiores ou inferiores humanos, os quais foram divididos em sete grupos, dependendo do sistema adesivo empregado, e em três subgrupos, dependendo do tratamento dado a superficie de esmalte e dentina, previamente à restauração. Assim, os dentes foram restaurados de forma a preparar corpos-de-prova envolvendo uma área de $3 \mathrm{~mm}$ de diâmetro em esmalte ou em dentina. As condições dadas à superfície dentária foram: superfície úmida, superfície seca por 3 segundos e superfície seca por 15 segundos. Após um período de armazenamento em água destilada a $37^{\circ} \mathrm{C}$ durante 24 horas, realizou-se o teste de cisalhamento. Os resultados revelaram que os valores de resistência de união ao esmalte ou à dentina não apresentaram diferenças significantes. Entretanto, nos espécimes de dentina, dois sistemas com primers a base de água apresentaram valores de resistência mais elevados deixando-se a superfície de dentina úmida, o que não ocorreu com os sistemas à base de acetona. Assim, os autores concluíram que uma certa quantidade de água é necessária para se conseguir valores de resistência de união mais elevados em dentina; porém, em esmalte, a secagem não afeta a resistência de união.

Avaliando que o tempo e a distância de secagem do primer são considerações que deveriam ser incluídas nas recomendações dos fabricantes para o uso dos sistemas adesivos, KANCA III3, em 1998, realizou um estudo com o objetivo de examinar o efeito do tempo de aplicação do primer de cinco sistemas adesivos, Amalgambond, Linerbond 
1, One-Step, Optibond FL e Scotchbond Multiporpose Plus, sobre a resistência de união ao cisalhamento. Empregando-se molares humanos extraídos, as restaurações foram feitas variando-se o tempo de aplicação do primer em 5 e 30 segundos, para todos os sistemas adesivos em teste, o que correspondeu à formação de dois grupos diferentes para cada material. Cilindros de resina composta Bisfil All-Purpose foram construídos, com uma área adesiva de 4,0 $\mathrm{mm}$ de diâmetro. Os valores médios de resistência de união ao cisalhamento encontrados com o tempo de 5 segundos foram: Scotchbond Multipurpose Plus, 9,2 MPa; Linerbond 1, 15,8 MPa; Optibond FL, 15,1 MPa; Amalgambond, 18,8 MPa; e One Step, 29,6 MPa. Com o tempo de 30 segundos foram, na mesma ordem, respectivamente: 25,7, 18,5, 19,6, 26,2 e 28,2 MPa. Somente para o Linerbond 1 e o One Step, não houve diferença estatística variando-se o tempo; para os demais materiais, um tempo de aplicação do primer mais prolongado propiciou melhoras marcantes na resistência de união. Assim, os autores concluíram o trabalho comentando que o tempo de aplicação do primer tem um efeito marcante sobre a resistência de união ao cisalhamento e que o efeito parece estar relacionado ao tipo de solvente empregado no primer e com o tratamento ácido dado ao subtrato. Comentam ainda que primers à base de álcool e acetona provavelmente interagem rapidamente com a superfície úmida e assim, aumentando-se o tempo de aplicação não há melhora na resistência. Por fim, em todos os casos, a água facilitou a interação da resina com a superfície do substrato dentinário.

Partindo da hipótese de que o colágeno exposto e desnaturado resultante do condicionamento ácido da dentina prejudica a obtenção de uma adesão efetiva e durável a longo prazo, KATO; NAKABAYASHI ${ }^{55}$, em 1998, realizaram um estudo com o objetivo de investigar a influência da área de dentina desmineralizada e não infiltrada com resina, in vitro, durante um período de acompanhamento de 1 ano. Para tanto, utilizou-se dentina de dentes bovinos, num total de 30 espécimes, 5 para cada período testado: 1 dia, 1 semana, 1 mês, 3 meses, 6 meses e 1 ano. Realizou-se restaurações 
na dentina, e esta recebeu condicionamento ácido com ácido fosfórico 65\%, seguida da aplicação de um primer à base de acetona contendo 4-META a $5 \%$ em peso, e de um adesivo que constituía-se de 4-META/TEGDMACQ/NPG. As restaurações, após os períodos pré-determinados, foram então submetidas ao teste de resistência de união à tração e posterior avaliação da superfície dentária em MEV. Os resultados encontrados mostraram que não houve diferença estatisticamente significante entre o período de 1 dia $(6,6 \pm 1,0 \mathrm{MPa})$ e 1 semana $(5,3 \pm 1,8 \mathrm{MPa})$. Entretanto, a resistência de união diminuiu significantemente da primeira semana para o período de 1 mês $(3,4 \pm 1,7 \mathrm{MPa})$. Entre 1 mês e 6 meses $(3,9 \pm 0,9 \mathrm{MPa})$, os valores foram estatisticamente os mesmos, porém, do sexto mês para o período de 1 ano $(2,0 \pm 1,0 \mathrm{MPa})$, novamente a diferença encontrada foi significante. Analisando-se as fotomicrografias, verificou-se que a porcentagem de falhas coesivas na resina diminuiu no período decorrente de 1 dia para 6 meses, ao passo que a porcentagem de falhas adesivas e coesivas na área da dentina desmineralizada, aumentou. Além disso, a porcentagem de falha coesiva na resina não diminuiu após o período de 6 meses. Assim, os autores concluíram que a durabilidade da união resina/dente não foi tão boa quanto a esperada e que a presença de uma camada de dentina desmineralizada, não reforçada pela impregnacão de resina, precisa ser cuidadosamente estudada para melhor compreender-se os mecanismos de adesão e seu potencial de falhas à longo-prazo. As fibras de colágeno expostas sofreram hidrólise durante o longo período de imersão na água, justificam.

MANFIO ${ }^{60}$, em 1998, em seu trabalho de tese, procurou comparar a resistência de união à microtração de 3 sistemas adesivos em diferentes regiões de uma cavidade classe II. Terceiros molares humanos, não cariados, extraídos e armazenados em solução salina $0,9 \%$ contendo cristais de timol por um período entre 15 e 90 dias, foram preparados com cavidades MOD de dimensões padronizadas e restaurados com One Step, Scotchbond Multiuso e Prime \& Bond, usando uma técnica incremental com resina 
composta Z100. Após restaurados, os dentes foram armazenados durante sete dias em água destilada, sendo então seccionados longitudinalmente com um disco diamantado em três fatias com uma espessura de $\pm 0,8 \mathrm{~mm}$, no sentido mésio-distal. Essas fatias foram desgastadas e refinadas com pontas diamantadas de granulação fina, de maneira a formar uma curva suave com menor largura na região da interface adesiva pulpar, gengival e axial, com uma área de $\pm 1 \mathrm{~mm}^{2}$. Os espécimes foram tracionados em uma máquina de testes Kratos com velocidade de $0,5 \mathrm{~mm} / \mathrm{min}$. Os resultados foram expressos em MPa. A análise dos resultados demonstrou diferenças significantes $(p<0,05)$ entre os materiais e localizações. A resistência de união à microtração na parede pulpar foi maior que a resistência de união na parede gengival e na parede axial para os três sistemas adesivos empregados, não havendo diferença estatística entre os mesmos: One Step $=24,2 \mathrm{MPa}$, Scotchbond Multiuso = 26,1 MPa e Prime \& Bond $2.0=22,1$ $\mathrm{MPa}$. Na parede gengival, a resistência de união foi superior para o adesivo One-Step (19,3 MPa), não havendo diferença estatística entre o Scotchbond Multiuso (13,6MPa) e o Prime \& Bond 2.0 (11,3 MPa). Na parede axial, não houve diferença estatística entre os três adesivos usados, sendo esta, semelhante à resistência de união da parede gengival para o Scotchbond Multiuso (12,3 MPa) e para o Prime \& Bond 2.0 (10,6 MPa). Os resultados confirmam que a resistência de união em um preparo cavitário classe II, tipo MOD, não é uniforme.

Considerando que normalmente na bula dos sistemas adesivos o fabricante recomenda que o primer deve ser ligeiramente seco com um jato de ar, provavelmente com o intuito de deixar uma camada bem fina da solução sobre a estrutura dentária assim como para permitir a evaporação da água que serve como solvente do HEMA, PASHLEY et al. ${ }^{89}$, em 1998, realizaram um estudo com dois objetivos: 1) determinar as taxas de evaporação da água e do HEMA e 2) os efeitos do aumento da concentração de HEMA sobre a taxa de evaporação da água em misturas de água e HEMA. Para tanto, 10 microlitros de cada solução $\left(100 \% \mathrm{H}_{2} \mathrm{O}\right.$, 
$75 \% \mathrm{H}_{2} \mathrm{O} / 25 \% \mathrm{HEMA}, \quad 50 \% \mathrm{H}_{2} \mathrm{O} / 50 \% \mathrm{HEMA}, \quad 25 \% \mathrm{H}_{2} \mathrm{O} / 75 \% \mathrm{HEMA} \quad \mathrm{e}$ $100 \%$ HEMA) foram colocados em um recipiente de alumínio adaptado a um aparelho para análise de termogravimetria, ajustados a $37^{\circ} \mathrm{C}$. Foram avaliadas duas condições diferentes de alterações em peso durante 30 minutos. A taxa de evaporação da água pura foi 32 vezes maior do que a do HEMA $100 \%$. A adição de HEMA à água diminuiu a taxa de evaporação da água das misturas de forma que esta foi proporcional ao seu efeito de diminuir a pressão de vapor da água. Além disso, a taxa de evaporação da água das misturas foi maior quando a umidade relativa do ambiente era zero, sob efeito do ar comprimido do que quando a umidade era de $51 \%$. O significado desses resultados seria que com a evaporação da água das misturas $\mathrm{H}_{2} \mathrm{O} / \mathrm{HEMA}$, a concentração de HEMA aumenta porque este é relativamente não-volátil. Este aumento na concentração de HEMA diminui a pressão de vapor da água, dificultando mais ainda a remoção das últimas porções de água. Esta água residual poderia assim, interferir com a polimerização dos monômeros o que, consequentemente, afetaria a qualidade da camada híbrida.

Em 1998, PHRUKKANON; BURROW; TYAS $^{97}$ realizaram um trabalho com o objetivo inicial de desenvolver uma técnica de adesão com uma área superficial bem pequena, com um formato circular de secção transversal e determinar, posteriormente, o efeito da área superficial de adesão sobre a resistência adesiva de quatro sistemas adesivos: One-Step, OptiBond FL, OptiBond Solo e Scotchbond Multi Purpose Plus. Para tanto, utilizou-se sessenta molares humanos extraídos, os quais foram cortados verticalmente. Em seguida removeu-se o esmalte oclusal de forma que metade do dente foi usada para avaliar a resistência adesiva frente a uma força de tração e a outra metade, à força de cisalhamento. A dentina exposta na superfície oclusal foi tratada com um dos diferentes sistemas adesivos seguindo-se as recomendações do fabricante e restaurada com resina composta. Desta forma, cada metade de dente reconstruída foi seccionada em pelo menos três espécimes em forma de barras quadrangulares, as 
quais, em seguida, foram trabalhadas com um ponta diamantada em alta rotação que possibilitava a produção de espécimes cilíndricos com 1,2, 1,4 ou 2,0 $\mathrm{mm}$ de diâmetro na região da interface adesiva. Confeccionado os espécimes, esses foram armazenados durante 48 horas em água a $37^{\circ} \mathrm{C}$ para, em seguida, serem avaliados quanto a resistência adesiva, tanto à tração quanto ao cisalhamento. Para todos os materiais, o grupo com 2,0 mm de diâmetro na área de secção transversal apresentou uma resistência adesiva significantemente menor do que o grupo de 1,2 mm de diâmetro; tanto para o teste de tração quanto para o de cisalhamento. Além disso, a maioria dos espécimes de 1,2 ou 1,4 mm de diâmetro apresentou falha adesiva na interface entre dentina e adesivo. Os resultados indicaram que áreas superficiais de adesão pequenas estão associadas a uma resistência adesiva maior e que o efeito da força, seja ela de tração ou de cisalhamento, é semelhante.

SCHREINER et al. ${ }^{115}$, em 1998, realizaram um trabalho para testar a hipótese nula de que não existe diferença significante entre os valores de resistência de união obtidos ao empregar-se um teste de cisalhamento ou um teste de microtração. Para a avaliação da resistência de união pela técnica de microtração, utilizou-se 30 dentes divididos em cinco grupos, dependendo do sistema adesivo a ser testado: Clearfil Liner Bond, Prime e Bond, Scotchbond Multipurpose com ácido fosfórico a 37\%, Scotchbond Multipurpose com ácido maleico e Scotchbond Multipurpose Plus. Após a realização das restaurações, os dentes foram seccionados e preparados para o teste, cuja área de adesão foi de aproximadamente 1,7 $\pm 0,1 \mathrm{~mm}^{2}$. Assim, após um período de armazenamento de 24 horas a $37^{\circ} \mathrm{C}$ em solução salina a $0,9 \%$, realizou-se as leituras. Para a avaliação da resistência de união pela técnica de cisalhamento, empregou-se 35 dentes divididos em 5 grupos, dependendo da mesma forma do sistema adesivo empregado. Neste caso, a área de união testada foi de $3,4 \mathrm{~mm}$ de diâmetro. Todos os espécimes, independentemente do tipo de teste, foram posteriormente 
observados em microscópio óptico em aumento de 10X e em seguida preparados e analisados em MEV. Os resultados obtidos com a técnica de microtração foram significantemente maiores do que os obtidos com a técnica de cisalhamento. Comparando-se os resultados com o teste de microtração, o sistema Clearfil apresentou valores de resistência de união significantemente maiores do que os outros materiais; já para o teste de cisalhamento, todos os materiais apresentaram valores semelhantes. Analisando-se o modo de fratura em microscopia óptica, para o teste de microtração os espécimes tratados com o sistema Clearfil apresentaram um total de falhas coesivas significantemente maior do que os outros materiais, cuja fratura foi predominantemente adesiva; para o teste de cisalhamento, o número total de falhas coesivas em dentina e resina foi significantemente maior do que para o teste de microtração. Analisando-se as fraturas em MEV, para o teste de microtração, exceto em um caso, estas foram coesivas no próprio adesivo ou adesivas entre o adesivo e a resina composta; para o teste de cisalhamento, quase todos os espécimes apresentaram fratura envolvendo parcialmente resina ou dentina e o número de falhas adesivas foi maior, quando comparado com o teste de microtração. Assim, os autores concluíram que o teste de microtração produz um meio mais definitivo de avaliar a resistência de união do que o teste de cisalhamento.

VAN MEERBBEK et al. ${ }^{144}$, em 1998, realizaram uma revisão da literatura sobre a performance clínica dos sistemas adesivos, discutindo os parâmetros mais relevantes. Procuraram também propor uma classificação dos materiais disponíveis no comércio, de acordo com os procedimentos clínicos necessários para serem empregados. Várias foram as considerações mencionadas como parâmetros que afetam a performance clínica dos adesivos: o próprio material em si, a variabilidade do substrato, a forma e o tamanho da lesão, idade do paciente, umidade superficial da dentina, localização do dente na arcada. Os autores informaram que efetivamente, a performance clínica dos sistemas adesivos disponíveis melhorou significantemente, permitindo que as restaurações sejam inseridas 
com um nível de predição muito bom. A porcentagem de retenção das restaurações é alta quando comparada com os primeiros sistemas e ela não é mais a principal causa de falhas clinicamente, já que os sistema atuais ainda não conseguiram garantir margens de restaurações livres de descoloração marginal decorrente de uma microinfiltração. Neste mesmo raciocínio, os autores comentaram que assim, ao invés da retenção, o índice de microinfiltração clínica, portanto, poderia ser mais útil em diferenciar a efetividade clínicia dos sistemas adesivos modernos e do futuro; contudo, infelizmente, a retenção é um critério mais objetivo do que a mensuração da microinfiltração, que requer treinamento e calibração entre os examinadores, argumentaram. Foi relatado ainda que embora os sistemas adesivos atuais sejam capazes de selar as margens, existe uma perda progressiva dessa integridade marginal, provavelmente devida aos estresses residuais da contração de polimerização e das alterações dimensionais do material restaurador, o que levou os autores a concluirem que o progresso no campo da adesão deverá ser voltado ao desenvolvimento de materiais restauradores com pouca ou nenhuma contração e com coeficiente de expansão términa mais próximo ao da estrutura dentária.

Como existem poucos trabalhos na literatura relacionados com a tentativa de avaliar os efeitos dos ácidos comumente empregados em clínica sobre as propriedades da matriz de dentina desmineralizada, ZHANG et al. ${ }^{160}$, em 1998, realizaram um trabalho com este objetivo, testando a hipótese nula de que os ácidos não provocam um efeito adverso sobre a resistência à tração e o módulo de elasticidade da matriz de dentina desmineralizada. Para tanto, foram preparados discos de dentina de $0,5 \mathrm{~mm}$ de espessura obtidos de terceiros molares humanos não erupcionados, os quais foram desgastados em formato de "ampulheta" ou em "P'. As extremidades de todos os espécimes foram recobertas com esmalte e desta forma, os mesmos foram imersos em 0,5 M EDTA $(\mathrm{pH} 7,4)$ durante cinco dias a $25^{\circ} \mathrm{C}$ para que a área não protegida fosse completamente desmineralizada. Para o teste de resistência à tração, os espécimes foram 
divididos em sete grupos com cinco a seis espécimes em formato de ampulheta cada: PBS, solução 10-3, ácido cítrico 10\%, ácido fosfórico 37\%, ácido nítrico 2,5\%, ácido nítrico $17,5 \%$ e ácido nítrico $17,5 \%$ contendo cloreto férrico 3\%. O tempo de imersão em cada solução ácida foi de 10 minutos, e em seguida, os espécimes eram lavados em água, colocados em PBS e levados para teste. Para o teste de módulo de elatsicidade, foram usados os espécimes em forma de I, tanto de forma destrutiva quanto não destrutiva, ou seja, para o teste destrutivo, foi feita somente a mensuração da relação carga/deslocamento de cada espécime imersa em PBS até a ruptura. Para o tese não destrutivo, cada espécime serviu como seu próprio controle visto que foram feitas várias mensurações no mesmo espécime a fim de aumentar o poder do teste. Os espécimes foram divididos em 6 grupos de 6 espécimes cada, empregando-se as mesmas soluções, exceto o PBS. Os resultados do teste de tração revelaram que não houve diferença estatisticamente significante entre o tratamento com a solução 10-3, o ácido cítrico $10 \%$ e o controle de PBS. O ácido fosfórico 37\% diminuiu ligeiramente o valor da resistência, mas não de forma estatisticamente significante. Já o tratamento com ácido nítrico a $2,5 \%$ ou a $17,5 \%$, diminuiu significantemente a resistência à tração e a adição de cloreto férrico ao ácido nítrico 17,5\% ajudou a evitar os efeitos do ácido de forma que a resistência final foi semelhante à do grupo controle. Com relação ao módulo de elasticidade, no teste destrutivo não apareceram diferenças estatisticamente significantes entre os grupos. No teste não destrutivo, entretanto, verificou-se que o ácido cítrico $10 \%$, a solução $10-3$ e o ácido fosfórico não produziram nenhuma alteração significante, porém, o ácido nítrico diminuiu o módulo de elasticidade. Diante desses resultados, os autores concluíram que após o condicionamento ácido realizado clinicamente, as alterações produzidas na propriedade de resistência à tração da matriz de dentina são mínimas.

As pesquisas mais recentes em adesão têm demonstrado a superioridade da técnica úmida sobre a aplicação dos sistemas adesivos em uma dentina seca, mas ainda não apontam claramente se esta técnica 
também é preferira quando o substrato de adesão for uma dentina afetada por cárie. Baseados nessas considerações, NAKAJIMA et al. ${ }^{73}$ no ano de 1999, levantaram a hipótese de que não existe diferença na resistência de união empregando-se ou não a técnica úmida de adesão e um primer aquoso, quando se compara dentina normal com dentina afetada por cárie. Assim, o objetivo deste trabalho foi avaliar, através de MEV e dos valores de resistência de união à microtração, o comportamento do sistema adesivo SMPP em dentina normal e afetada por cárie, empregando-se a técnica úmida de adesão ou não, com ou sem a adição de ácido polialcenóico ao primer. Quinze molares humanos com presença de cárie na porção coronária, extraídos, foram usados no trabalho de forma que a superfície oclusal foi desgastada com lixa, perpendicularmente ao longo eixo do dente, até expor uma área onde a lesão de cárie, não mais detectável por um evidenciador de cárie, ficasse cinrcunscrita por dentina normal. Realizadas as restaurações, os dentes foram seccionados em cinco ou seis fatias e, após um período de 24 horas, cada fatia foi desgastada em forma de ampulheta, cuja região a ser analisada, cariada ou não, foi primeiramente isolada para que a constricção coincidisse exatamente neste ponto, numa área de aproximadamente $0,9 \mathrm{~mm}^{2}$. Em seguida, partiu-se para a análise da resistência de união à microtração. Assim, quando não foi empregada a técnica úmida, em dentina normal, a resistência de união foi somente a metade $(21,0 \pm 9,9 \mathrm{MPa})$ daquela obtida com a técnica úmida $(42,4 \pm 9,0$ $\mathrm{MPa}$ ). Comparando-se a dentina normal com a dentina afetada por cárie empregando-se a técnica úmida, não houve diferença estatisticamente significante (42,4 \pm 9,0 MPa e 48,2 $\pm 3,9 \mathrm{MPa}$, respectivamente). Além destes resultados, observou-se que a remoção do ácido polialcenóico do primer, empregando-se a técnica úmida, diminui a resistência de união em dentina afetada por cárie (37,8 \pm 7,9 MPa), o que não ocorreu com a dentina normal (46,0 \pm 7,5 MPa). Consequentemente, os autores concluíram que os benefícios da técnica úmida de adesão estendem-se à dentina afetada por cárie e que, a presença de ácido polialcenóico no primer do SMPP contribui para a alta adesão encontrada na dentina afetada por cárie. 
OGATA et al. ${ }^{76}$, em 1999, realizaram um trabalho com o objetivo de avaliar 0 efeito da aplicação de várias camadas de primer autocondicionantes sobre a resistência adesiva analisada pela técnica de microtração em cavidades artificiais em forma de cunha, realizadas em 18 molares humanos, extraídos e hígidos. Além destes dentes, quatro dentes adicionais foram usados para analisar a interface adesiva em MEV. Os preparos foram feitos na área cervical e vestibular e desta forma, os dentes foram montados de modo qe o eixo mésio-distal da cavidade ficasse paralelo a direção da gravidade, para simular a posição supina durante o tratamento clinicamente. Dividiu-se os dentes em dois grupos, de acordo com o sistema adesivo empregado (Clearfil Liner Bond II e Imperva Fluoro Bond) e em dois subgrupos, sendo que em um subgrupo a aplicação do material foi feita seguindo-se as recomendações do fabricante e, no outro, o primer foi aplicado várias vezes, no mesmo período recomendado pelo fabricante. Para a restauração da cavidade, utilizou-se a resina Protect Liner F e, após um período de armazenamento de 24 horas, os dentes foram seccionados e preparados para o teste de resistência adesiva sendo que, foram obtidos espécimes tanto da parede gengival quanto oclusal. Assim, para ambos sistemas adesivos e métodos de aplicação do primer, a resistência adesiva na parede gengival foi significantemente menor do que na parede oclusal. Além disso, a resistência adesiva do Clearfil, independente da parede do preparo avaliada, aumentou significantemente quando foram aplicadas várias camadas de primer, o que não aconteceu com o Imperva Fluoro Bond. A análise das fotomicrografias revelou que a espessura da camada híbrida, quando foram aplicadas várias camadas de primer do Clearfil, foi cerca de $2 \mu \mathrm{m}$; o dobro de quando este foi aplicado somente em uma camada. Com o sistema Imperva Fluoro Bond, a camada híbrida não pode ser claramente observada.

PAUL et al. ${ }^{90}$ em 1999, realizaram um trabalho com o objetivo de avaliar as propriedades fisicas de um modelo laboratorial de primer a base 
de HEMA e de um modelo laboratorial de adesivo, a base de HEMA e BISGMA. Tanto o primer quanto o adesivo foram diluidos em quantidades específicas de água antes da polimerização, para simular o potencial de diluição dos primers e dos adesivos pela água que está presente na superfície dentinária. A hipótese testada foi que, aumentar a quantidade de água presente antes da polimerização, leva a formação de polímeros com propriedades físicas inferiores. Para tanto, foram confeccionados corpos-deprova em forma de ampulheta ou em forma de I, do primer e do adesivo preparados, os quais foram obtidos a partir de moldes de cera ou de polivinil siloxano. Entretanto, o conteúdo de água, tanto do primer quanto do adesivo, variou de $0,5,9,17$ ou $29 \%$ do volume. Uma hora após a polimerização, metade dos espécimes foram submetidos aos testes de resistência a tração máxima, módulo de elasticidade, porcentagem de alongamento na fratura e tenacidade, em condições secas. A outra metade, foi imersa em água durante 24 horas e posteriormente submetida aos testes, em condições úmidas. Foram avaliados 3 a 6 espécimes para cada condição testada. Assim, as propriedades tanto do primer quanto do adesivo avaliados na condição seca, não foram alteradas pela incorporação de água até a proporção de $9 \%$ do volume. Um conteúdo maior de água diminuiu as propriedades físicas testadas. Além disso, a imersão do primer em água durante 24 horas também diminuiu significantemente suas propriedades, o que não ocorreu, por outro lado, com os adesivos contendo 0 ou $5 \%$ de volume de água.

PERDIGÃO et al. ${ }^{94}$, em 1999, comentando que recentemente tem sido introduzida uma nova geração de sistemas adesivos de frasco único, sistemas estes, sensíveis às variações do grau de umidade do substrato, realizaram um trabalho com o objetivo de avaliar a resistência de união ao cisalhamento e a ultramorfologia interfacial formada por três sistemas adesivos após a secagem e subseqüente reumedecimento da dentina com uma solução de HEMA em água a $35 \%$. A hipótese nula testada foi: o reumedecimento da superfície de dentina não produz uma resistência de 
união comparável àquela obtida com a dentina previamente úmida e que a impregnação de monômeros na dentina desmineralizada também não é a mesma que aquela obtida quando são seguidas as recomendações dos fabricantes. Os sistemas adesivos empregados foram o OptiBond SOLO, o Prime\&Bond 2.1 e o Single Bond, respectivamente, sistemas à base de etanol, acetona e etanol mais água. Para tanto, utilizou-se noventa incisivos inferiores bovinos os quais foram divididos em três grupos, dependendo do tipo de tratamento: grupo controle, de dentina úmida; grupo de dentina seca por 5 segundos; grupo de dentina seca por 5 segundos e reumedecida com a solução aquosa de HEMA 35\%. Após a realização do corpo-de-prova com resina composta Bisfil All-Purpose, os espécimes foram armazenados em água destilada a $37^{\circ} \mathrm{C}$ durante 24 horas e em seguida, termociclados por 500 vezes em imersões de 30 segundos a 5 e $55^{\circ} \mathrm{C}$, com intervalo de 10 segundos entre uma imersão e outra. Posteriormente, realizou-se a leitura da resistência de união ao cisalhamento. Para a análise ultramorfológica em MEV e MET, foram utilizados 18 terceiros molares humanos, os quais receberam os mesmos tipos de tratamentos mencionados acima. Os resultados revelaram que houve diferenças significantes entre 0 fator condição da superfície e sistemas adesivos individualmente, porém, não foram encontradas interações entre estes fatores.Para a dentina úmida, a morfologia da interface dentina/resina mostrou uma penetração dos adesivos até a linha de transição entre dentina sadia e dentina desmineralizada. Secando-se a dentina por 5 segundos, a resistência de união diminuiu significantemente e a rede de colágenos não foi infiltrada completamente. Já o reumedecimento da dentina com a solução aquosa de HEMA, restabeleceu o nível de resistência de união e provocou um reaumento das dimensões dos espaços interfibrilares. O significado do presente trabalho, destacam os autores, é que os resultados sugerem que o uso de uma solução aquosa de HEMA pode compensar a secagem da dentina e que, como o comportamento do Single Bond, um sistema à base de água, também foi afetado pela condição seca da dentina, então, a porcentagem de água incluída na composição de sistemas semelhantes pode não ser 
suficiente para compensar o colapso das fibras colágenas após uma secagem.

Em 1999, PRATI et al. ${ }^{103}$ realizaram um estudo objetivando avaliar a morfologia dos tags de resina e a camada de dentina infiltrada com resina de vários sistemas adesivos, sobre a dentina jovem, madura ou esclerosada, superficial e profunda. Para tanto, os espécimes de dentina foram obtidos após a remoção do esmalte oclusal de dentes humanos extraídos e posteriormente tratados para receberem o sistema adesivo. Assim, a superfície dentinária foi condicionada com ácido fosfórico na forma de gel $35-37 \%$ e os materiais foram aplicados de acordo com as recomendações dos fabricantes. Testou-se os seguintes sistemas adesivos: OptiBond FL, Prime\&Bond 2.0, Scotchbond Multi-Purpose Plus, Scotchbond 1 e One-Step. Cada dente foi dividido em duas metades, sendo que em uma delas, foi feita toda seqüência de polimento, ou seja, um procedimento padrão para avaliar a espessura da camada de dentina infiltrada com resina e sua morfologia, através de fotomicrografia eletrônica de varredura. A outra metade foi desmineralizada e desproteinizada para avaliar a presença e a morfologia dos tags de resina. A análise das fotomicrografias revelou que a camada de dentina infiltrada com resina foi mais fina na dentina superficial do que profunda para todos os materiais testados e, independentemente do tipo de dentina. Além disso, a dentina madura e esclerótica apresentaram uma camada de dentina infiltrada com resina mais fina, com tags mais curtos e com menos ramificações laterais do que a dentina normal.

Considerando que durante o desenvolvimento da técnica de microtração para avaliação da resistência de união foi observada uma grande variação nos valores de resistência entre os vários espécimes obtidos de um mesmo dente, SHONO et al. ${ }^{118}$, em 1999, realizaram um estudo com o objetivo de determinar a consistência ou a uniformidade dos valores de resistência de união em um mesmo dente, empregando-se uma 
resina composta e dois diferentes sistemas adesivos, One-Step e MacBond, à dentina. Para tanto, desenvolveu-se uma nova maneira de preparar-se os espécimes para serem testados pelo método de microtração, onde então os dentes restaurados eram cortados em várias fatias no sentido mésio-distal e vestíbulo-lingual, longitudinalmente, permitindo a obtenção de espécimes em forma de "palitos" de 1 x $1 \mathrm{~mm}$ de largura e espessura de aproximadamente $8 \mathrm{~mm}$ de comprimento, após realizar-se um corte perpendicular ao longo eixo do dente, no terço cervical da raiz. Após a realização das restaurações, as quais foram feitas tanto em dentina profunda quanto em dentina superficial, e decorrido um período de armazenagem dos dentes a $37^{\circ} \mathrm{C}$ de 24 horas, os dentes foram seccionados e os espécimes obtidos avaliados quanto a resistência de união à tração após terem sido devidamente identificadas as coordenadas $x-y$ a partir de onde cada espécime localizavase com relação à sua posição na superfície oclusal do dente. Em um estudo paralelo, um outro operador realizou os mesmos procedimentos com o sistema adesivo One-Step com o intuito de avaliar a influência do operador na variabilidade dos resultados. Assim, empregando-se o sistema One-Step, o operador A obteve um grande número de valor zero de resistência de união em dentina superficial e um pouco menos em dentina profunda, o que resultou em um desvio-padrão muito alto $(22 \pm 20 \mathrm{MPa}$ em dentina superficial e $27 \pm 14 \mathrm{MPa}$ em dentina profunda). O operador B obteve resultados numéricos bem mais elevados e uniformes: $56 \pm 13 \mathrm{MPa}$ em dentina superficial e $57 \pm 12 \mathrm{MPa}$ em dentina profunda. Com o sistema adesivo MacBond, não houve resultados com valor zero de união e a variação foi menor, com uma média de $41 \pm 13 \mathrm{MPa}$ na dentina superficial e $27 \pm 12$ MPa na dentina profunda. Como controle, foi também avaliada a resistência de união da resina composta com ela mesma, aderida com o sistema adesivo One-Step. Neste caso, houve pouca variação da resistênia de união (37 $\pm 1 \mathrm{MPa}$ ). Os autores concluíram o trabalho dizendo que o método empregado no presente estudo permitiu detectar a presença de diferenças regionais na resistência de união da resina à dentina, que as maiores diferenças relacionaram-se muito mais à técnica do que ao material 
empregado e que os resultados indicam que a resistência de união resina/dentina pode não ser tão homogênea como se pensava previamente.

Considerando que embora muitos estudos têm sido conduzidos para avaliar a integridade da interface de união resina/dentina e que a maioria desses estudos, entretanto, são feitos em períodos de tempo muito curtos, de 24 horas, HASHIMOTO et al. ${ }^{44}$, em 2000, realizaram uma pesquisa in vivo, em humanos, para avaliar a degradação da união após 1, 2 e 3 anos. Para tanto, foram feitos preparos cavitários Classe II em molares decíduos empregando o sistema adesivo Scotchbond Multi-Purpose, e após o período pré-determinado, e respeitando a erupção do dente permanente, os dentes foram extraídos para avaliação. Imediatamente após a extração, esses dentes foram seccionados perpendicularmente à interface adesiva e cada espécime assim obtido, foi desgastado em forma de ampulheta para ser submetido ao teste de resistência de união por microtração. Todas as superfícies fraturadas foram posteriormente avaliadas em MEV e o modo de fratura foi determinado. Assim, houve uma diferença estatisticamente significante entre os três períodos de grupo avaliados. Para o grupo controle, o valor da resistência de união foi de 28,3 \pm 11,3 MPa; para o grupo 1, que correspondia ao período de restauração de 1 a 2 anos, o valor da resistência de união foi de 15,2 \pm 4,4 MPa; e para o terceiro grupo (restaurações com 2 a 3 anos), a resistência foi de $9,1 \pm 5,1 \mathrm{MPa}$. Através da análise das superfícies fraturadas, verificou-se que a proporção de dentina desmineralizada presente nos espécimes envelhecidos em meio oral foi maior do que a encontrada nos espécimes do grupo controle. Verificou-se também que a degradação da resina composta e das fibras colágenas esteve presente nesses mesmos espécimes que permaneceram por algum tempo na cavidade bucal. A análise dos resultados permitiu concluir que a degradação da interface de união resina/dentina efetivamente ocorre após um certo período na cavidade bucal. 
KITASAKO et al. ${ }^{57}$, no ano de 2000 , realizaram um trabalho in vivo empregando macacos, com o objetivo de avaliar a biocompatibildade e a resistência de união por microtração, de um sistema adesivo experimental autocondicionante. Foram realizadas restaurações Classe $V$ na superfície vestibular de 36 dentes, e as alterações histopatológicas foram observadas 3, 30 e 90 dias após a realização do procedimento restaurador. A avaliação da resistência de união foi feita 3 e 90 dias após a realização das restaurações. Somente duas de 30 amostras pulpares apresentaram uma ligeira infiltração de células inflamatórias e a espessura média de dentina remanescente vista histologicamente, foi de $0,77 \mathrm{~mm}$. Não houve diferença estatisticamente significante na incidência de células inflamatórias entre os diferentes períodos de observação. Não notou-se nenhuma penetração de bactérias ao longo das paredes cavitárias em todos os espécimes. Com relação à resistência de união, o valor encontrado após 3 dias foi de 20,6 MPa, e após 90 dias, 14,9 MPa, ou seja, houve uma diminuição significante. As conclusões estabelecidas pelo trabalho mostram que a aplicação deste sistema adesivo experimental em macacos apresentou uma compatibilidade biológica aceitável. Embora tenham sido observadas diferenças significantes nos valores de resistência de união entre os períodos avaliados, relata-se que o material também proporciona um selamento hermético, eliminando a infiltração bacteriana.

Considerando que existe a dúvida de que alguns agentes condicionantes não são fortes o suficiente para atacar adequadamente a dentina esclerótica ou afetada pela cárie, NAKAJIMA et al. ${ }^{74}$, em 2000, realizaram um trabalho com o objetivo de testar a hipótese de que não existem diferenças significantes nos valores de resistência de união quando dois sistemas adesivos de frasco único, One-Step e Single Bond, são aplicados em dentina normal ou afetada por cárie, independentemente da concentração do ácido fosfórico empregado. Para tanto, foram utilizados dentes extraídos com cárie oclusal, onde a superfície de dentina foi preparada deixando-a plana. O sistema adesivo One-Step foi aplicado após 
o condicionamento ácido da superfície com ácido fosfórico a 10 ou 32\%. O sistema Single Bond, após o condicionamento da superfície com ácido fosfórico a 10 ou 35\%. Após um período de armazenagem dos dentes em água durante 24 horas, os mesmos foram seccionados em quatro a cinco segmentos verticais de $0,7 \mathrm{~mm}$, alguns deles envolvendo dentina afetada por cárie e outros não. Cada segmento foi posteriormente desgastado em forma de ampulheta, limitando-se a área do teste em dentina normal ou não. Os resultados obtidos com o One-Step/ácido fosfórico a 10\% em dentina afetada por cárie $(36,9 \pm 8,0 \mathrm{MPa})$, foram significantemente menores do que em dentina normal $(47,7 \pm 6,5 \mathrm{MPa})$. Esta diferença desapareceu quando foi empregado o ácido fosfórico a 32\%: 45,0 \pm 7,2 MPa e 49,7 \pm 6,1 MPa, respectivamente para dentina afetada e dentina normal. Para o sistema adesivo Single Bond, a união feita em dentina afetada por cárie sempre foi menor do que aquele encontrada em dentina normal, independentemente da concentração do ácido fosfórico. Assim, os autores concluíram que para se conseguir uma boa resistência de união e uma dentina desmineralizada bem infiltrada, o uso de um ácido fosfórico na concentração de 32-35\% é necessário para que uma superfície de dentina afetada por cárie seja adequadamente condicionada.

Com o objetivo de avaliar a resistência de união por microtração de sete sistemas adesivos disponíveis comercialmente, TANUMIHARJA; BURROW, TYAS ${ }^{124}$, em 2000, realizaram um estudo in vitro, empregando 28 molares humanos extraídos. Após expor a superfície oclusal de dentina, realizou-se um polimento com disco de lixa granulação 600 e os sistemas adesivos e um bloco de resina composta foram aplicados de acordo com as recomendações dos fabricantes. Os sistemas adesivos avaliados foram: Clearfil Liner Bond 2V, EBS-Multi, Gluma One Bond, One Coat Bond, PermaQuik, Prime \& Bond NT/NRC e Solid Bond. Os dentes foram armazenados em água durante 24 horas a $37^{\circ} \mathrm{C}$, e em seguida, seccionados e recortados em forma de ampulheta deixando a área de união 
com um diâmetro de 1,2 \pm 0,02 mm. Foram obtidos aproximadamente 3 ou 4 espécimes de cada dente. Os valores de resistência de união variaram de 17,8 \pm 7,0 MPa para o Solid Bond a 36,0 \pm 8,1 para o Clearfil Liner Bond 2V. As resistências de união do Clearfil e do PermaQuik (30,8 \pm 8,5 MPa) não foram diferentes estatisticamente e foram maiores do que todos os outros materiais. Os valores obtidos para os sistemas Solid Bond, EBS-Multi, One Coat Bond e Gluma OneBond não foram diferentes. O significado do trabalho apontado pelos autores é que o sistema autocondicionante Clearfil Liner Bond 2V, baseado em uma técnica de adesão bem simples, juntamente com o PermaQuik, apresentaram os maiores valores de resistência de união à dentina.

YOSHIYAMA et al. ${ }^{159}$, em 2000, considerando que o mecanismo de adesão em dentina afetada por cárie ainda não está completamente estabelecido, realizaram um estudo com o propósito de avaliar a morfologia interfacial de dois sistemas adesivos aplicados sobre dentina afetada por cárie, Single Bond e FluroBond, empregando-se a técnica de microtração. Após o preparo dos espécimes conservando uma área de união de aproximadamente $1 \mathrm{~mm}^{2}$, foi feita a avaliação da resistência de união em um dispositivo Bencor Multi-T para testes de microtração e, em seguida, foi feita uma análise em MEV das interfaces resina/dentina, antes e após as alterações ácido/base. A força de adesão encontrada em dentina normal, para os dois sistemas adesivos, foi significantemente maior do que aquela encontrada em dentina afetada por cárie. Verificou-se que empregando a técnica úmida para o sistema Single Bond, houve um aumento significante no valor de resistência de união, tanto em dentina normal quanto em dentina afetada por cárie. A análise das fotomicrografias revelou a formação de uma camada híbrida típica, e em dentina afetada não foi observada a presença de tags. Esses resultados sugerem que a penetração da resina pode ser impedida pela oclusão dos túbulos dentinários com depósitos minerais, o 
que também, em parte, contribui com a característica ácido-resistente da matriz de dentina intertubular encontrada em dentina afetada por cárie. 


\section{Proposição}

"volente nihit difficile..." 


\section{3 - PROPOSIÇÃO}

Os objetivos deste estudo, in vitro, são:

\section{Objetivo geral:}

- testar a hipótese de que existe uma variação regional da resistência de união em superfícies planas de dentina.

\section{Objetivos específicios:}

- testar a hipótese de que a variação regional da resistência de união é determinada por variações no substrato e independe do sistema adesivo empregado;

- testar a hipótese de que não haverá diferença de resistência de união entre os sistemas adesivos testados;

- testar a hipótese de que a resistência de união à dentina central é menor do que a periférica, para os três sistemas adesivos testados. 


\section{4 - MATERIAL E MÉTODOS}

Para o desenvolvimento deste trabalho, foram selecionados 12 terceiros molares humanos extraídos e livres de cárie do banco de dentes do Departamento de Biologia Oral e Patologia Maxilo-facial ${ }^{*}$, armazenados a uma temperatura aproximada de $4^{0} \mathrm{C}$ em solução salina a $0,9 \%$ contendo 0,2\% de azido de sódio como preservativo por um período não superior a seis meses. Estes dentes foram empregados em três grupos, dependendo do sistema adesivo, cujas marcas comerciais e respectivos fabricantes são apresentados no Quadro 1. Três dentes foram empregados com o sistema adesivo One-Step (OS), três com o Single Bond (SB) e seis com o Clearfil Liner Bond 2V (CLB 2V).

QUADRO 1 - Sistemas adesivos.

\section{Clearfil Liner Bond 2V, Kuraray Co., Ltd., Osaka, JAPAN - Lote 11153}

1. Primer A e B: MDP, HEMA, dimetacrilatos hidrofílicos, dl-canforoquinona, N,Ndietanol $p$-toluidina, água

2. Adesivo: MDP, Bis-GMA, HEMA, dimetacrilatos hidrofóbicos, dlcanforoquinona, $\mathrm{N}, \mathrm{N}$-dietanol $\mathrm{p}$-toluidina, sílica coloidal silanizada

One-Step, Bisco Dental Products, Schaumburg, IL, USA - Lote 129206

1. Primer: Bis-GMA, BPDM, HEMA, acetona

2. Uni-Etch (Ácido fosfórico a 32\%, BAC)

Single Bond, 3M, St. Paul, MN, USA - Lote 19980729

1. Primer: Bis-GMA, HEMA, água, etanol, copolímero de ácido polialcenóico

2. Ácido Fosfórico a $35 \%$

\footnotetext{
* School of Dentistry, Medical College of Georgia, Augusta, Georgia, USA
} 


\section{Preparo dos dentes}

Todo o esmalte oclusal de cada dente foi removido através de um desgaste perpendicular ao longo eixo do dente, empregando-se uma politriz com um disco de lixa de carbureto de silício de granulação $320^{\circ}$, sob irrigação abundante. Para certificar-se de que todo o esmalte fora removido durante esse procedimento, a superfície plana obtida era avaliada em microscópio óptico ${ }^{\wedge}$ com 30X de aumento. $\mathrm{Na}$ eventual existência de áreas de esmalte remanescentes, um novo desgaste era feito até conseguir-se uma superfície de dentina plana e uniforme, representativa de um plano de dentina superficial (Figuras 1A, 1B e 2A). Após o desgaste com o disco de lixa degranulação 320 , a superfície de dentina foi polida com um disco de lixa de granulação $600^{\circ}$ para a criação de uma smear layer padrão.

A superfície de dentina exposta de cada grupo de dentes foi tratada com o sistema adesivo apropriado, seguindo-se as recomendações do fabricante (Figura 2C e Quadro 2), com exceção do sistema CLB2V. Os procedimentos de secagem da dentina e aplicação de ar para facilitar a evaporação do solvente do primer foram executados utilizando-se papel absorvente* (Figura 2B) e ar comprimido livre de impurezas e óleo $^{\circ}$, respectivamente. Em seguida, a porção oclusal do dente que fora removida, foi reconstruída de maneira incremental com resina composta Z100", sem preocupar-se, contudo, em restabeler a anatomia oclusal, mas tomando-se o cuidado de observar que pelo menos $1 \mathrm{~cm}$ de resina, em altura, fora acrescentado (Figuras 1C e 2D). Para o grupo do sistema adesivo Clearfil, apenas um detalhe quanto à aplicação deste material foi modificado com re-

- Ecomet III, Buehler, Ltd., Lake Bluff, IL, USA

- SiC, Carbimet, Paper Discs, Buehler, Ltd., Lake Bluff, IL, USA

- Stereozoom 4, Bausch \& Lomb, Rochester, NY, USA

* Kimwipes, Kimberly Clark Corporation, Roswell, GA., USA

Dust-Off Plus, Falcon Safety Products, Inc., Branchburg, NJ, USA

- Z1000, 3M Dental Products Division, St. Paul, MN, USA 


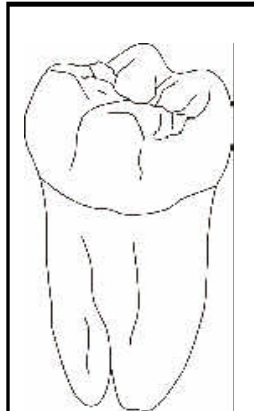

Fig. $1 \mathrm{~A}$

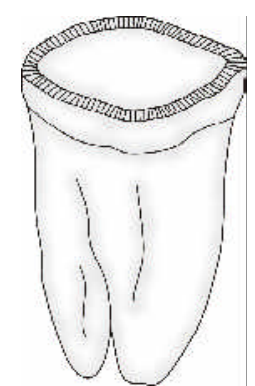

Fig. 1B

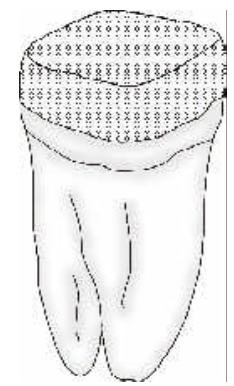

Fig. 1C

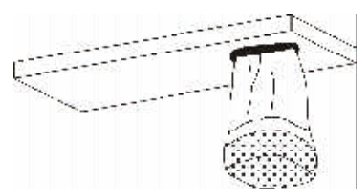

Fig. 1D

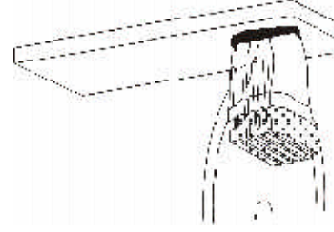

Fig. 1E

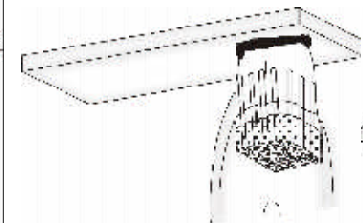

Fig. 1F

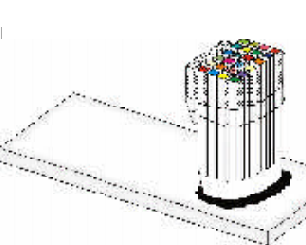

Fig. 1G

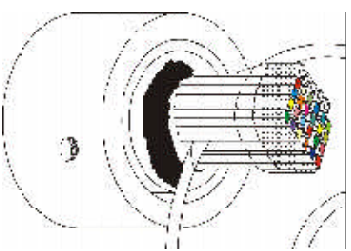

Fig. 1H

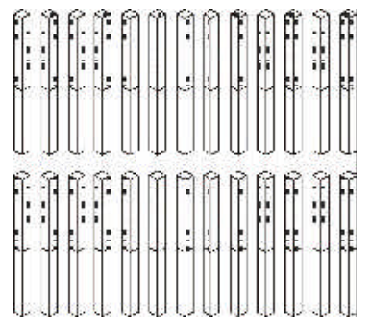

Fig. 1 I

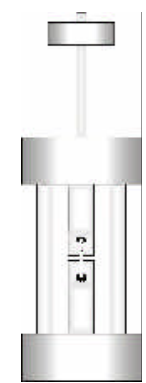

Fig. 1J

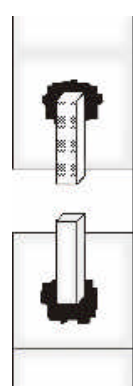

Fig. 1K

FIGURA 1 - A) Terceiro molar; B) Superfície de dentina plana e uniforme, obtida após desgaste do esmalte; C) Porção oclusal reconstruída com resina composta; D) Fixação do dente com cera pegajosa em um suporte plástico; E,F) Realização dos cortes seriados nos sentidos mésio-distal e vestíbulo-lingual, respectivamente, para obtenção dos espécimes; G) Identificação dos espécimes; H) Corte perpendicular ao longo eixo do dente para individualização dos espécimes; I) Espécimes em forma de "palitos"; J) Fixação de um espécime ao dispositivo de microtração; K) Espécime fraturado. 


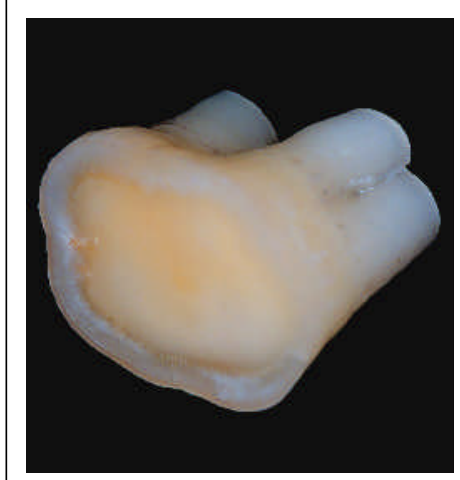

Fig. $2 \mathrm{~A}$

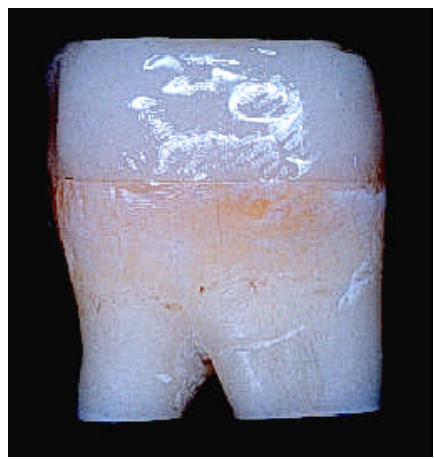

Fig. 2D

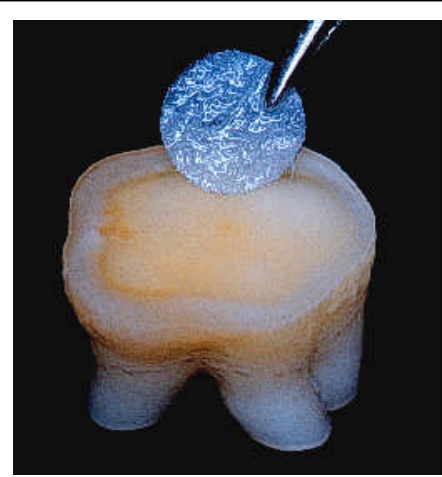

Fig. 2B

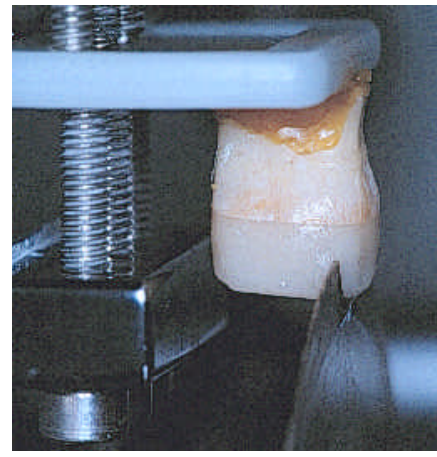

Fig. 2E

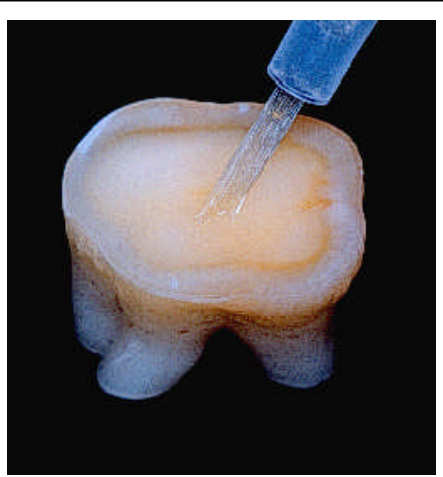

Fig. 2C

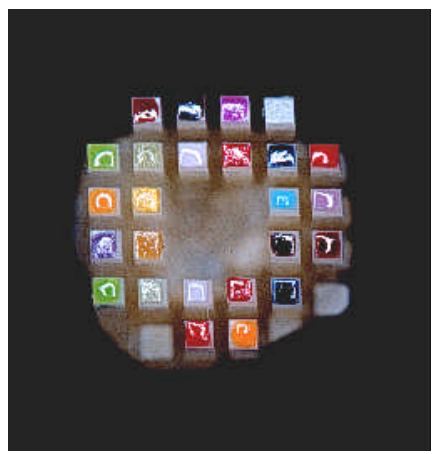

Fig. 2F

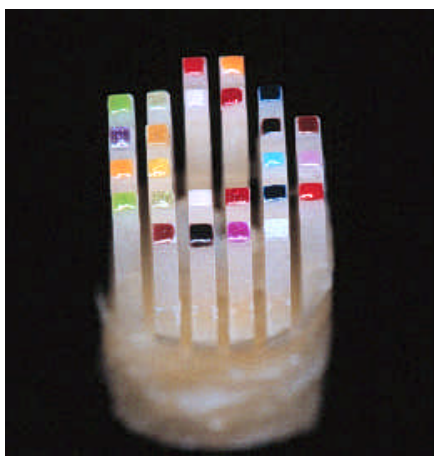

Fig. 2G

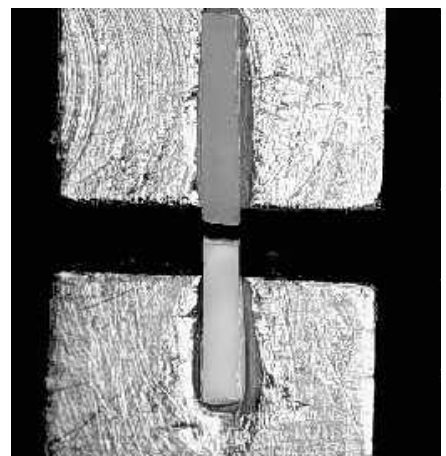

Fig. $2 \mathrm{H}$

FIGURA 2 - A) Superfície plana de dentina, sem remanescentes de esmalte oclusal, pronta para receber o processo de adesão; B) Secagem da superfície com papel absorvente, após o condicionamento ácido e lavagem com água.; C) Aplicação do sistema adesivo de acordo com as recomendações do fabricante; D) Reconstrução da porção coronária com resina composta; E) Cortes seriados nos sentidos mésiodistal e vestíbulo-lingual realizados com um disco de diamante, sob refrigeração abundante; F) Identificação dos espécimes através de um código de cores (vista oclusal); G) Vista lateral; H) Vista aproximada do espécime após a fratura.

OBS.: Os espécimes ausentes nas Figs. 2F e $2 \mathrm{G}$ são aqueles que se encontravam aderidos sobre a câmara pulpar e se desprenderam durante o corte. Estes respresentaram, posteriormente, os espécimes do grupo denominado de dentina central. Os remanescentes representaram o grupo denominado de dentina periférica. 
lação às recomendações do fabricante. Após um estudo piloto, verificou-se que eram necessários três minutos de intervalo entre a aplicação do primer e a colocação da resina e não 30 segundos, como preconizado pelo fabricante (ver discussão). Todas as etapas de fotopolimerização foram realizadas com o mesmo aparelho de luz visível".

QUADRO 2 - Aplicação dos sistemas adesivos.

\section{Clearfil Liner Bond 2V}

1. Dispensar quantidades iguais de Primer A e Primer B, misturando-os imediatamente antes da aplicação.

2. Aplicar a solução sobre toda a superfície de dentina com uma esponja ou um pincel deixando-a atuar durante 30 segundos (no presente estudo, 3 minutos). Para evaporar os ingredientes voláteis do primer, secar com um leve jato de ar.

3. Aplicar o adesivo e um leve jato de ar para permitir a obtenção de uma camada o mais uniforme possível. Polimerizar com luz visível por 20 segundos.

\section{One-Step}

1. Condicionar a superfície de dentina por 15 segundos, lavar por 15 segundos, secar suavemente utilizando papel absorvente e deixar a dentina úmida.

2. Aplicar duas camadas do adesivo com ligeira agitação, não secando entre as aplicações. Secar levemente com ar por 10 segundos com a finalidade de evaporar o solvente. Observar a presença de uma camada uniforme e brilhante, reaplicando-se uma camada adicional de adesivo, se necessário. Polimerizar com luz visível por 10 segundos.

\section{Single Bond}

1. Condicionar a superfície de dentina por 15 segundos, lavar por 10 segundos, retirar o excesso de água com papel absorvente ou algodão e deixar a superfície úmida.

2. Aplicar duas camadas do adesivo com um pincel completamente saturado pelo material. Secar levemente com ar por 2-5 segundos. Polimerizar com luz visível por 10 segundos.

- Visilux, 3M Dental Division, St. Paul, MN, USA 
Terminada a confecção da camada de resina sobre as superfícies, os dentes foram armazenados em água destilada em estufa a $37^{\circ} \mathrm{C}$ por um período de 24 horas.

\section{Preparo dos espécimes}

Após o período de armazenagem, cada dente foi fixado com cera pegajosa ${ }^{*}$ pela porção radicular, perpendicularmente ao seu longo eixo, em um suporte plástico (Figura 1D), para ser adaptado à uma máquina de cortes seriados ${ }^{\prime}$. Utilizando um disco de diamante girando em baixa velocidade com constante irrigação, foram feitos vários cortes seriados paralelos ao longo eixo do dente, em espessuras de aproximadamente $0,8 \mathrm{~mm}$, nos sentidos mésio-distal (Figura 1E) e vestíbulo-lingual (Figuras 1F e 2E), tomando o cuidado para não separar totalmente as "fatias" da base fixada com cera pegajosa. Nesta etapa, após o segundo sentido de corte ser realizado, os espécimes localizados sobre o órgão pulpar permaneciam fixos pelo tecido pulpar ainda presente e assim, observando-se suas localizações com relação ao dente, eram removidos. Concluída essa etapa, cada espécime a ser obtido, todos eles ainda presos pela porção radicular do dente, foi identificado através de um código de cores empregando diferentes matizes de esmalte de unha+ (Figuras 1G, 2F e 2G). O "mapeamento" dos espécimes, identificados através das cores, foi anotado em uma ficha (Anexos 1 a 12) e em seguida, a base dos espécimes foi seccionada perpendicularmente ao seu longo eixo (Figura $1 \mathrm{H}$ ), obtendo-se vários espécimes em forma de "palitos" (Figura 11).

\footnotetext{
Kerr, Orange, CA, USA

$\checkmark$ Isomet, Buehler, Ltd., Lake Bluff, II, USA

+ Esmalte de unha Colorama, Brasil
} 
Antes de serem submetidos à força de tração, os espécimes foram avaliados lateralmente em microscópio óptico* com 30X de aumento, para verificar se na área de adesão não havia falhas no processo adesivo, como presença de bolhas ou presença de esmalte. Os espécimes com defeitos visíveis na interface adesiva foram descartados.

Para avaliar a resistência de união à microtração, os espécimes foram individualmente afixados ao dispositivo de microtração Bencor Multi-T* (Figura 1J), adaptado à uma máquina de ensaios universal*, com um adesivo à base de cianocrilato", pelas suas extremidades, de modo a posicionar a interface adesiva em orientação perpendicular ao sentido de aplicação da força. Os testes foram realizados com uma velocidade de movimentação da máquina de $1,0 \mathrm{~mm} / \mathrm{min}$.

Após o teste, as duas porções fraturadas (Figuras $1 \mathrm{~K} \mathrm{e} 2 \mathrm{H}$ ) foram cuidadosamente removidas e a área transversal correspondente à fratura foi medida, utilizando-se um paquímetro universal com leitura digital eletrônica* com precisão de 0,01 mm. O valor da área de secção trasnversal foi transformado $\mathrm{em} \mathrm{cm}^{2}$ e o valor da carga em $\mathrm{Kg}$. Os valores finais de resistência de união foram calculados e expressos em MPa.

A distribuição da amostra empregada neste estudo se encontra descrita no Quadro 3.

- Stereozoom 4, Bausch \& Lomb, Rochester, NY, USA

* Danville Engineering, Danville, CA, USA

* Instron, USA

* Zapit, DVA, Yorba Linda, CA, USA

* Sylvae Ultra-Cal II, Fowler Co., Inc., Newton, MA, USA 
O modo de fratura da interface adesiva foi avaliado em microscopia óptica* com 40X de aumento e classificada em cinco tipos: adesiva em resina (entre a camada de adesivo e a de resina composta), adesiva em dentina (entre a camada de adesivo e a de dentina), coesiva em dentina, coesiva em resina e mista (envolvendo dois ou mais planos distintos de fratura: dentina, adesivo ou resina).

QUADRO 3 - Número de dentes, número de espécimes e materiais empregados.

\begin{tabular}{|cccc|}
\hline Dente & $\begin{array}{c}\text { No de } \\
\text { Espécimes }\end{array}$ & Sistema Adesivo & $\begin{array}{c}\text { Resina } \\
\text { Composta }\end{array}$ \\
\hline 1 & 25 & Clearfil Liner Bond 2V & Z 100 \\
2 & 20 & Clearfil Liner Bond 2V & Z 100 \\
3 & 23 & Clearfil Liner Bond 2V & Z 100 \\
4 & 25 & Clearfil Liner Bond 2V & Z 100 \\
5 & 26 & Clearfil Liner Bond 2V & Z 100 \\
6 & 24 & Clearfil Liner Bond 2V & Z 100 \\
1 & 23 & One-Step & Z 100 \\
2 & 29 & One-Step & Z 100 \\
3 & 20 & One-Step & Z 100 \\
1 & 19 & Single Bond & Z 100 \\
2 & 18 & Single Bond & Z 100 \\
3 & 23 & Single Bond & Z 100 \\
\hline
\end{tabular}

OBS.: O número de espécimes se refere à quantidade obtida por dente.

- Stereozoom 4, Bausch \& Lomb, Rochester, NY, USA 


\section{Análise estatística}

A relação entre área de secção transversal e respectiva resistência adesiva foi examinada individualmente para cada material empregando-se 0 método de regressão linear. As diferenças entre as médias das áreas de secção transversal dos grupos de materiais foram examinadas pelo método de análise de variância (ANOVA), seguido do teste "post-hoc" de StudentNewman-Keuls (SNK). A variação da resistência adesiva intradente foi determinada pelo cálculo do coeficiente de variação. A variação interdentes para cada material foi analisada por ANOVA e SNK. Empregou-se ANOVA a Dois Critérios para examinar as interações entre as variáveis material e substrato, considerando para a variável substrato, os espécimes obtidos da porção central da coroa e os obtidos da porção periférica. Para todas as análises, estipulou-se o nível de significância em $\alpha=5 \%$. 


\section{Resultados}

"ratiolegis..." 


\section{5 - RESULTADOS}

Os valores de resistência de união à microtração de cada dente preparado para cada sistema adesivo, podem ser observados na Tabela 1. Os valores individuais de resistência de união de cada espécime podem ser observados nos Anexos 13 a 24.

TABELA 1 - Valores médios de resistência de união à microtração de cada dente preparado para cada sistema adesivo

\begin{tabular}{cccccc}
$\begin{array}{c}\text { NNo do Dente } \\
\text { e No de } \\
\text { Espécimes } \\
(\mathrm{n})\end{array}$ & $\begin{array}{c}\text { Sistema } \\
\text { Adesivo }\end{array}$ & $\begin{array}{c}\text { Médiae Desvio- } \\
\text { padrão da } \\
\text { Resistência } \\
\text { Adesiva(MPa) }\end{array}$ & $\begin{array}{c}\text { Médiae } \\
\text { Desvio- } \\
\text { padrão da } \\
\text { Area de União } \\
\left(\mathrm{mm}^{2}\right)\end{array}$ & $\begin{array}{c}\text { Coeficiente de } \\
\text { Variação }\end{array}$ & $\begin{array}{c}\text { № de } \\
\text { Espécimes } \\
\text { perdidos/ } \\
\text { excluídos* }\end{array}$ \\
\hline $1(25)$ & CLB2V & $24,35 \pm 7,63$ & $0,66 \pm 0,03$ & $31,34 \%$ & $2 / 3$ \\
$2(20)$ & CLB2V & $44,83 \pm 12,07$ & $0,66 \pm 0,01$ & $26,92 \%$ & $3 /-$ \\
$3(23)$ & CLB2V & $45,42 \pm 10,41$ & $0,71 \pm 0,05$ & $22,92 \%$ & $1 /-$ \\
$4(25)$ & CLB2V & $31,61 \pm 10,89$ & $0,71 \pm 0,02$ & $34,45 \%$ & $-/-$ \\
$5(26)$ & CLB2V & $24,16 \pm 6,66$ & $0,68 \pm 0,02$ & $27,57 \%$ & $2 /-$ \\
$6(24)$ & CLB2V & $30,71 \pm 6,63$ & $0,70 \pm 0,02$ & $21,60 \%$ & $-/ 1$ \\
$1(23)$ & OS & $50,93 \pm 11,73$ & $0,74 \pm 0,02$ & $23,03 \%$ & $1 /-$ \\
$2(29)$ & OS & $56,48 \pm 12,49$ & $0,76 \pm 0,02$ & $22,12 \%$ & $2 / 2$ \\
$3(20)$ & OS & $53,82 \pm 13,46$ & $0,74 \pm 0,02$ & $25,01 \%$ & $-/-$ \\
$1(19)$ & SB & $44,19 \pm 11,29$ & $0,69 \pm 0,05$ & $25,55 \%$ & $-/-$ \\
$2(18)$ & SB & $46,66 \pm 10,97$ & $0,75 \pm 0,02$ & $23,52 \%$ & $1 /-$ \\
$3(23)$ & SB & $64,15 \pm 20,27$ & $0,72 \pm 0,03$ & $31,60 \%$ & $3 /-$ \\
\hline
\end{tabular}

* Espécimes que se fraturaram durante o preparo/espécimes que foram excluídos por defeitos ou excluídos por área de secção transversal fora da média dos grupos. 
A Análise de Variância a Dois Critérios, material e substrato, não detectou uma dependência dos resultados aos fatores e, portanto, foi possível agrupar toda a amostra referente a substrato de cada material para a análise comparativa. Os valores (média e desvio-padrão) e as comparações da resistência de união para cada sistema adesivo empregado, podem ser observados na Tabela 2 e no Gráfico 1. Na mesma tabela, também encontram-se os valores médios e respectivos valores de desvio-padrão das áreas de união e o coeficiente de variação encontrado com relação ao material adesivo.

TABELA 2 - Comparação da resistência de união à microtração entre materiais.

\begin{tabular}{|c|c|c|c|}
\hline $\begin{array}{c}\text { Material e № } \\
\text { de Espécimes } \\
\text { (n) }\end{array}$ & $\begin{array}{l}\text { Média e Desvio- } \\
\text { Padrão da } \\
\text { Resistência de União } \\
\text { (MPa) }\end{array}$ & $\begin{array}{l}\text { Média e Desvio- } \\
\text { Padrão da Área } \\
\text { de União }\left(\mathrm{mm}^{2}\right)\end{array}$ & $\begin{array}{c}\text { Coeficiente de } \\
\text { Variação da } \\
\text { Resistência de } \\
\text { União }\end{array}$ \\
\hline CLB2V (143) & $32,90 \pm 12,43^{a}$ & $0,69 \pm 0,03^{c}$ & $37,78 \%$ \\
\hline OS (72) & $53,97 \pm 12,58^{b}$ & $0,75 \pm 0,02^{c}$ & $23,31 \%$ \\
\hline SB (60) & $52,59 \pm 17,67^{b}$ & $0,72 \pm 0,04^{c}$ & $33,61 \%$ \\
\hline
\end{tabular}

${ }^{*}$ Os valores com mesma letra não apresentam diferenças estatisticamente significantes $(p>0,05)$. 
GRÁFICO 1 - Comparação da resistência de união à microtração

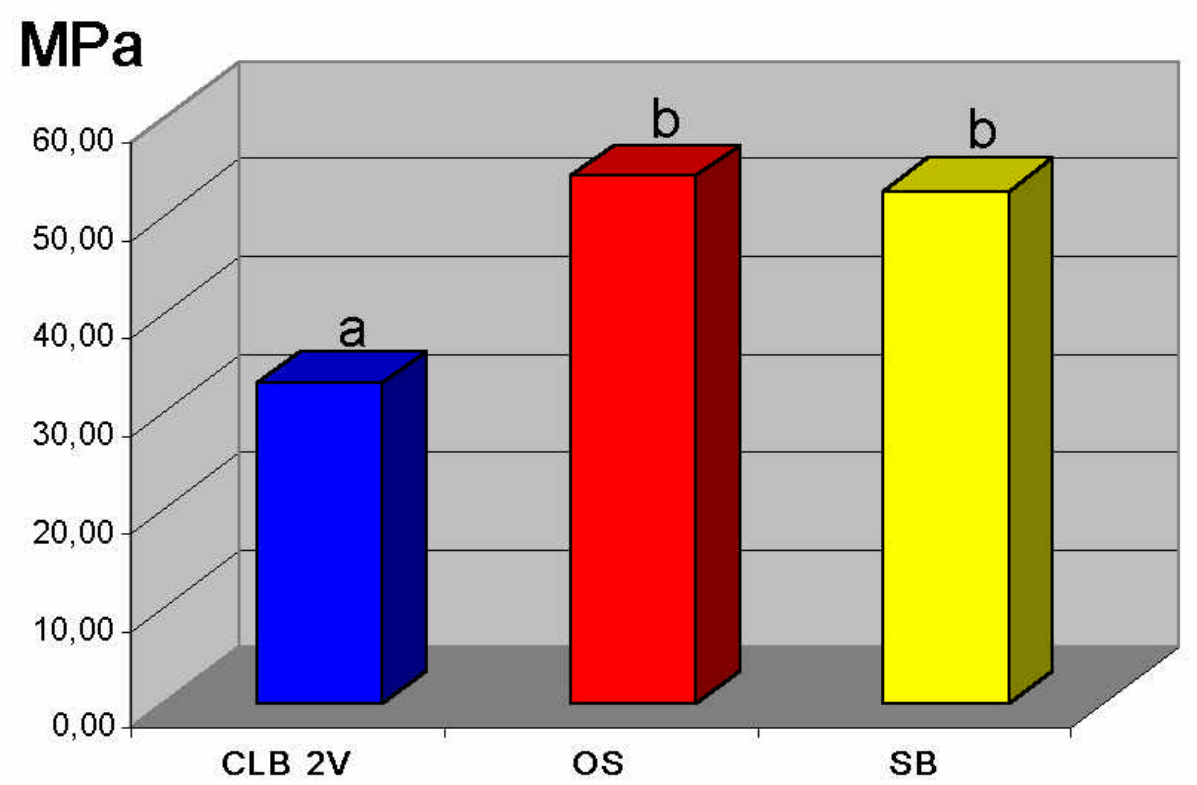

${ }^{*}$ Os valores com mesma letra não apresentam diferenças estatisticamente significantes $(p>0,05)$.

A análise de variância e o teste de Student-Newman-Keuls demonstraram que os valores de resistência de união à microtração encontrados para os sistemas adesivos One-Step e Single Bond não foram diferentes estatisticamente $(p>0,05)$. Já 0 valor médio de resistência de união do sistema Clearfil Liner Bond $2 \mathrm{~V}$ foi significantemente menor do que os demais sistemas adesivos avaliados $(p<0,05)$.

As Tabelas 3, 4 e 5 e os Gráficos 2, 3 e 4 apresentam os dados e as comparações após uma análise de variância e o teste de Student-NewmanKeuls, de cada dente, para cada sistema adesivo. 
TABELA 3 - Comparação dos valores de resistência de união à microtração entre os dentes, para o sistema adesivo CLB2V.

\begin{tabular}{cccc}
$\begin{array}{c}N^{N} \text { de dentes e } \\
N^{\circ} \text { de } \\
\text { Espécimes }(\mathrm{n})\end{array}$ & $\begin{array}{c}\text { Média e Desvio- } \\
\text { Padrão da } \\
\text { Resistência de } \\
\text { União }(\mathrm{MPa})\end{array}$ & $\begin{array}{c}\text { Média e Desvio- } \\
\text { Padrão da Área de } \\
\text { União }\left(\mathrm{mm}^{2}\right)\end{array}$ & $\begin{array}{c}\text { Coeficiente } \\
\text { de Variação } \\
\text { da } \\
\text { Resistência } \\
\text { de União }\end{array}$ \\
\hline $1(25)$ & $24,35 \pm 7,63^{\mathrm{a}}$ & $0,66 \pm 0,03^{\mathrm{d}}$ & $31,34 \%$ \\
$2(20)$ & $44,83 \pm 12,07^{\mathrm{b}}$ & $0,66 \pm 0,01^{\mathrm{d}}$ & $26,92 \%$ \\
$3(23)$ & $45,42 \pm 10,41^{\mathrm{b}}$ & $0,71 \pm 0,05^{\mathrm{e}}$ & $22,92 \%$ \\
$4(25)$ & $31,61 \pm 10,89^{\mathrm{c}}$ & $0,71 \pm 0,02^{\mathrm{e}}$ & $34,45 \%$ \\
$5(26)$ & $24,16 \pm 6,66^{\mathrm{a}}$ & $0,68 \pm 0,02^{\mathrm{e}}$ & $27,57 \%$ \\
$6(24)$ & $30,71 \pm 6,63^{\mathrm{c}}$ & $0,70 \pm 0,02^{\mathrm{e}}$ & $21,60 \%$ \\
\hline
\end{tabular}

${ }^{*}$ Os valores com mesma letra não apresentam diferenças estatisticamente significantes $(p>0,05)$.

GRÁFICO 2-Comparação dos valores de resistência de união à microtração entre os dentes, para o sistema adesivo CLB2V.

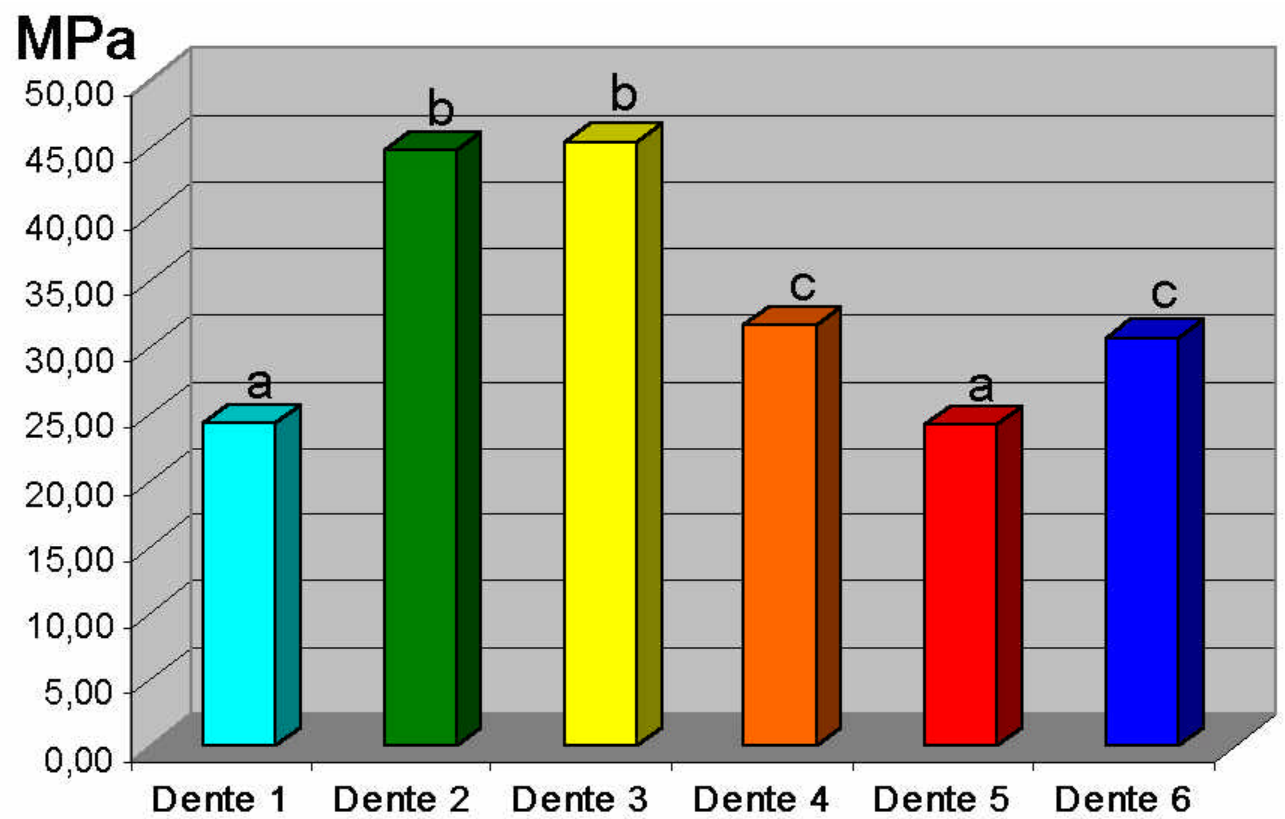

*Os valores com mesma letra não apresentam diferenças estatisticamente significantes $(p>0.05)$. 
TABELA 4 - Comparação dos valores de resistência de união à microtração entre os dentes, para o sistema adesivo OS.

\begin{tabular}{|c|c|c|c|}
\hline $\begin{array}{l}\mathbf{N}^{\circ} \text { de dentes e } \\
\qquad \mathbf{N}^{\circ} \text { de } \\
\text { Espécimes (n) }\end{array}$ & $\begin{array}{c}\text { Média e Desvio- } \\
\text { Padrão da } \\
\text { Resistência de União } \\
\text { (MPa) }\end{array}$ & $\begin{array}{c}\text { Média e Desvio- } \\
\text { Padrão da Área de } \\
\text { União }\left(\mathrm{mm}^{2}\right)\end{array}$ & $\begin{array}{c}\text { Coeficiente } \\
\text { de Variação } \\
\text { da } \\
\text { Resistência } \\
\text { de União }\end{array}$ \\
\hline $1(23)$ & $50,93 \pm 11,73^{a}$ & $0,74 \pm 0,02^{c}$ & $23,03 \%$ \\
\hline $2(29)$ & $56,48 \pm 12,49^{a}$ & $0,76 \pm 0,02^{c}$ & $22,12 \%$ \\
\hline $3(20)$ & $53,82 \pm 13,46^{a}$ & $0,74 \pm 0,02^{c}$ & $25,01 \%$ \\
\hline
\end{tabular}

${ }^{*}$ Os valores com mesma letra não apresentam diferenças estatisticamente significantes $(p>0,05)$.

GRÁFICO 3 - Comparação dos valores de resistência de união à microtração entre os dentes, para o sistema adesivo OS.

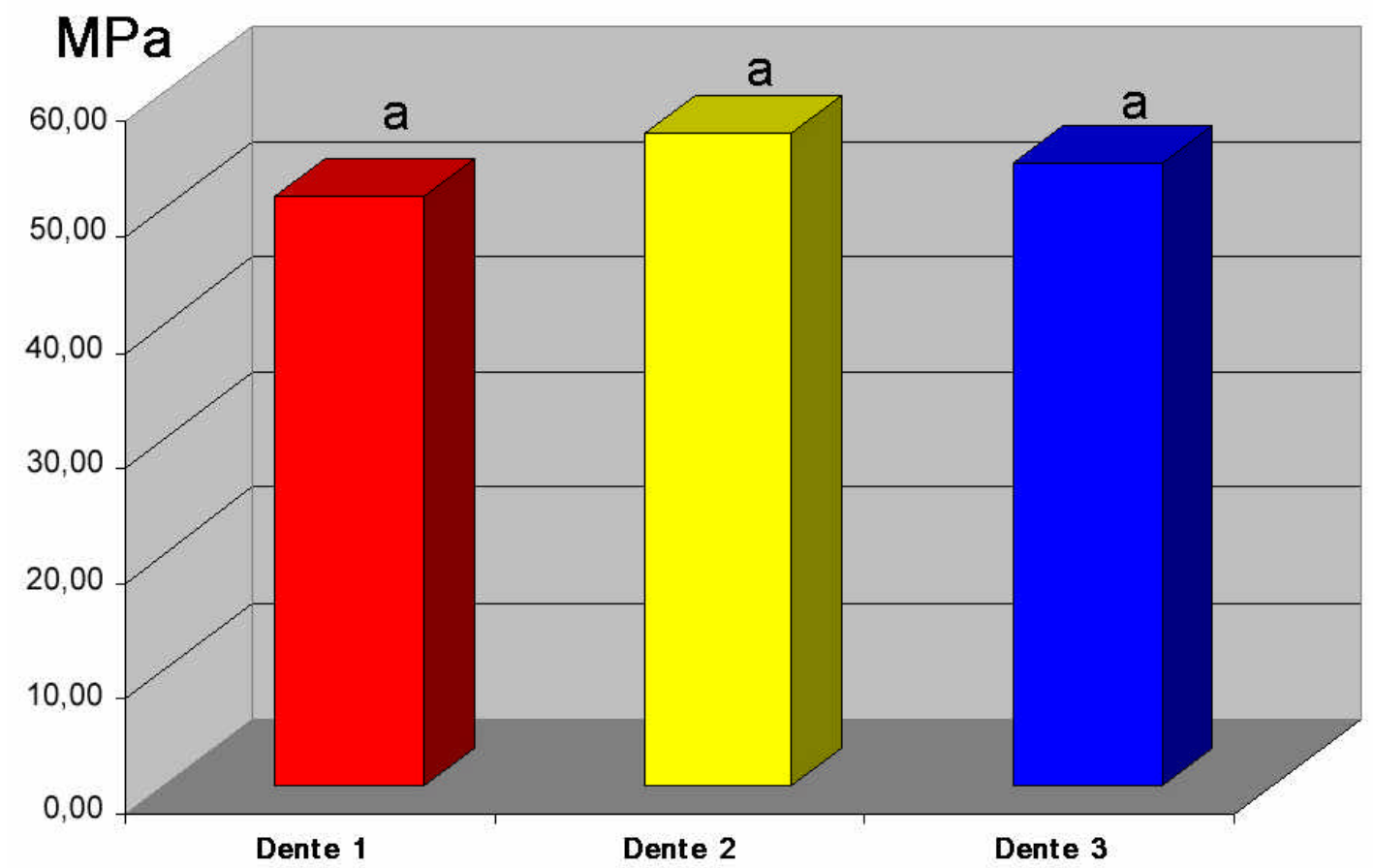

${ }^{*}$ Os valores com mesma letra não apresentam diferenças estatisticamente significantes $(p>0.05)$. 
TABELA 5 - Comparação dos valores de resistência de união à microtração entre os dentes, para o sistema adesivo SB.

\begin{tabular}{|c|c|c|c|}
\hline $\begin{array}{l}N^{0} \text { de dentes e } \\
\qquad N^{0} \text { de } \\
\text { Espécimes (n) }\end{array}$ & $\begin{array}{c}\text { Média e Desvio- } \\
\text { Padrão da } \\
\text { Resistência de União } \\
\text { (MPa) }\end{array}$ & $\begin{array}{l}\text { Média e Desvio- } \\
\text { Padrão da Área de } \\
\text { União }\left(\mathrm{mm}^{2}\right)\end{array}$ & $\begin{array}{c}\text { Coeficiente } \\
\text { de Variação } \\
\text { da } \\
\text { Resistência } \\
\text { de União }\end{array}$ \\
\hline 1 (19) & $44,19 \pm 11,29^{a}$ & $0,69 \pm 0,05^{c}$ & $25,55 \%$ \\
\hline $2(18)$ & $46,66 \pm 10,97^{a}$ & $0,75 \pm 0,02^{d}$ & $23,52 \%$ \\
\hline $3(23)$ & $64,15 \pm 20,27^{b}$ & $0,72 \pm 0,03^{e}$ & $31,60 \%$ \\
\hline
\end{tabular}

${ }^{*}$ Os valores com mesma letra não apresentam diferenças estatisticamente significantes $(p>0,05)$.

GRÁFICO 4 - Comparação dos valores de resistência de união à microtração entre os dentes, para o sistema adesivo SB.

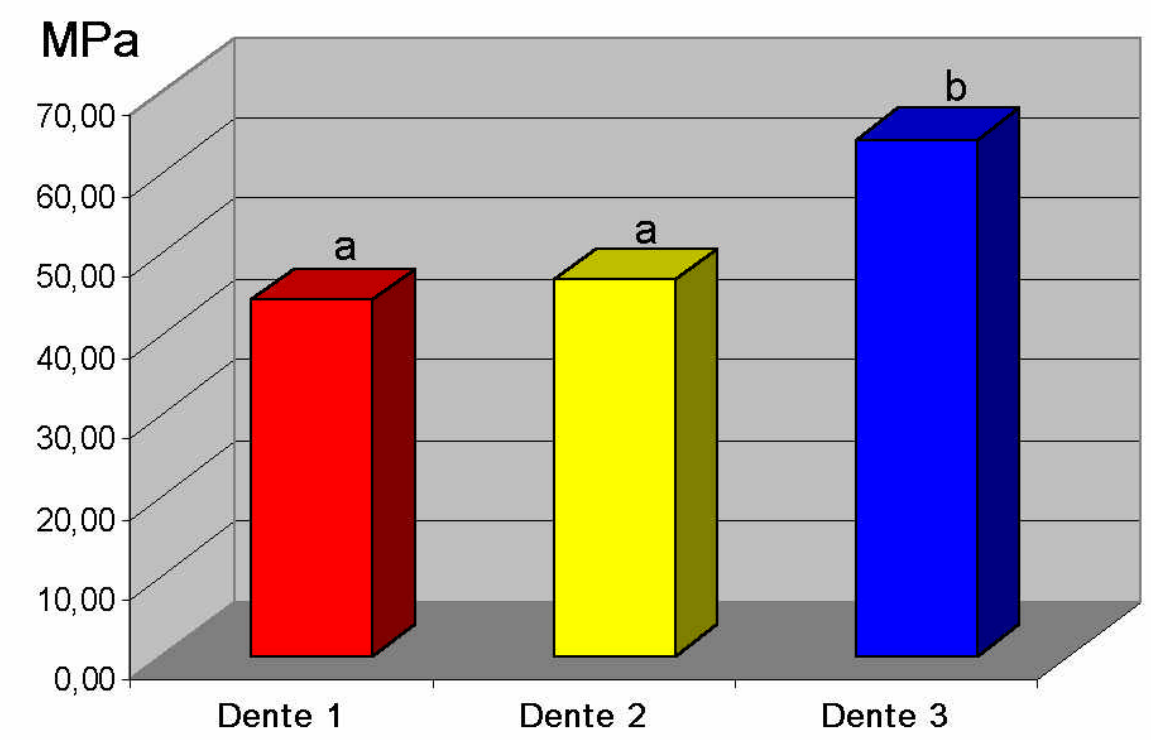

*Os valores com mesma letra não apresentam diferenças estatisticamente significantes ( $p>0.05)$.

Analisando-se as variações entre os dentes para cada sistema adesivo, observou-se que houve uma variação significante $(p<0,05)$ nos 
valores médios encontrados para o sistema CLB2V e para o SB. Para o sistema OS, os três dentes avaliados apresentaram um valor de resistência adesiva média estatisticamente semelhante.

Analisando a variação dos valores de resistência de união de cada dente, observou-se que a média dos coeficientes de variação para os sistemas Clearfil Liner Bond 2V, One-Step e Single Bond, foram, respectivamente, de 27,46\%,23,38\% e 26,89\%. A análise de variância desses valores não mostrou diferenças significantes ( $p>0,05)$, o que permite dizer que todos os materiais, dentro de um mesmo dente, variaram de forma semelhante.

As Figuras 3 e 4 apresentam ilustrativa e tridimensionalmente a variação observada na resistência de união obtida pelo mapeamento dos espécimes em um mesmo dente.

FIGURA 3 - Desenho esquemático do gráfico de mapeamento da Amostra 1 do grupo do sistema adesivo CLB2V.

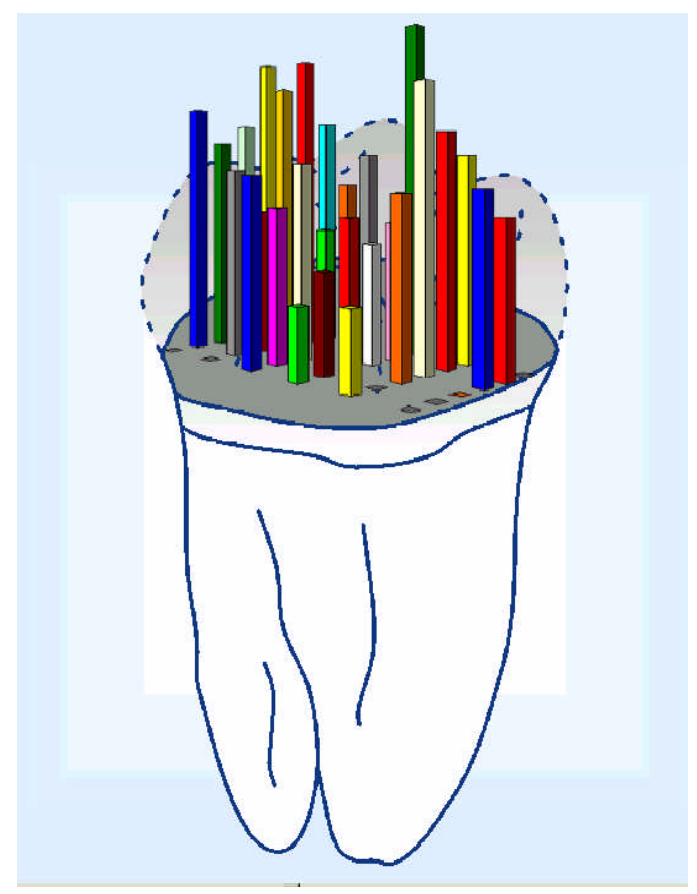


FIGURA 4 - Desenho esquemático do gráfico de mapeamento da Amostra 2 do grupo do sistema adesivo SB.

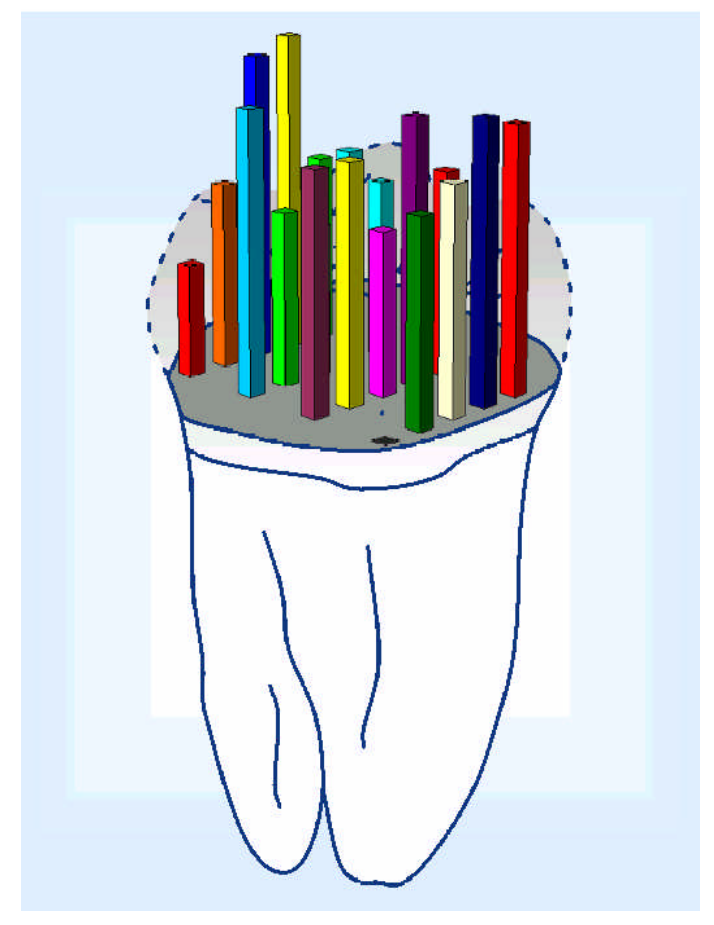

Todos os sistemas adesivos não apresentaram uma diferença estatisticamente significante nos valores de resistência de união entre os espécimes localizados ao centro ou na periferia do dente. A Tabela 6 e 0 Gráfico 5 apresentam esses valores médios.

TABELA 6 - Médias da resistência de união para cada material e substrato.

\begin{tabular}{cccc} 
Material & $\begin{array}{c}\text { Número de } \\
\text { espécimes: } \\
\text { centro/periferia }\end{array}$ & $\begin{array}{c}\text { CENTRO } \\
\text { Resistência de união } \\
(\mathrm{MPa}) \pm \text { Desvio-Padrão }\end{array}$ & $\begin{array}{c}\text { PERIFERIA } \\
\text { Resistência de } \\
\text { união (MPa) } \pm \\
\text { Desvio-Padrão }\end{array}$ \\
\hline CLB2V & $\mathbf{3 7 / 1 0 6}$ & $\mathbf{3 1 , 0 2 \pm 1 2 , 6 6}$ & $\mathbf{3 3 , 5 6 \pm 1 2 , 3 4}$ \\
OS & $12 / 60$ & $51,58 \pm 8,94$ & $54,45 \pm 13,20$ \\
SB & $15 / 45$ & $46,64 \pm 11,07$ & $54,57 \pm 19,07$ \\
\hline
\end{tabular}

* Os valores unidos por barras horizontais não apresentam diferenças significantes (p>0,05). 
GRÁFICO 5-Médias da resistência de união para cada material e substrato.

\section{MPa}

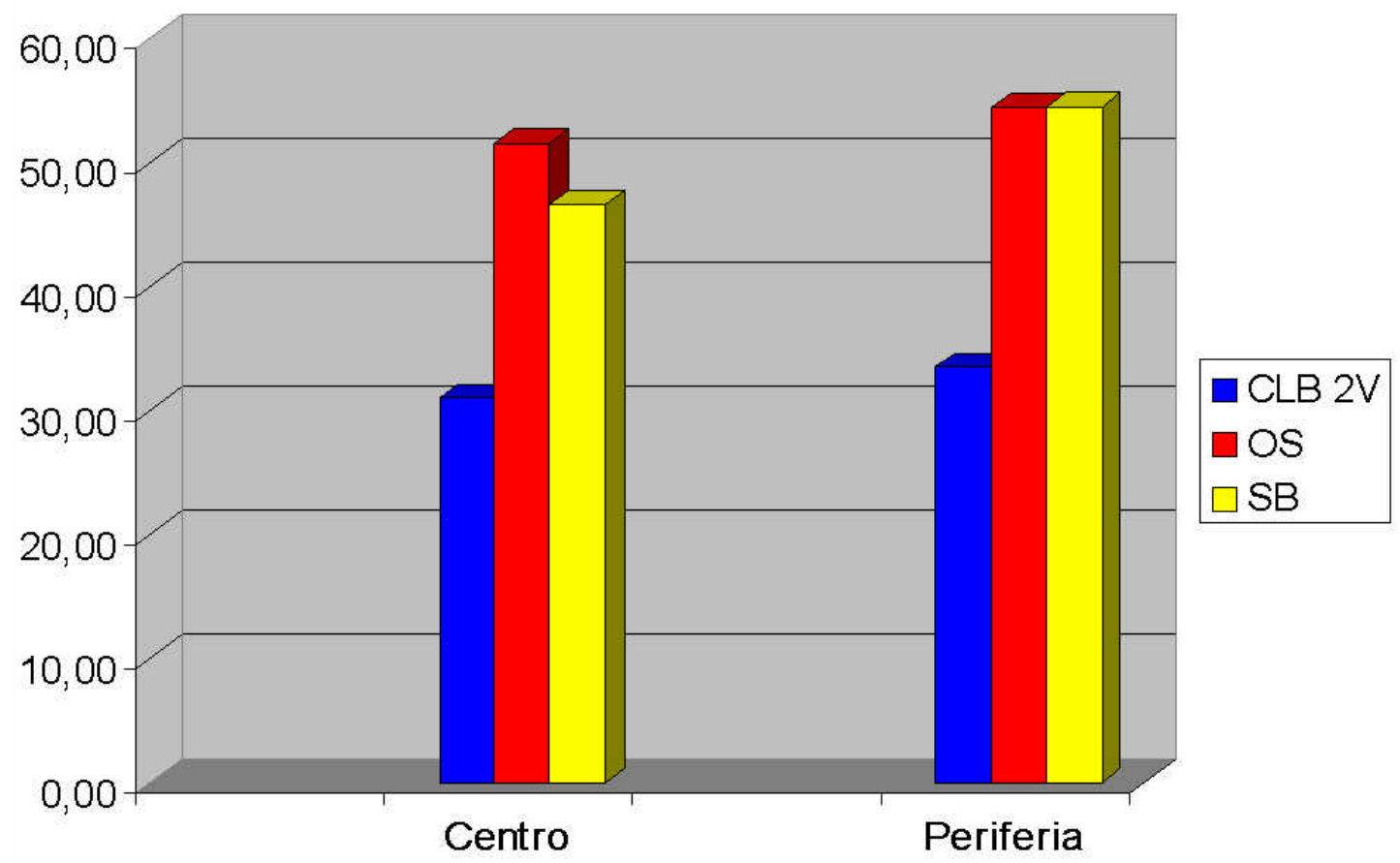

A avaliação dos modos de fratura das interfaces adesivas dos corpos-de-prova realizada em microscopia óptica com 40X de aumento, demonstrou que aproximadamente $30 \%$ das fraturas encontradas no grupo do sistema Clearfil Liner Bond 2V foram adesivas em dentina. Para o grupo do sistema One Step, houve aproximadamente $75 \%$ de fraturas do mesmo tipo e para o grupo do sistema Single Bond, houve $80 \%$ de fraturas adesivas em dentina; ou seja, para estes dois materiais, o tipo de fratura mais frequentemente encontrado foi a fratura adesiva em dentina. $\mathrm{O}$ tipo de fratura mais predominantemente encontrado no grupo do sistema Clearfil Liner Bond 2V foi a fratura mista, aproximadamente 60\%. A Tabela 7 e 0 Gráfico 6 apresentam os diferentes tipos de fratura dependendo do sistema adesivo empregado. 
TABELA 7 - Porcentagem (\%) do tipo de fratura das interfaces adesivas e número de espécimes $(\mathrm{n})$, dependento do sistema adesivo empregado.

\begin{tabular}{|c|c|c|c|c|c|}
\hline$\frac{\text { Fratura }}{\text { Material }}$ & $\begin{array}{c}\text { adesiva em } \\
\text { dentina }\end{array}$ & $\begin{array}{l}\text { adesiva } \\
\text { em resina }\end{array}$ & mista & $\begin{array}{c}\text { coesiva em } \\
\text { dentina }\end{array}$ & $\begin{array}{l}\text { coesiva } \\
\text { em resina }\end{array}$ \\
\hline CLB2V & $29,37 \%(42)$ & $5,59 \%(8)$ & $62,24 \%(89)$ & $1,40 \%(2)$ & $1,40 \%(2)$ \\
\hline OS & $77,78 \%(56)$ & - & $15,28 \%(11)$ & $6,94 \%$ (5) & - \\
\hline SB & $80,0 \%(48)$ & - & $15,0 \%(9)$ & $5,0 \%(3)$ & - \\
\hline
\end{tabular}

GRÁFICO 6 - Porcentagem (\%) do tipo de fratura das interfaces adesivas e número de espécimes (n), dependendo do sistema adesivo empregado.

$\%$ de fratura

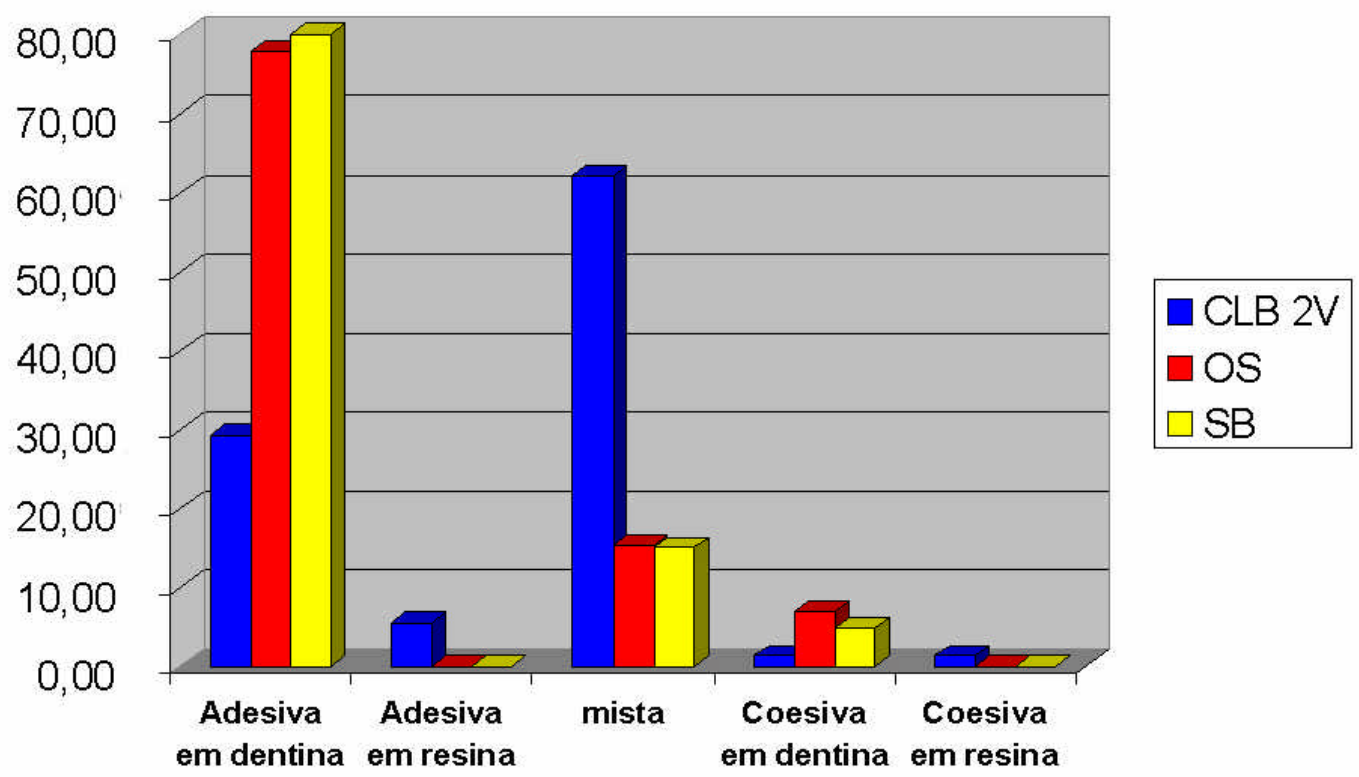




\section{Discussão}

"scribitur ad narrandum, non ad probandum..." 


\section{6 - DISCUSSÃO}

\section{1 - Da Metodologia}

Os sistemas adesivos são empregados atualmente em vários tipos de procedimentos dentro do que se convencionou chamar de odontologia adesiva. A determinação da eficácia desses materiais requer sua avaliação em diversos testes in vivo ou in vitro, embora nenhum seja capaz de, individualmente, categorizar os materiais ${ }^{77}$. Evidentemente, são os trabalhos clínicos $44,59,62,88,114,116,134,135,151$ que mostram a eficácia final dos materiais, mas a longa duração dos estudos, aliada à dificuldade de padronização dos métodos, de bioética e a evolução crescente no campo dos materiais dentários, fazem com que os testes laboratoriais, cuja obtenção de resultados demanda menos tempo, ainda sejam necessários para 0 desenvolvimento e a avaliação inicial dos produtos a serem empregados na clínica $^{145}$.

Dentre os vários testes mecânicos que estão disponíveis para se avaliar a união resina/dente em laboratório, destacam-se aqueles que se baseiam na aplicação de uma força de deslocamento dos dois substratos diretamente na interface ou à distância desta. Os testes de tração $8,11,25,55,64,68,69,70,96,150,153$ 
complexos tecnicamente e de fácil preparação dos corpos-de-prova. Nesses trabalhos, a média da área adesiva empregada varia de 7 a $12 \mathrm{~mm}^{2}$, o espécime é confeccionado no centro da face oclusal ou vestibular do dente e emprega-se dentina normal, a uma distância padronizada da polpa, normalmente superficial. Outros testes objetivam mensurar a quantidade de energia necessária para provocar a fratura de união ou medir a tenacidade da mesma, como o "blister test", um teste que baseia-se na aplicação de uma pressão crescente de ar na união através de um orifício realizado no substrato, e o teste de centrifugação, que baseia-se na aplicação de uma determinada velocidade periférica ao corpo-de-prova, fazendo que as forças de tração geradas induzam a ruptura de união, permitindo o cálculo da resistência adesiva. Ambos o "blister test" e o teste de centrifugação não são rotineiramente empregados na avaliação da união de materiais adesivos à estrutura dentária, pois são de preparação complexa e de difícil interpretação. Além destes, na busca de melhorar a avaliação da resistência de união com o objetivo de forçar a fratura na interface sem exceder a resistência intrínseca da dentina ou da resina, outros testes mecânicos também vêm sendo desenvolvidos ${ }^{13,70,86,107,110,122,123,149}$.

Em um teste de cisalhamento, a união é rompida por uma força aplicada paralelamente à interface adesiva ${ }^{77}$. $O$ teste pode ser realizado através de uma haste metálica ou uma alça de fio de aço justapostas o mais próximo possível da interface adesiva. É o teste mais frequentemente empregado para a avaliação da resistência de união ${ }^{1}$, provavelmente pela simplicidade do método e pela facilidade de adequação aos diferentes equipamentos disponíveis nos diversos laboratórios. A falta de padronização nos testes, entretanto, é um fato que compromete a comparação direta dos diferentes estudos e uma das críticas frequentemente direcionada aos testes de cisalhamento é que o mesmo induz a união a falhar em um plano determinado pelo teste e não pelas próprias características da interface adesiva; em outras palavras, no teste de cisalhamento, a fratura se inicia no ponto onde a haste aplica uma força normal, e portanto, a fratura nem 
sempre ocorre no ponto mais fraco. Isso foi demonstrado em um trabalho realizado por Van Noort et al. ${ }^{147}$ (1989), empregando-se a análise por elemento finito.

Analisando-se um teste de cisalhamento por elemento finito, os autores demonstraram que esse teste é influenciado significativamente pela distância entre o ponto de aplicação da carga e a interface adesiva. Quando esta aumenta, aumenta o "momento de dobramento", causando alterações significantes nos resultados observados. Além disso, verificaram que a falha se inicia na superfície do material, e não na interface adesiva. Os autores concluem que uma força de cisalhamento uniforme não é conseguida na interface adesiva. Além dessas considerações, também já foi demonstrado através de análise por elemento finito ${ }^{24}$, que existe uma grande concentração de tensões na interface próxima à área de aplicação da força e, geralmente, as tensões alcançam valores máximos aproximadamente a 0,3 mm abaixo do local de aplicação da carga, diminuindo a partir daí em todas as direções.

Em um teste de tração, a união é estressada por uma força aplicada perpendicularmente à interface adesiva ${ }^{77}$. Dessa maneira, um dos principais problemas com esse modo de teste é a manutenção do alinhamento do corpo-de-prova durante o ensaio, evitando a orientação inadequada da força devido a uma geometria interfacial incorreta ${ }^{77}$. Devido à essa preocupação, vários dispositivos têm sido sugeridos com o objetivo de manter a reprodutibilidade dos ensaios sempre dentro do requerido alinhamento. Entretanto, a despeito do alerta e das constantes recomendações encontradas na literatura, a falta de padronização nos testes de resistência adesiva é rotina nos diferentes estudos. Isso se deve principalmente à falta de similaridade de dispositivos e equipamentos disponíveis nos diversos laboratórios de pesquisa; muitas vezes por motivos de economia e 
conveniência, cada laboratório adapta seus métodos de acordo com sua disponibilidade.

A escolha do dispositivo e respectivo método para a realização dos testes de tração, além disso, não é a única variável frequentemente observada nos estudos: a delimitação da área adesiva é certamente uma variável ainda mais relevante ${ }^{13,97,98,110}$, e esta influencia diretamente os resultados, não dependendo, inclusive, do teste selecionado, se por tração ou por cisalhamento.

O efeito da área adesiva na resistência de união foi conclusivamente demonstrado por Sano et al. ${ }^{110}$ (1994) e Carvalho et al. ${ }^{13}$ (1994). Esses autores empregaram uma metodologia denominada de microtração, a qual permite avaliar a resistência adesiva dentro de um largo espectro de dimensões de área de secção transversal (0,3 a 15,0 mm², por exemplo). Nesses estudos ficou demonstrado haver uma relação inversa entre área de união e respectiva resistência adesiva. Um importante achado desses trabalhos foi a demonstração de que em áreas reduzidas $\left(<2,0 \mathrm{~mm}^{2}\right)$, embora os valores de resistência adesiva fossem mais elevados, o modo de fratura dos espécimes ocorria quase que na sua totalidade na interface adesiva. No estudo de Sano et al. ${ }^{110}$ (1994), quando empregou-se o sistema adesivo Clearfil Liner Bond 2 em áreas adesivas entre 7,0-12,0 mm², a resistência de união encontrada variou de 15 a $20 \mathrm{MPa}$, e algumas falhas coesivas em dentina foram verificadas. Quando se reduziu a área adesiva para valores inferiores a $2,0 \mathrm{~mm}^{2}$, os valores de resistência adesiva aumentaram para 50-60 MPa, com 100\% de falhas adesivas. A interpretação dos resultados dos testes de microtração baseia-se na teoria de Griffith (Griffith, 1920) ${ }^{37}$, a qual demonstra que a resistência coesiva de corpos sólidos diminui com o aumento do volume e da área de secção transversal, devido ao fato de que espécimes de dimensões maiores contêm mais defeitos estruturais do que espécimes menores. Indubitavelmente, a 
interface adesiva não é uniforme. Irregularidades de superfície, presença de bolhas e variações decorrentes do próprio procedimento de aplicação do sistema adesivo estão invariavelmente presentes. Assim, a menor resistência adesiva encontrada em áreas adesivas maiores, provavelmente se deve a uma maior quantidade de defeitos presentes tanto na interface quanto nos substratos, determinando pontos de concentração e propagação de tensões que causam a falha da união em valores aparentemente menores.

É curioso observar alguns estudos que utilizam áreas adesivas maiores que 2,0 $\mathrm{mm}$ de diâmetro $\left(7-11 \mathrm{~mm}^{2}\right)$, reportarem um grande número de falhas coesivas em dentina, principalmente quando o teste empregado é o de cisalhamento, e encontrarem valores de "resistência de união" em torno de 20-25 MPa. Preparando espécimes de dentina com forma semelhante aos espécimes empregados para os testes de resistência de união por cisalhamento, Gwinnett ${ }^{40}$ observou que a média da resistência coesiva da dentina é de aproximadamente $36 \mathrm{MPa}$, valor este, portanto, bem maior do que os valores reportados para falha coesiva da dentina nos testes de resistência de união. Em um trabalho de revisão ${ }^{82}$, relatou-se que cerca de $80 \%$ das fraturas nesses experimentos são de natureza coesiva em dentina, quando a resistência de união atinge valores superiores a $25 \mathrm{MPa}$. Em função desses achados, os autores interpretam que a resistência de união ultrapassa a resistência coesiva da dentina ${ }^{96}$. Em um estudo recente de Sano et al. ${ }^{109}$ sobre as propriedades mecânicas das dentinas humana e bovina, demonstrou-se valores de resistência coesiva da dentina em torno de $100 \mathrm{MPa}$, pela técnica de microtração. Portanto, a fratura da dentina com cargas aparentemente inferiores, é um evento determinado pelo tipo de teste empregado e causa, muitas vezes, interpretações errôneas dos resultados, o que tem levado alguns autores a contestarem a eficácia do teste, particularmente de cisalhamento, para mensurar a resistência de união à dentina. Estas conclusões foram também observadas por Versluis; Tantbirojn; Douglas ${ }^{149}$; ou seja, a fratura da dentina, em parte, 
deve-se à biomecânica do teste e não necessariamente significa uma resistência adesiva superior ou que a resistência coesiva da dentina seja inferior.

Van Noort et al. ${ }^{148}$ (1991) também demonstraram o efeito da geometria interfacial na avaliação da resistência de união à tração em dentina, variando-se apenas a forma de aplicação do sistema adesivo: limitado à area de união ou aplicado sem restrições sobre toda a superfície de dentina exposta. Somente este detalhe já foi suficiente para alterar a área de superfície aderida e influenciar os resultados. Pela característica de permitir trabalhar em áreas diminutas, ou seja, com uma região onde as chances de presença de irregularidades são da mesma forma diminuídas, já teríamos como vantagem o emprego do teste de microtração com o objetivo de avaliar a resistência de união de alguns sistemas adesivos.

Segundo Pashley et al. $^{82}$, uma das principais vantagens do teste de microtração é a possibilidade de obtenção de falhas quase que exclusivamente adesivas na interface, permitindo uma análise da real resistência de união entre o material e a estrutura dentária. Entre outras vantagens, os autores citam a possibilidade de obtenção de vários espécimes de um único dente, permitindo comparações intra e interdentes; a possibilidade de avaliação da resistência adesiva em área diminutas, o que favorece a mensuração da resistência adesiva em substratos clinicamente relevantes como dentina afetada por cárie ou dentina esclerótica; e também, o tamanho reduzido dos espécimes facilita a análise completa das superfícies em microscopia eletrônica de varredura. São apontadas também algumas desvantagens, melhor seria dificuldades da técnica, como o maior rigor técnico para preparar os corpos-de-prova, a dificuldade de mensurar valores de resistência de união inferiores a $5 \mathrm{MPa}$, a necessidade de empregar-se um equipamento especial e a facilidade com que os espécimes podem sofrer desidratação em função do tamanho. Schreiner et al. ${ }^{115}$ (1998), 
ressaltam ainda que o teste de microtração, pelo fato de produzir um maior número de fraturas na camada de adesivo do que o teste de cisalhamento, produz uma melhor estimativa da verdadeira resistência de união de um material.

Obviamente que o mapeamento da resistência de união sobre uma determinada superfície dentária, como por exemplo a superfície plana de dentina empregada no presente trabalho, só poderia ser exeqüível por uma técnica de avaliação baseada em áreas de união menores, de aproximadamente $1 \mathrm{~mm}^{2}$. Da mesma forma, comparar em um mesmo dente a resistência de união à dentina central ou periférica, dentre os métodos atualmente disponíveis, só é possível pela técnica de microtração.

Em função de suas vantagens operacionais e principalmente dos aspectos mecânicos relacionados com a distribuição das tensões durante 0 teste, a técnica de microtração vem sendo considerada como o método mais confiável e fidedigno para a avaliação da união de sistemas adesivos com a estrutura dentária, principalmente à dentina. Após sua introdução na literatura em 1994 (Sano et al. ${ }^{110}$ e Carvalho et al. ${ }^{13}$ ), vários outros estudos têm usufruído das vantagens da técnica para fins diversos $3,5,11,17,21,23,28,30,31,35,44,57,71,72,73,74,75,76,90,95,97,98,99,109,110,112,114,115,117,118,119,124,137$, $138,154,155,156,157,158,159,160$

Alguns trabalhos têm procurado comparar os diferentes tipos de teste $11,24,146$. Como exemplo, podemos citar os resultados obtidos por Cardoso et al. ${ }^{11}$. Os valores de resistência de união empregando-se o sistema adesivo Single Bond, respectivamente para os testes de microtração, cisalhamento e tração, foram: 34,60 $\pm 10,88,12,96 \pm 5,37$ e $9,34 \pm 4,33 \mathrm{MPa}$. Os valores aparentemente mais altos de resistência de união obtidos pela técnica de microtração, entrentanto, não significam que 
as uniões sejam mais fortes. Apenas sugerem que a distribuição de tensões em todo o espécime seja mais uniforme, de forma que a união falhe adesivamente na interface resina/dentina, ao invés de coesivamente na dentina ${ }^{67}$. Infelizmente os autores não reportaram o modo de fratura dos espécimes, respectivamente aos testes empregados. Esses dados ofereceriam provavelmente subsídios para discussão dos aspectos mencionados acima.

Finalmente, devemos considerar que: as fraturas que ocorrem clinicamente, acontecem após vários ciclos de carga aplicados, enquanto que no teste laboratorial, a fratura é induzida por uma carga estática única. Dessa maneira, a previsão da performance clínica de restaurações adesivas deveria basear-se nos conceitos de mecanismo de fratura e em parâmetros de carregamento cíclico, o que poderá aperfeiçoar a metodologia empregada. Portanto, o emprego de dados tradicionais de resistência adesiva deveria ser restrito à comparações dos efeitos relativos das propriedades e da microestrutura dos materiais e das condições de tratamento que poderiam melhorar a resistência à fratura, e não para fazer interpretações clínicas sobre resistência de união. 


\section{2 - Dos resultados}

A dentina é um substrato naturalmente heterogêneo em sua morfologia e dinâmico em sua fisiologia ${ }^{12}$. Por definição, ela pode ser considerada um composto biológico formado por uma matriz de colágeno circundada por cristais de apatita ricos em carbonato e deficientes em cálcio, dispersa entre vários túbulos cilíndricos, paralelos, hipermineralizados e pobres em colágeno (os túbulos dentinários envoltos pela dentina peritubular) ${ }^{67}$. A presença dos túbulos, sua distribuição espacial e a variação regional de diâmetro ${ }^{33}$ caracterizam as diferenças da dentina em relação ao esmalte.

O substrato dentinário é composto por aproximadamente $50 \%$ (em volume) de material inorgânico, $30 \%$ de material orgânico - particularmente colágeno tipo I - e $20 \%$ de fluidos ${ }^{60}$.

Devido à mineralização fisiológica normal e progressiva, essa composição pode variar ligeiramente dependendo da idade do dente ${ }^{66}$ ou também dentro de um mesmo dente ${ }^{78}$. Entretanto, a média, em volume, da composição mineral da dentina deve ser relativamente constante com relação à profundidade, mesmo que a quantidade de dentina intertubular diminua gradualmente da dentina superficial para a dentina profunda. Isso provavelmente ocorra porque a quantidade de dentina peritubular hipermineralizada aumenta aproximadamente na mesma taxa que a quantidade de dentina intertubular diminui, deixando uma média de conteúdo mineral muito semelhante na dentina superficial e profunda ${ }^{67}$, o que não acontece com a dureza. A microdureza da dentina superficial é maior do que da dentina profunda, devido à diminuição da rigidez da matriz de dentina intertubular ${ }^{56}$. 
Com relação à quantidade de colágeno por unidade de volume, esta diminui da dentina superficial para a dentina profunda, provavelmente porque na dentina profunda a espessura dos túbulos dentinários é maior do que na dentina superficial ${ }^{67}$. O diâmetro das fibras de colágeno varia de 50 a $100 \mathrm{~nm}(0,05 \mathrm{a} 0,1 \mu \mathrm{m})$ e os espaços entre elas variam de 15 a $30 \mathrm{~nm}^{67,81}$.

Considerando o mecanismo de união desenvolvido pelos sistemas adesivos atualmente disponíveis no mercado, a variação morfológica regional da dentina pode influenciar a qualidade de união sobre esse substrato. Em áreas onde houver maior concentração de dentina intertubular, poderia-se esperar uma maior contribuição da camada híbrida para a adesão total e vive e versa ${ }^{84}$.

Adicionalmente, se considerarmos que os túbulos dentinários estão preenchidos pelos fluidos pulpares - constituídos essencialmente por água e, parcialmente, pelos prolongamentos das células odontoblásticas, é aceitável admitirmos que além da variação regional de estrutura, a dentina também apresente uma variação regional em seu conteúdo de água ${ }^{12,100,101}$. A dentina superficial é menos úmida que a dentina profunda e isso significa que o maior conteúdo de água ou umidade da dentina profunda pode diluir as formulações dos sistemas adesivos mais facilmente neste substrato do que na camada de dentina mais superficial.

Para que um sistema adesivo possa desenvolver uma eficiente adesão sobre o substrato dentinário, é fundamental que o mecanismo de adesão promovido pelo mesmo seja minimamente influenciado por todas essas variáveis. A variação observada na resistência de união para os diferentes sistemas adesivos no presente trabalho, reflete diretamente as variações inerentes do próprio substrato dentinário além de ser dependente 
também das próprias características dos materiais. Alguns materiais são mais ou menos sensíveis às variações do substrato dentinário ${ }^{48}$.

No presente estudo, foram selecionados dois sistemas adesivos que baseiam-se na técnica de condicionamento ácido da dentina com ácido fosfórico como etapa inicial do processo adesivo (One-Step e Single Bond) e um sistema que faz uso de uma solução de monômeros resinosos acidificados como primeira etapa, seguida da aplicação do agente adesivo propriamente dito (Clearfil Liner Bond 2V). Todos eles desenvolvem uma adesão à dentina formada às custas de retenções micromecânicas (camada híbrida), embora existam diferenças ultra-estruturais entre eles. Os diferentes tipos de camada híbrida não são, por si só, os responsáveis pelos valores de resistência de união; no entanto, a variação da técnica empregada para a sua formação permite um resultado mais ou menos favorável sob o ponto de vista de uniformidade de adesão.

Quando um ácido forte, como o ácido fosfórico a 37\%, é aplicado sobre a dentina durante 15 segundos e em seguida lavado com água, ocorre a dissolução da smear layer e a desmineralização dos cristais de apatita, expondo a matriz de colágeno, permitindo que a mesma sirva de estrutura para a infiltração do agente adesivo a uma profundidade de aproximadamente 2 a $7 \mu \mathrm{m}^{80}$, formando a camada híbrida. Evidentemente que esta profundidade de desmineralização varia dependendo de vários fatores como o tipo, o tempo, a concentração, o pH, a osmolalidade, a viscosidade do ácido, como também as características do próprio substrato em questão. Mais importante ainda do que a extensão de desmineralização, é a preservação dos espaços interfibrilares para a posterior infiltração do monômero resinoso. Após a remoção do ácido, a água será responsável pela sustentação das fibras em uma condição expandida, mantendo a permeabilidade intradentinária necessária para a difusão da resina ${ }^{80,85}$. A maior ou menor permeabilidade da zona desmineralizada, é, por sua vez, 
determinada pelo controle da umidade de superfície mantida após o condicionamento ácido. Assim, a permeabilidade da rede dentinária intertubular desmineralizada aos monômeros é uma variável crítica no processo de adesão à dentina ${ }^{67}$. Idealmente, o espaço anteriormente ocupado pela porção mineral deverá permanecer ocupado pela água oriunda do processo de lavagem do ácido até o momento de se substituir a água pelo monômero resinoso. Quando a matriz de colágeno exposta pelo processo de desmineralização é seca com um jato de ar, ela contrai cerca de $65 \%$ em volume ${ }^{15}$, prejudicando sensivelmente o processo de adesão porque a ausência de água causa um colapso dessas fibras de colágeno, reduzindo os espaços interfibrilares e comprometendo a infiltração dos agentes resinosos. A importância da água para favorecer o processo de adesão foi inicialmente observada por Kanca ${ }^{73}$ e Gwinnett $^{38}$ e confirmada posteriormente por outros autores ${ }^{49,50,93}$. As fibras de colágeno, quando desprovidas do componente mineral, apresentam um baixo módulo de elasticidade ${ }^{15,58}$ e só são mantidas em uma condição "expandida" devido à presença de água nos espaços interfibrilares ${ }^{80,85}$. Sabe-se que ao longo das fibras de colágeno existem proteínas não-colagênicas que constituem cerca de $10 \%$ do conteúdo de proteína da matriz orgânica dentinária, tais como: fosfoforina, sialoproteina dentinária e também, glicosaminoglicanas. Essas moléculas são altamente carregadas ionicamente e contribuem para a retenção de água na dentina desmineralizada. A combinação de colágeno, proteínas não-colagênicas e glicosaminoglicanas, com grande quantidade de água, cria uma matriz que é considerada um hidrogel; ou seja, uma rede de polímero hidrofílico que é capaz de absorver grandes quantidades de água. Esses hidrogéis servem para manter a hidratação do substrato úmido ${ }^{67}$, até que a água seja substituída gradualmente pelo monômero resinoso quando da aplicação correta do sistema adesivo.

Até o momento, viu-se que a água tem um papel fundamental no processo de adesão. A quantidade de água deixada na superfície após a lavagem do ácido é determinante da qualidade final da infiltração do 
primer/adesivo, o que passa a ser um desafio para o clínico, que deve controlar adequadamente essa umidade de superfície. A quantidade crítica de água deveria permitir a conservação dos espaços entre as fibras e ser facilmente substituída pelos monômeros resinos, sem competir com os mesmos $^{80}$. A aplicação de sistemas adesivos sobre a dentina úmida é uma técnica recomendada para a maioria dos sistemas adesivos disponíveis atualmente. As instruções dos fabricantes para os sistemas adesivos OneStep e Single Bond, recomendam que a superfície seja mantida úmida, entretanto, não especificam um método de secagem que permita uma padronização dessa umidade de superfície. A secagem com papel absorvente como utilizada neste estudo é preferida à secagem com ar porque ela evita espalhamentos e eventuais acúmulos de água em ângulos internos das cavidades ${ }^{49,128,129,131}$.

No sistema adesivo One-Step, o solvente orgânico presente é a acetona e no sistema Single Bond, o álcool e a água. As vantagens do uso da acetona como solvente orgânico nos primers é que ela é altamente volátil, podendo evaporar da superfície dentinária muito rapidamente; além disso, os monômeros adesivos são muito solúveis neste solvente ${ }^{67}$. Durante os procedimentos de adesão, a primeira camada de monômeros em acetona ou álcool que é aplicada sobre a dentina desmineralizada umedecida com água, se mistura com a água residual pois esses solventes e a água são muitos miscíveis, o que pode fazer com que o monômero desprenda-se da solução antes que tenha chance de se difundir na rede de colágenos. Isso pode bloquear fisicamente e temporariamente a penetração do monômero e é por este motivo que, normalmente, recomenda-se aplicar mais de uma camada de primer, para que com cada aplicação subsequente, o solvente presente possa redissolver o monômero e permitir que o mesmo se difunda mais profundamente no interior da dentina desmineralizada ${ }^{67}$. 
Uma vez que toda estrutura mineral que circundava a rede de colágeno tenha sido totalmente substituída pelos monômeros resinosos presentes no primer e no adesivo, uma camada híbrida é formada: um híbrido de resina-colágeno com propriedades físico-químicas muito diferentes das estruturas originais, e que portanto, não é nem resina nem dente, mas os dois ${ }^{67}$. A camada híbrida apresenta um baixo módulo de elasticidade, 4,8 a 9,7 $\mathrm{GPa}^{143}$, o que a torna capaz de absorver as forças de contração de polimerização da resina, servindo como um "colchão" que minimiza as diferenças de módulos de elasticidade e de coeficientes de expansão térmica linear do dente e do material restaurador ${ }^{141}$.

O processo para obtenção da camada híbrida para sistemas adesivos "autocondicionantes" como o Clearfil Liner Bond 2V, é diferente principalmente no que se refere ao tratamento dado à smear layer. Enquanto que para o One-Step e o Single Bond toda a camada de detritos remanescente do preparo cavitário é removida pelo condicionamento ácido, nesses sistemas, a superfície é tratada com um primer/acidificado que tem o papel de dissolver a fase mineral da smear layer e permitir a penetração subseqüente do adesivo na intimidade do tecido dentinário subjacente. Em outras palavras, essas soluções seriam responsáveis tanto pela desmineralização da superfície quanto pela infiltração dos monômeros $\operatorname{adesivos}^{22,28,153}$. Como o primerlácido é aplicado sobre a smear layer, sem nenhum tratamento prévio desmineralizante, elimina-se a necessidade de controle inicial da umidade de superfície. Para esses sistemas, em uma condição clínica, a umidade requerida para ionização do componente ácido seria oriunda do fluido pulpar que permeia os túbulos e a smear layer, ou ainda da própria água contida no primerlácido ${ }^{28}$ o que leva a teorizar que, considerando exclusivamente os efeitos da umidade nesse sistema, é de se esperar uma maior uniformidade nos resultados de adesão, uma vez que as variações morfológicas regionais da dentina estariam encobertas pela smear layer $^{28}$. O pH do sistema adesivo Clearfil Liner Bond 2, uma versão anterior ao Clearfil Liner Bond 2V é de aproximadamente 1,4. Deste último, o pH é 
ligeiramente maior, aproximadamente $\mathrm{pH}=2,5$, em função da substituição do phenyl-P pelo MDP ${ }^{137,138}$.

Conhecendo a dinâmica para a obtenção de uma camada híbrida ideal, é possível imaginar o quão árduo e difícil, se não impossível, é controlar todas as variáveis do condicionamento, da quantidade de água necessária, da infiltração do monômero resinoso etc. A durabilidade da união resina/dentina está relacionada com a profundidade de desmineralização versus a profundidade de penetração do monômero; com o grau de conversão do monômero em polímero; e com a capacidade do polímero de envolver por completo as fibras colágenas sem a formação de fendas entre a resina e as fibras ${ }^{28}$. Titley et al. ${ }^{139}$ já demonstraram que essa infiltração do monômero normalmente é incompleta. Sano et al. ${ }^{111}$, descreveram o fenômeno da nano-infiltração: a permeação de fluidos por entre as porosidades de uma camada híbrida não perfeitamente infiltrada pelos agentes adesivos, as quais são decorrentes, principalmente, pela discrepância entre a profundidade de desmineralização da dentina intertubular e posterior infiltração do monômero resinoso ${ }^{80}$.

Alguns trabalhos na literatura mostram o efeito deletério do excesso de água durante o procedimento de adesão ${ }^{128,129,130,131,133}$ e a diferença de camada híbrida ou nos resultados de resistência de união obtidos quando é feito o condicionamento ácido da dentina seguido por uma secagem em demasia, ou seguindo-se a técnica recomendada de deixar a superfície ligeiramente úmida, prevenindo 0 colapso da rede de colágeno desmineralizada $34,38,41,43,46,49,51,52,54,73,93,100,136$. Segundo Tay et al. ${ }^{128,129}$, quando a umidade superficial da dentina é excessiva, ocorre um fenômeno por eles denominado de "overwet", onde as moléculas do agente resinoso sofrem uma separação de fases e formam micelas que se acumulam na superfície, não ocorrendo também adequada infiltração por entre as fibras colágenas, prejudicando a adesão e o selamento. 
No presente trabalho, os nossos resultados de resistência de união obtidos para os materiais One-Step e Clearfil Liner Bond 2V são coerentes com os resultados da literatura consultada que empregaram a mesma técnica de microtração e os mesmos materiais ${ }^{28,30,31,74,76,95,119,124,158}$. Para o sistema Single Bond, encontramos na literatura consultada apenas o trabalho de Cardoso et al. ${ }^{11}$, no qual os resultados foram ligeiramente inferiores aos nossos (34,60 $\pm 10,88 \mathrm{MPa}$ e 52,59 $\pm 17,67$, respectivamente), apesar de os autores terem trabalhado com uma área menor $\left(0,25 \mathrm{~mm}^{2}\right)$ do que nós (aproximadamente $0,70 \mathrm{~mm}^{2}$ ). No entanto, vale dizer que para alcançarmos os resultados de resistência de união já mencionados na literatura, particularmente para o sistema adesivo One-Step ${ }^{28,30,31,95,118}$ pela técnica de microtração, foi necessário um período prévio de treinamento até atingirmos o domínio das características manipulativas do material e extrair a sua resistência ótima. Certamente, portanto, deve-se considerar que existe a influência do domínio do operador sobre um determinado material diante dessas condições particularmente subjetivas de controle de umidade, para que uma adesão eficiente seja alcançada. Os resultados de resistência de união podem variar dependendo da habilidade do operador ou das características do próprio substrato. Shono et al. ${ }^{118}$ demonstraram haver diferenças significantes entre os valores de resistência de união à microtração dependendo do operador. Isso, em função muito mais da técnica de trabalho empregada por cada operador do que do próprio material ou do substrato. Para um operador (A), em dentina superficial e profunda, respectivamente, os valores de resistência de união do sistema adesivo One-Step foram $22 \pm 20 \mathrm{MPa}$ e $27 \pm 14 \mathrm{MPa}$. Para um operador (B), os resultados obtidos para o mesmo sistema adesivo foram significantemente maiores e mais uniformes: $56 \pm 13 \mathrm{MPa}$ e $57 \pm 12 \mathrm{MPa}$ (respectivamente para dentina superficial e profunda), estando bem próximos dos resultados obtidos no nosso presente trabalho, ou seja, 53,97 $\pm 12,58 \mathrm{MPa}$. O coeficiente de variação obtido pelo operador B para o sistema adesivo One-Step, em dentina superficial, foi de 22,24\%; ou seja, aproximadamente o mesmo que o obtido por nós $(23,31 \%)$. Para o operador A, o coeficiente foi de $94,44 \%$. 
Estes resultados nos permitem crer que existe realmente uma variação dependendo do operador, do domínio da técnica pelo mesmo, e que, praticamente, o valor de coeficiente de variação encontrado de $23 \%$ traduz, mais provavelmente, a variação oriunda das variações inerentes do próprio substrato.

Sob esse aspecto e em função da própria característica do material, é mais fácil trabalhar com um sistema adesivo autocondicionante (Clearfil Liner Bond $2 \mathrm{~V}$, em nosso trabalho), que parece ser menos sensível às variáveis do processo adesivo do que os sistemas que requerem uma etapa inicial de condicionamento ácido da superfície. Do ponto de vista clínico, uma adesão uniforme sobre a dentina em diferentes condições e regiões é interessante. Assim, o profissional poderia dispor de um único material, de aplicação simples e eficaz em todas as paredes cavitárias ${ }^{28}$. De fato, alguns pesquisadores têm relatado que existe uma notável uniformidade de valores médios de adesão quando se emprega o sistema adesivo Clearfil Liner Bond $^{28,95}$. Pelos resultados do nosso trabalho, o coeficiente de variação nos resultados de adesão para o sistema CLB2V, 37,78\%, foi maior do que para os demais sistemas (OS $=23,31 \%$ e SB $=33,61$ ), mas sem levar em conta o estudo prévio feito com estes materiais para conseguir os resultados já comentados de resistência adesiva próxima a $50 \mathrm{MPa}$; e portanto, esta variação depende da forma como é interpretada. A variação nos resultados é maior, mas a variação de profissional para profissional, de cada caso em particular, até que se domine a técnica de uso do material, no total, é menor, como pudemos notar em nosso trabalho e ser observado por Shono et $\mathrm{al}^{118}$. Quando começamos a trabalhar com o sistema CLB2V, notamos dificuldade em conseguir todos os espécimes em um mesmo dente que permitisse realizar um mapeamento da superfície. A resistência de união média obtida era de $20 \mathrm{MPa}^{\star}$, e a quantidade de espécimes com valores de resistência zero ou menor do que $5 \mathrm{MPa}$, apesar de bem menor do que aquela obtida

\footnotetext{
- Dados não publicados.
} 
quando foi deixada a superfície de dentina relativamente úmida para o sistema Single Bond, por exemplo, quando tentávamos dominar as características manipulativas daquele material, ainda não era suficiente para realizar um mapeamento completo. O Single Bond requer uma superfície úmida, mas ligeiramente mais seca do que aquela do One-Step. Este fato nos levou a aumentar o tempo de aplicação do primer numa tentativa de melhorar os resultados de resistência de união, baseado nos trabalhos de Ferrari et al. ${ }^{32}$ e Miyazaki et al. ${ }^{65}$, o que foi conseguido. Nós inicialmente hipotetizamos que este aumento no valor da resistência de união média com um tempo de aplicação do primer maior, perceptível diretamente pela obtenção de um maior número de espécimes durante o procedimento de corte para o mapeamento, era devido ao maior tempo disponível para volatilização do álcool presente na composição do material. Sabemos que quando os solventes orgânicos não são totalmente volatilizados, eles intereferem com a polimerização dos monômeros resinosos ${ }^{12}$, o que pode interferir com a resistência de união. Para testarmos esta hipótese, realizamos um estudo paralelo com o objetivo de analisar a evaporação do material em função do tempo. Se o material evapora, ele perde peso, e para tanto, empregamos uma balança de precisão para realizarmos esta análise. Sobre uma placa de vidro, dispensamos $20 \mu \mathrm{L}$ do primer e observamos a variação de peso durante 30 minutos. Nos primeiros 10 minutos, observamos essa variação a cada 10 segundos e dos 10 aos 30 minutos finais, observamos a variação a cada minuto. Repetimos o procedimento por três vezes. Esse teste foi feito para os três sistemas adesivos empregados. Para todos os materiais ocorreu a maior variação de volume já nos primeiros 3 minutos, o que denota que praticamente todo solvente orgânico evaporou; e portanto, não seria este o fator que estaria interferindo nos resultados. Poderíamos hipotetizar que uma camada de primer muito fina estava sendo aplicada e a mesma estaria sendo rapidamente tamponada pela dentina. Entretanto, ao realizarmos um experimento aplicando uma camada ou duas camadas de primer, verificamos que com apenas uma camada, diferente da forma como estávamos comumente empregando, ou seja, com duas 
camadas, novamente a quantidade de espécimes obtidos era menor. Esse ponto foi estudado também por Ogata et $\mathrm{al}^{76}$, onde os autores observaram que quando o sistema adesivo Clearfil Liner Bond 2 foi aplicado usando múltiplas camadas de primer, a resistência adesiva melhorou. Uma outra forma que poderia nos auxiliar a descobrir por que a resistência de união era melhor com um tempo de aplicação de primer maior, seria analisando microscopicamente a permeação do sistema adesivo. Hipotetizamos que com um tempo de aplicação do primer de 30 segundos, talvez não estivéssemos obtendo uma camada híbrida eficiente. Para tanto, quatro dentes foram preparados para análise em microscopia eletrônica de varredura: dois deles com um tempo de aplicação do primer por 30 segundos e os outros dois, por 3 minutos. A espessura da camada híbrida formada é a mesma, aproximadamente $0,5 \mu \mathrm{m}$, e coerente com o resultado de Tay et al. ${ }^{137}$, independentemente do tempo de atuação do primer. Apenas a profundidade de prolongamento dos tags no interior e nas paredes dos túbulos dentinários foi maior, quando o tempo de aplicação do primer foi maior. Sabemos que a presença de tags de resina mais longos, não necessariamente aumentam a resistência da adesão da resina nos túbulos ${ }^{83}$ e assim, descartada a hipótese de uma formação deficiente de camada híbrida com um tempo de aplicação do primer de 30 segundos, uma possível explicação para tais resultados mais satisfatórios com um tempo de aplicação de primer maior, poderiam estar relacionadas com o próprio material ou outros fatores: os lotes de fabricação diferem constantemente, as variações de condições de armazenagem do material em refrigeração e o tempo esperado para empregá-lo, ou também, da própria variação da umidade relativa do ar, que sabidamente pode interferir com o resultados de resistência adesiva. Baseado num estudo mais aprofundado com o sistema Clearfil Liner Bond $2 \mathrm{~V}$ podemos, de maneira geral, dizer que o mesmo é menos sensível às variações técnicas do que os outros materiais, One-Step e Single Bond. 
Com relação a análise da variação regional da resistência de união intradente, efetivamente realizada com espécimes provenientes de um mesmo dente, dois trabalhos na literatura baseados na técnica de microtração merecem ser destacados: a tese de $M_{a n f i o}{ }^{60}$ e o estudo de Shono et $\mathrm{al}^{118}$.

Manfio $^{60}$, em 1998, em seu trabalho de tese, procurou comparar a resistência de união à microtração de 3 sistemas adesivos em diferentes regiões de uma cavidade de Classe II. Foram preparadas cavidades MOD de dimensões padronizadas em terceiros molares humanos extraídos e restaurados com One-Step, Scotchbond Multiuso ou Prime \& Bond, usando uma técnica incremental com resina composta Z100. A análise dos resultados demonstrou diferenças significantes $(p<0,05)$ entre os materiais e as localizações das paredes do preparo. A resistência de união à microtração na parede pulpar foi maior que a resistência de união na parede gengival e na parede axial para os três sistemas adesivos empregados, não havendo diferença estatística entre os mesmos: One-Step $=24,2 \mathrm{MPa}$, Scotchbond Multiuso $=26,1 \mathrm{MPa}$ e Prime \& Bond $2.0=22,1 \mathrm{MPa} . \mathrm{Na}$ parede gengival, a resistência de união foi superior para o adesivo One-Step (19,3 MPa), não havendo diferença estatística entre o Scotchbond Multiuso (13,6MPa) e o Prime \& Bond 2.0 (11,3 MPa). Na parede axial, não houve diferença estatística entre os três adesivos usados, sendo esta, semelhante à resistência de união da parede gengival para o Scotchbond Multiuso (12,3 $\mathrm{MPa}$ ) e para o Prime \& Bond 2.0 (10,6 MPa). Os resultados demonstram que a resistência de união em um preparo cavitário classe II, tipo MOD, está sujeita, entre outros fatores, às variações determinadas pelas características do substrato nas diferentes regiões de um preparo cavitário.

Shono et al. ${ }^{118}$, em 1999, realizaram um estudo com o objetivo de determinar a consistência ou a uniformidade dos valores de resistência de união à dentina, em um mesmo dente, empregando-se uma resina composta 
e dois diferentes sistemas adesivos, One-Step (Bisco) e MacBond (Tokuyama). Para tanto, empregaram uma técnica de obtenção de espécimes muito semelhante àquela por nós adotada no presente trabalho. Como controle, foi também avaliada a resistência de união de espécimes de resina composta, unidos entre si com sistema adesivo One-Step. Os autores concluíram o trabalho dizendo que o método empregado permitiu detectar a presença de diferenças regionais na resistência de união da resina à dentina, que as maiores diferenças relacionaram-se muito mais à técnica do que ao material empregado e que os resultados indicam que a resistência de união resina/dentina pode não ser tão homogênea como se pensava previamente.

Esses trabalhos só começaram a ser viáveis após o desenvolvimento da técnica de microtração e têm confirmado a hipótese de que a resistência de união não é uniforme em uma mesma superfície dentinária ou mesmo dentro de um preparo cavitário, em função das variações morfológicas e fisiológicas do substrato.

Alguns trabalhos na literatura consultada também demonstram que existe uma variação nos resultados de adesão dependendo dos efeitos de diferentes características da dentina como o conteúdo de cálcio e fósforo, dureza, permeabilidade, orientação dos túbulos dentinários, umidade e profundidade

substrato 2,3,8,10,17,19,21,23,26,28,30,31,34,38,41,43,45,46,49,51,52,54,55,63,73,74,83,88,93,95,96,99,100, $102,103,118,119,120,121,125,127,129,131,133,152,154,155,156,157,158,159$. Todos esses fatores, em conjunto, interferem com os resultados de adesão em uma única superfície, como uma das paredes de um preparo cavitário.

Em nosso trabalho, também era um dos objetivos avaliar a existência de variações nos resultados de resistência de união interdentes. De fato, 
elas existem, como pode ser revisto nas Tabelas 3,4 e 5 dos Resultados. Podemos dizer que elas ocorrem em função das variações inerentes dos diferentes substratos porque 0 mesmo operador realizou todas as restaurações. Incluímos seis dentes para o grupo do sistema adesivo CLB2V porque o operador ao deparar-se aparentemente com uma maior variação intradente e de dente para dente na etapa inicial de dominar o uso do material, por curiosidade, foi querendo confirmar essas variações. Isso não implica dizer que para o sistema adesivo OS, todos os resultados serão os mesmos, ou que para alguns materiais, a variação entre dentes não exista, como visto pela análise estatística entre os três dentes avaliados. Existiu uma variação nos valores de resistência de união interdentes estatisticamente significante para os sistemas CLB2V e SB, mas possivelmente, podemos hipotetizar que se aumentássemos o número da amostra para o sistema OS, encontraríamos alguma diferença em função das próprias variações dos substratos já comentada anteriormente. Nenhum trabalho dentro da literatura consultada empregando a técnica de microtração procurou avaliar essas mesmas considerações de variações da resistência de união de vários espécimes dentro de um mesmo dente, com relação aos de outro dente.

Comparando a resistência de união dos espécimes obtidos do centro ou da periferia de um dente, não observamos diferenças estatísticas com relação à esta variação do substrato para nenhum material empregado. $\mathrm{Na}$ literatura consultada, vários trabalhos procuraram comparar a resistência de união diferentes profundidades de dentina $2,3,8,19,21,23,28,30,31,63,83,88,95,96,100,102,118,119,120,121,125,127$. A maioria dos trabalhos da década de $80^{19,63,120,125}$, do início da década de 9088,96,100,121 e outros mais recentes ${ }^{95,118,119}$ observaram que existe uma relação inversa entre os valores de resistência de união e a profundidade do substrato. Os trabalhos mais recentes, no entanto, em função da própria evolução dos sistemas adesivos e, aparentemente, de um maior conhecimento sobre os fatores que regem o domínio da técnica de aplicação desses sistemas, 
parecem mostrar uma tendência a uma menor sensibilidade dos materiais ao substrato dentinário 2,3,8,21,28,30,31,102,127. As explicações dadas para uma maior resistência de união em dentina mais superficial estão relacionadas com a menor permeabilidade que reduz a umidade e também em função da maior quantidade de dentina intertubular presente. Pashley et al. ${ }^{83}$ desenvolveram um modelo matemático para calcular a resistência adesiva à dentina em função da distância da polpa. Nesse modelo, os autores consideraram a contribuição individual dos mecanismos de formação da camada híbrida, a formação dos tags de resina dentro dos túbulos e a adesão de superfície. Desta maneira, a contribuição da resistência adesiva oferecida pela camada híbrida seria proporcionalmente maior em dentina superficial do que em dentina profunda. O inverso ocorreria em relação a contribuição oferecida pela formação de tags de resina. Segundo os autores, deveriam ser considerados ainda na composição da adesão total, a resistência do colágeno e do agente adesivo que se infiltra nos túbulos e na camada híbrida. Teoricamente, os tags polimerizados poderiam contribuir para a retenção da resina se eles estivessem firmemente aderidos às paredes dos túbulos. Sua contribuição para a resistência total de união deveria ser proporcional à area de secção transversa dos tags e à resistência coesiva do polímero. Como esse modelo desconsidera os fatores relacionados à presença de umidade oriunda do fluido pulpar ou as diferenças nas propriedades mecânicas da dentina com relação à profundidade, assumindo que os sistemas adesivos seriam capazes de desenvolver uma adesão frente a todas essas limitações in vivo, os valores teóricos de adesão deveriam, inclusive, ser maiores em dentina profunda do que em dentina superficial.

Teoricamente, a resistência de união de um determinado sistema adesivo à dentina é determinada pelo somatório da adesão de superfície, formação da camada híbrida na dentina intertubular e retenção proporcionada pela formação dos prolongamentos de resina dentro dos túbulos dentinários (tags de resina) ${ }^{83}$. Adicionalmente, devemos considerar a 
resistência coesiva de cada um dos elementos que compõem essa interface, ou seja, resina composta, resina adesiva, fibras de colágeno e dentina mineralizada. Quando a interface adesiva é submetida a um esforço, as tensões são distribuídas por todos esses elementos e a ruptura irá se iniciar no ponto mais fraco, quer seja numa interface entre os elementos ou na intimidade de um deles. O resultado é a falha catastrófica que se alastra pelos pontos de maior fragilidade, comprometendo, muitas vezes, os elementos adjacentes ao ponto inicial de fratura. Devido ao fato de que os mecanismos envolvidos na adesão ocorrem em magnitude reduzida, a observação dos modos de fratura sem o auxílio de lentes de aumento ou microscopia, limitam a classificação das fraturas em modo adesivo ou coesivo dos substratos (dentina ou resina) ${ }^{29}$. Neste estudo, analisamos o modo de fratura dos espécimes por microscopia óptica com 40X de aumento, o que nos permite visualizar em maior magnitude os elementos que formam a união e identificar qual foi o tipo de falha predominante. Alguns trabalhos da literatura, da mesma forma, fazem uso da análise de fratura por microscopia óptica com aumento variado de 20 a $40 X^{8,28,36,38,46,49,55,70,88,110,115,119,155,156,157}$, e outros, mais detalhadamente, através de MEV ou $\mathrm{MET}^{3,38,46,55,62,64,70,95,97,98,99,114,115,117,118,125,126,138,139,154}$. Todos os trabalhos deveriam classificar, de alguma forma, o modo de fratura dos espécimes, pois, dependendo do método empregado, alguma interferência da metodologia pode interferir com os resultados obtidos, como foi discutido anteriormente na seção de discussão da metodologia empregada no presente trabalho.

Um outro fator a ser considerado é que alguns trabalhos têm investigado o efeito da desproteinização da dentina desmineralizada na resistência adesiva ${ }^{41,42,54,150}$. Na desproteinização, a rede de colágenos é removida pela ação da aplicação de hipoclorito de sódio a $5 \%$ durante aproximadamente 2 minutos, com a finalidade de tornar o mecanismo de difusão dos monômeros resinosos semelhante àquele para o esmalte, ou seja, dando ênfase à importância da retenção micromecânica com a porção 
mineralizada ${ }^{42}$. Os valores de resistência de união, muito embora não sejam discrepantes daqueles obtidos com a incorporação do colágeno no processo adesivo formando a camada híbrida, podem ser diferentes a longo prazo porque a ausência da camada híbrida entre os diferentes substratos, resina e dente, promove uma alta concentração de estresses na superfície da interface aderida por esta apresentar uma grande rigidez e pouca flexibilidade. Este fato normalmente é minimizado pelo fato da camada híbrida apresentar um baixo módulo de elasticidade o que a torna capaz de absorver as forças de contração de polimerização da resina ${ }^{141}$, servindo como um "colchão" para diminuir as diferenças nos módulos de elasticidade e de coeficientes de expansão térmica linear dos dois substratos. Portanto, esta técnica não pode ser largamente recomendada até que seja investigado o efeito dos esforços mecânicos e/ou térmicos para avaliar o seu desempenho na capacidade de selar adequadamente a superfície de dentina, prevenindo a infiltração marginal ${ }^{141}$.

Clinicamente, a presença da infiltração marginal ainda é a maior causa de substituição de restaurações e o grande desafio da odontologia restauradora. Uma infitração incompleta da área de dentina desmineralizada, pode levar com o passar do tempo, a uma hidrólise do colágeno não infiltrado ${ }^{44,119}$. Além disso, a presença de umidade dentinária pode interferir na polimerização da resina e a conversão de monômeros em polímeros pode ser incompleta ${ }^{47,90}$, o que determinaria uma degradação hidrolítica da resina. Alguns trabalhos têm investigado quais os fatores que seriam mais responsáveis pela degradação hidrolítica do processo adesivo. Carvalho et al. ${ }^{18}$ relatam que 0 armazenamento do colágeno em solução salina por dois anos, não altera suas propriedades de resistência à tração. Zhang et al. ${ }^{160}$ demonstraram que as soluções ácidas normalmente aplicadas sobre a dentina durante um procedimento clínico, também não determinam alterações significantes nas propriedades do colágeno. Essas observações sugerem que o colágeno talvez não seja o elemento mais susceptível à degradação na interface adesiva e sem dúvida, apontam para 
a necessidade de que mais estudos clínicos e longitudinais sejam realizados nesta área, para que num futuro próximo, seja através da evolução da engenharia genética ou não ${ }^{91}$, tenhamos à disposição uma forma de substituição da porção do elemento dentário perdida que efetivamente seja definitiva pelo selamento proporcionado e por suas características de restabelecimento funcional, anatômico e estético. 


\section{Conclusão}

"sans peur et sans reproche..." 


\section{7 - CONCLUSÃO}

Com base nos resultados obtidos, pode-se concluir que:

1) existe uma variação regional de resistência de união em superfícies planas de dentina, intradente, para todos os sistemas adesivos empregados;

2) a variação regional da resistência de união é determinada por variações no substrato e independe do sistema adesivo empregado;

3) houve uma diferença significante nos valores de resistência de união encontrados para os três sistemas adesivos testados: o One-Step e o Single Bond apresentaram valores semelhantes e estatisticamente superiores ao resultado apresentado pelo sistema autocondicionante, Clearfil Liner Bond 2V;

4) os três materiais testados não apresentaram diferenças nos valores de resistência de união entre os espécimes obtidos do centro ou da periferia do dente, demonstrando uma menor sensibilidade às variações morfológicas do substrato. 


\section{Referênciass Bibliográficas}




\section{REFERÊNCIAS BIBLIOGRÁFICAS}

1 - AL-SALEHI,S.K.; BURKE,F.J.T. Methods used in dentin bonding tests: an analysis of 50 investigations on bond strength. Quintessence Int., v.28, n.11, p.717-23, Nov. 1997.

2 - AMORY,C,; YVON,J. Shear bons srength of a ligth-cured resin composite vs. dentin characteristics. Dent. Mat., v.10, n.3, p.203-9, May 1994.

3 - ARMSTRONG,S.R.; BOYER,D.B.; KELLER,J.C. Microtensile bond strength testing and failure analysis of two dentin adhesives. Dent. Mat., v.14, n.1, p.44-50, Jan. 1998.

4 - ATTAL,J-P.; ASMUSSEN,E.; DEGRANGE,M. Effects of surface treatment on the free energy of dentin. Dent. Mat., v.10, n.4, p.25964, July 1994.

5 - BELTRÃO,H.C.P. Avaliação da resistência adesiva à dentina de materiais à base de ácidos polialcenóicos e polímeros resinosos - efeito da variação morfológica do substrato dentinário. Bauru - 1998. Tese (Doutorado) 351p. - Faculdade de Odontologia de Bauru, Universidade de São Paulo.

6 - BUONOCORE,M.G. A simple method of increasing the adhesion of acrylic filling materials to enamel surfaces. J. dent. Res., v.34, n.6, p.849-53, Dec. 1955.

"Normas recomendadas para uso no âmbito da Universidade de São Paulo, com base no documento "Referências Bibliográficas: exemplos", emanado do Conselho Supervisor do Sistema Integrado de Bibliotecas da USP, em reunião de 20 de setembro de 1990. 
7 - BUONOCORE,M.; WILEMAN,W.; BRUDEVOLD,F. A report on a resin composition capable of bonding to human dentin surfaces. J. dent. Res., v.35, n.6, p.846-51, Dec. 1956.

8 - BURROW,M.F. et al. The influence of age and depth of dentin on bonding. Dent. Mat., v.10, n.4, p.241-6, July 1994.

9 - BURROW,M.F. et al. Bond strength to crown and root dentin. Amer. J. Dent., v.9, n.5, p.223-9, Oct. 1996.

10 - CAGIDIACO,M.C. et al. Mapping of tubule and intertubule surface areas available for bonding in class $\mathrm{V}$ and class II preparations. J. Dent., v.25, n.5, p.379-89, Sept. 1997.

11 - CARDOSO,P.E.C.; BRAGA,R.R.; CARRILHO,M.R.O. Evaluation of micro-tensile, shear and tensile tests determining the bond strength of three adhesive systems. Dent. Mat., v.14, n.6, p.394-8, Nov. 1998.

12 - CARVALHO,R.M. Adesivos dentinários - Fundamentos para aplicação clínica. Revista de Dentística Restauradora, v.1, n.2, abr./maio/jun., 1998.

13 - CARVALHO,R.M. et al. Determinação da resistência adesiva a dentina através de um dispositivo de micro-tração. Rev. FOB, v.2, n.3, p.77-82, jul./set. 1994.

14 - CARVALHO,R.M. et al. A review of polymerization contraction: the influence of stress development versus stress relief. Oper. Dent., v.21, n.1, p.17-24, Jan./Feb. 1996. 
15 - CARVALHO,R.M. et al. In vitro study on the dimensional changes of human dentine after demineralization. Arch. oral Biol., v.41, n.4, p.369-77, Apr. 1996.

16 - CARVALHO,R.M. et al. Effects of dehydration on the modulus of elasticity of demineralized human dentin. Rev. FOB, v.4, n. 1/2, p.1-7, jan./jun. 1996.

17 - CARVALHO,R.M. et al. Dentin strength as a function of tubule orientation and density. J. dent. Res., v.78, p.284, 1999. Special issue /Abstract n. 1428/

18 - CARVALHO,R.M. et al. Tensile properties of demineralized dentin matrix after 40 months. J. dent. Res., v.79, p.249, 2000. Special issue /Abstract n. 844/

19 - CAUSTON,B.E. Improved bonding of composite restorative to dentine. A study in vitro of the use of a commercial halogenated phosphate ester. Brit. dent. J., v.156, n.3, p.93-5, Feb. 1984.

20 - CHAPPELL,R.P. et al. Dentinal tubule anastomosis: a potencial factor in adhesive bonding? J. Prosth. Dent., v.72, n.2, p.183-8, Aug. 1994.

21 - CHAPPELL,R. et al. Pilot study to determine sample size for microtensile testing. J. dent. Res., v.76, p.38, 1997. Special issue /Abstract n.193/

22 - CHIGIRA,H. et al. Self-etching dentin primers containing PhenylP. J. dent. Res., v.73, n.5, p.1088-95, Mar. 1994. 
23 - CIUCCHI,B. et al. Bond strength to dentin surfaces of Cl. II cavities. J. dent. Res., v.75, p.257, 1996. Special issue /Abstract n.1917/

24 - DEHOFF,P.H.; ANUSAVICE,K.J.; WANG,Z. Three-dimensional finite element analysis of the shear bond test. Dent. Mat., v.11, n.2 , p.126-31, Mar. 1995.

25 - DELLA BONA,A.; VAN NOORT,R. Shear vs. tensile bond strength of resin composite bonded to ceramic. J. dent. Res., v.74, n.9, p.1591-6, Sept. 1995.

26 - DUKE,E.S.; LINDEMUTH,J. Variability of clinical dentin substrates. Amer. J. Dent., v.4, n.5, p.241-6, Oct. 1991.

27 - EICK,J.D. et al. Scanning transmission electron microscopy/energydispersive spectroscopy analysis of the dentin adhesive interface using a labeled 2-hydroxyethylmethacrylate analogue. J. dent. Res., v.74, n.6, p.1246-52, June 1995.

28 - FERNANDES,C.A.O. Avaliação da influência da profundidade do substrato dentinário na resistência adesiva de dois novos sistemas adesivos. Bauru - 1997. Dissertação (Mestrado) 102 p. Faculdade de Odontologia de Bauru, Universidade de São Paulo.

29 - FERNANDES,C.A.O. Estudo comparativo da resistência adesiva à dentina superficial e profunda testada simultaneamente, empregando-se dois sistemas adesivos. Bauru - 2000. Tese (Doutorado) 181 p. - Faculdade de Odontologia de Bauru, Universidade de São Paulo. 
30 - FERNANDES,C.A.O. et al. Bond strengths of adhesives to dentin tested as an array. J. dent. Res., v.77, p.205, 1998. Special issue /Abstract n.798/

31 - FERNANDES,C.A.O.; CARVALHO,R.M,; PASHLEY,D.H. Strengths of resins to superficial versus deep dentin. J. dent. Res., v.78, p.233, 1999. Special issue /Abstract n.1018/

32 - FERRARI,M. et al. Effect of two etching times on the sealing ability of Clearfil Liner Bond 2 in class $\mathrm{V}$ restorations. Amer. J. Dent., v.10, n.2, p.66-70, Apr. 1997.

33 - GARBEROGLIO,R.; BRÄNNSTRÖM,M. Scanning electron microscopic investigation of human dentinal tubules. Arch. oral Biol., v.21, n.6, p.355-62, June 1976.

34 - GLASSPOOLE,E.A.; ERICKSON,R.L.; PASHLEY,D.H. In Vitro bonding to wet dentin. J. dent. Res., v.71, p.615, 1992. Special issue /Abstract n.795/

35 - GOMES,J.C. Análise in vitro do efeito dos sistemas adesivos e meteriais restauradores, cerâmica e cerômetro, na resistência adesiva com substrato dentinário através do teste de microtração. Araraquara - 1999. Tese (Doutorado) 189p. Faculdade de Odontologia de Araraquara, Universidade Estadual Paulista.

36 - GORDAN,V.V. et al. Evaluation of adhesives systems using acidic primers. Amer. J. Dent., v.10, n.5, p.219-23, Oct. 1997.

37 - GRIFFTH,A.A. The phenomena of ruptures and flow in solids. Phil. Trans. Roy Soc. London, v.221, P.168-98, 1920. 
38 - GWINNETT,A.J. Moist versus dry dentin: its effect on shear bond strength. Amer. J. Dent., v.5, n.3, p.127-9, June 1992.

39 - GWINNETT,A.J. Quantitative contribution of resin infiltration/hibridization to dentin bonding. Amer. J. Dent., v.6, n.1, p.7-9, Feb. 1993.

40 - GWINNETT,A.J. A new method to test the cohesive strength of dentin. Quintessence Int., v.25, n.3, p.215-8, Mar. 1994.

41 - GWINNETT,A.J. Dentin bond strength after air drying and rewetting. Amer. J. Dent., v.7, n.3, p.144-8, June 1994.

42 - GWINNETT,A.J. Altered tissue contribution to interfacial bond strength with acid conditioned dentin. Amer. J. Dent., v. 7, n.5 , p.243-6, Oct. 1994.

43 - GWINNETT,A.J.; KANCA III, J. Micromorphology of the bonded dentin interface and its relationship to bond strength. Amer. J. Dent., v.5, n.2, p.73-7, Apr. 1992.

44 - HASHIMOTO,M. et. al. In vivo degradation of resin-dentin bonds in humans over 1 to 3 years. J. dent. Res., v.79, n.6, p.1385-91, June 2000.

45 - INOKOSHI,S.; IWAKU,M.; FUSAYAMA,T. Pulpal response to a new adhesive restorative resin. J. dent. Res., v.61, n.8, p.1014-9, Aug. 1982.

46 - IWAMI,Y. et al. Effect of enamel and dentin surface wetness on shear bond strength of composites. J. prosth. Dent., v.80, n.1, p.20-6, July 1998. 
47 - JACOBSEN,T.; SÖDERHOLM,K-J. Some effects of water on dentin bonding. Dent. Mat., v.11, n.2, p.132-6, Mar. 1995.

48 - JACOBSEN,T.; SÖDERHOLM,K-J. Effect of primer solvent, primer agitation, and dentin dryness on shear bond strength to dentin. J. Dent., v.11, n.5, p.225-8, Oct. 1998.

49 - KANCA III,J. Resin bonding to wet substrate. I. Bonding to dentin. Quintessence Int., v.23, n.1, p.39-41, Jan. 1992.

50 - KANCA III,J. Effect of resin primer solvents and surface wetness on resin composite bond strength to dentin. Amer. J. Dent., v.5, n.4 , p.213-5, Aug. 1992.

51 - KANCA III,J. Improving bond strength through acid etching of dentin and bonding to wet dentin surfaces. J. Amer. dent. Ass., v.123, n.9 , p.35-43, Sept. 1992.

52 - KANCA III,J. Wet bonding: effect of drying time and distance. Amer. J. Dent., v.9, n.6, p.273-6, Dec. 1996.

53 - KANCA III,J. Effect of primer dwell time on dentin bond strength. Gen. Dent., v. 46, n.6, p. 608-12, Nov./Dec. 1998.

54 - KANCA III,J.; SANDRIK,J. Bonding to dentin. Clues to the mechanism of adhesion. Amer. J. Dent., v.11, n.4, p.154-9, Aug. 1998.

55 - KATO,G.; NAKABAYASHI,N. The durability of adhesion to phosphoric acid etched, wet dentin substrates. Dent. Mat., v.14, n.5, p.347-52, Sept. 1998. 
56 - KINNEY,J.H. et al. Hardness and Young's modulus of human peritubular and intertubular dentine. Arch. oral Biol., v.41, n.1, p.913, Jan. 1996.

57 - KITASAKO,Y. et al. Monkey pulpal response and microtensile bond strength beneath a one-application resin bonding system in vivo. J. Dent., v.28, n.3, p.193-8, Mar. 2000.

58 - MACIEL,K.T. et al. The effects of acetone, ethanol, HEMA, and air on the stiffness of human decalcified dentin matrix. J. dent. Res., v.75, n.11, p.1851-8, Nov. 1996.

59 - MANDRAS,R.S. et al. Three-year clinical evaluation of the Clearfil Liner Bond System. Oper. Dent., v.22, n.6, p.266-70, Nov./Dec. 1997.

60 - MÂNFIO,A.P. Avaliação da variabilidade regional de união à dentina de três sistemas adesivos em restaurações simuladas de classe II de resina composta. Bauru - 1998. Tese (Doutorado) 137p. - Faculdade de Odontologia de Bauru, Universidade de São Paulo.

61 - MARSHALL JR,G.W. et al. The dentin substrate: structure and properties related to bonding. J. Dent., v.25, n.6, p.441-58, Nov. 1997.

62 - MASON,P.N. et al. Shear bond strength of four dentinal adhesives applied in vivo and in vitro. J. Dent., v.24, n.3, p.217-22, May/June 1996.

63 - MITCHEM,J.C.; GRONAS,D.G. Effects of time after extraction and depth of dentin on resin dentin adhesives. J. Amer. dent. Ass., v.113, n.8, p.285-7, Aug. 1986. 
64 - MIYASAKA,K. NAKABAYASHI,N. Combination of EDTA conditioner and Phenyl-P/HEMA self-etching primer for bonding to dentin. Dent. Mat., v.15, n.3, p.153-7, May 1999.

65 - MIYAZAKI,M. et al. Influence of self-etching primer drying time on enamel bond strength of resin composites. J. Dent., v.27, n.3 , p.203-7, Mar. 1999.

66 - MJÖR,I.A.; FEJERSKOV,O. Embriologia e histologia oral humana. Panamericana, São Paulo, 1990. Cap. 4 Dentina e polpa, p.90- 130.

67 - NAKABAYASHI,N.; PASHLEY,D.H. Hybridization of dental hard tissues. Tokio, Quintessence Publishing Co, Ltd, 1998.

68 - NAKABAYASHI,N.; SAIMI,Y. Bonding to intact dentin. J. dent. Res., v.75, n.9, p.1706-15, Sept. 1996.

69 - NAKABAYASHI,N.; KOJIMA,K.; MASUHARA,E. The promotion of adhesion by the infiltration of monomers into tooth substrates. J. Biomed. Mat. Res., v.16, n.3, p.265-73, May 1982.

70 - NAKABAYASHI,N.; WATANABE,A.; ARAO,T. A tensile test to facilitate identification of defects in dentine bonded specimens. J. Dent., v.26, n.4, p.379-85, May 1998.

71 - NAKAJIMA,M. et al. Tensile bond strength and SEM evaluation of caries-affected dentin using dentin adhesives. J. dent. Res.,v.74, n.10, p.1679-88, Oct. 1995.

72 - NAKAJIMA,M. et al. Tensile bond strength to caries-affected dentin. J. dent. Res., v.76, p.416, 1997. Special issue /Abstract n.3223/ 
73 - NAKAJIMA,M. et al. Effect of moist vs. dry bonding to normal vs. caries-affected dentin with Scotchbond Multi-Purpose Plus. J. dent. Res., v.78, n.7, p.1298-303, July 1999.

74 - NAKAJIMA,M. et al. Bond strengths of single-bottle dentin adhesives to caries-affected dentin. Oper. Dent., v.25, n.1, p.2-10, Jan./Feb. 2000.

75 - NISHIDA,H. et al. Bonding to clinical substrates: normal vs. cariesaffected dentin. In: INTERNATIONAL CONFERENCE ON DENTIN/PULP COMPLEX 1995 AND THE INTERNATIONAL MEETING ON CLINICAL TOPICS OF DENTIN/PULP COMPLEX, Japan, 1995. Proceedings... Tokyo, Quintessence, 1996. P.355-6.

76 - OGATA,M. et al. Effect of dentin primer application on regional bond strength to cervical wedge-shaped cavity walls. Oper. Dent., v.24, n.2, p.81-8, Mar./Apr. 1999.

77 - OILO,G. Bond strength testing - what does it mean? Int. Dent. J., v.43, n.5, p.492-8, Oct. 1993.

78 - PANIGHI,M.; G'SELL,C. Effect of the tooth microstructure on the shear bond strength of a dental composite. J. Biomed. Mater. Res., v.27, n.8, p.975-81, Aug. 1993.

79 - PASHLEY,D.H. Clinical correlations of dentin structure and function. J. prosth. Dent., v.66, n.6 , p.777-81, Dec. 1991.

80 - PASHLEY,D.H.; CARVALHO,R.M. Dentine permeability and dentin adhesion. J. Dent., v.25, n.5, p.355-72, Sept./Oct. 1997.

81 - PASHLEY,D.H. et al. Permeability of dentin to adhesive resins. Quintessence Int., v.24, n.9, p.618-31, Sept. 1993. 
82 - PASHLEY,D.H. et al. Adhesion test of dentin bonding agents: a review. Dent. Mat., v.11, n.2, p.117-25, Mar. 1995.

83 - PASHLEY,D.H. et al. Bond strength versus dentin structure: a modelling aproach. Arch. oral Biol., v.40, n.12, p.1109-18, Dec. 1995.

84 - PASHLEY,D.H. et al. Dentin, a dynamic bonding substrate: the effects of dentin variables on resin adhesion. In: INTERNATIONAL CONFERENCE ON DENTIN/PULP COMPLEX 1995 AND THE INTERNATIONAL MEETING ON CLINICAL TOPICS OF DENTIN/PULP COMPLEX. Japan, 1995. Proceedings... Tokyo, Quintessence, 1996, p.11-21.

85 - PASHLEY,D.H. et al. The effects of dentin bonding procedures on the dentin/pulp complex. In: INTERNATIONAL CONFERENCE ON DENTIN/PULP COMPLEX 1995 AND THE INTERNATIONAL MEETING ON CLINICAL TOPICS OF DENTIN/PULP COMPLEX. Japan, 1995. Proceedings... Tokyo, Quintessence, 1996, p.193201.

86 - PASHLEY,D.H. et al. The micro-tensile bond test: a review. J. Adhes. Dent., v.1, n.4, p.1-12, Oct./Nov./Dec. 1999.

87 - PASHLEY,E.L. et al. Permeability of normal versus carious dentin. Endod. Dent. Traumatol., v.7, p.207-11, 1991.

88 - PASHLEY,E.L. et al. Bond strengths to superficial, intermediate and deep dentin in vivo with four dentin bonding systems. Dent. Mat., v.9, n.1, p.19-22, Jan. 1993.

89 - PASHLEY,E.L. et al. Effects of HEMA on water evaporation from water-HEMA mixtures. Dent. Mat., v.14, n.1, p.6-10, Jan. 1998. 
90 - PAUL,S.J. et al. Effect of water content on the physical properties of model dentine primer and bonding resins. J. Dent., v.27, n.3, p.20914, Mar. 1999.

91 - PERDIGÃO,J.; LOPES,M. Dentin bonding - questions for the new millennium. J. Adhes. Dent., v.1, n.3, p.191-208, 1999.

92 - PERDIGÃO,J.; RAMOS,J.C.; LAMBRECHTS,P. In vitro interfacial relationship between human dentin and one-bottle dental adhesives. Dent. Mat., v.13, n.4, p.218-27, July 1997.

93 - PERDIGÃO,J.; SWIFT JUNIOR,E.J.; CLOE,B.C. Effects of etchants, surface moistures, and resin composite on dentin bond strengths. Amer. J. Dent., v.6, n.2, p.61-4, Apr. 1993.

94 - PERDIGÃO,J. et al. The effect of a re-wetting agent on dentin bonding. Dent. Mat., v.15, n.4, p.282-95, July 1999.

95 - PEREIRA,P.N.R. et al. Effect of intrinsic wetness and regional difference on dentin bond strength. Dent. Mat., v.15, n.1, p.46-53, Jan. 1999.

96 - PERINKA,L.; SANO,H.; HOSODA, H. Dentin thickness, hardness, and Ca-concentration vs bond strength of dentin adhesives. Dent. Mat., v.8, n.4, p.229-33, July 1992.

97 - PHRUKKANON,S.; BURROW,M.F.; TYAS,M.J. Effect of crosssectional surface area on bond strengths between resin and dentin. Dent. Mat., v.14, n.2, p.120-8, Mar. 1998.

98 - PHRUKKANON,S.; BURROW,M.F.; TYAS,M.J. The influence of crosssectional shape and surface area on the microtensile bond test. Dent. Mat., v.14, n.3, p.212-21, June 1998. 
99 - PHRUKKANON,S.; BURROW,M.F.; TYAS,M.J. The effect of dentine location and tubule orientation on the bond strengths between resin and dentine. J. Dent., v.27, n.4, p.265-74, May 1999.

100 - PRATI,C.; PASHLEY,D.H. Dentin wetness, permeability and thickness and bond strength of adhesive systems. Amer. J. Dent., v.5, n.1, p.33-8, Feb. 1992.

101 - PRATI,C. et al. Measurement of dentin permeability and wetness using the Periotron device. Dent. Mat., v.7, n.4, p.268-73, Oct. 1991.

102 - PRATI,C. et al. Dentine permeability and bond quality as affected by new bonding systems. J. Dent., v.23, n.4, p.217-26, July/Aug. 1995.

103 - PRATI,C. et al. Thickness and morphology of resin-infiltrated dentin layer in young, old, and sclerotic dentin. Oper. Dent., v.24, n.2 , p.66-72, Mar./Apr. 1999.

104 - RUBEN,J.; ARENDS,J. Shrinkage prevention of in vitro demineralized human dentine in transversal microradiography. Caries Res., v.27, n.4, p.262-5, July/Aug. 1993.

105 - RUBEN,J.; ARENDS,J. Shrinkage of sound and demineralized human coronal dentine slabs. Caries Res., v.27, n.4 , p.266-70, July/Aug. 1993.

106 - RUSE,N.D.; SHEW,R.; FEDUIK,D. In vitro fatigue testing of a dental bonding system on enamel. J. Biomed. Mater. Res., v.29, n.3, p.411-5, Mar. 1995.

107 - RUSE,N.D. et al. Novel fracture toughness test using a notchless triangular prism (NTP) specimen. J. Biomed. Mater. Res., v.31, n.4, p.457-63, Aug. 1996. 
108 - SANO,H. et al. Microporous dentin zone beneath resin-impregnated layer. Oper. Dent., v.19, n.2, p.59-64, Mar./Apr. 1994.

109 - SANO,H. et al. Tensile properties of mineralized and demineralized human and bovine dentin. J. dent. Res., v.73, n.6, p.1205-11, June 1994.

110 - SANO,H. et al. Relationship between surface area for adhesion and tensile bond strength - evaluation of a micro-tensile bond test. Dent. Mat., v.10, n.4, p.236-40, July 1994.

111 - SANO,H. et al. Nanoleakage: leakage within the hybrid layer. Oper. Dent., v.20, n.1, p.18-25, Jan./Feb. 1995.

112 - SANO,H. et al. Tensile properties of resin-infiltrated demineralized human dentin. J. dent. Res., v.74, n.4, p.1093-102, Apr. 1995.

113 - SANO,H. et al. Comparative SEM and TEM observations of nanoleakage within the hybrid layer. Oper. Dent., v.20, n.4, p.160-7, July/Aug. 1995.

114 - SANO,H. et al. Long-term durability of dentin bonds made with a selfetching primer, in vivo. J. dent. Res., v.78, n.4, p.906-11, Apr. 1999.

115 - SCHREINER,R.F. et al. Microtensile testing of dentin adhesives. Dent. Mat., v.14, n.3, p.194-201, June 1998.

116 - SHIMADA, Y. et al. In vivo adhesive interface between resin and dentin. Oper. Dent., v.20, n.5, p.204-10, Sept./Oct. 1995.

117 - SHONO,Y. et al. Effects of cross-sectional area on resin-enamel tensile bond strength. Dent. Mat., v.13, n.5, p.290-6, Sept. 1997. 
118 - SHONO,Y. et al. Regional measurement of resin-dentin bonding as an array. J. dent. Res., v.78, n.2, p.699-705, Feb. 1999.

119 - SHONO,Y. et al. Durability of resin-dentin bonds. J. Adhes. Dent., v.1, n.3, p.211-8, 1999.

120 - SUZUKI,T.; FINGER,W.J. Dentin adhesives: site of dentin vs. bonding of composite resins. Dent. Mat., v. 4, n.6, p.379-83, Dec. 1988.

121 - TAGAMI,J.; TAO,L.; PASHLEY,D.H. Correlation among dentin depth, permeability, and bond strength of adhesive resins. Dent. Mat., v.6, n.1, p.45-50, Jan. 1990.

122 - TAM,L.E.; PILLIAR,R.M. Fracture toughness of dentin/resin-composite adhesive interfaces. J. dent. Res., v.72, n.5, p.953-9, May 1993.

123 - TAM,L.E.; PILLIAR,R.M. Fracture surface characterization of dentinbonded interfacial fracture toughness specimens. J. dent. Res., v.73, n.3, p.607-19, Mar. 1994.

124 - TANUMIHARJA,M.; BURROW,M.F.; TYAS,M.J. Microtensile bond strengths of seven dentin adhesive systems. Dent. Mat., v.16, n.3, p.180-7, May 2000.

125 - TAO,L.; PASHLEY,D.H. Shear bond strengths to dentin: effects of surface treatments, depth and position. Dent. Mat., v.4, n.6, p.3718, Dec. 1988.

126 - TAO;L.; PASHLEY,D.H.; BOYD,L. Effect of different types of smear layers on dentin and enamel shear bond strengths. Dent. Mat., v.4, n.4, p.208-16, Aug. 1988. 
127 - TAO,L.; TAGAMI,J.; PASHLEY,D.H. Pulpal pressure and bond strengths of Super Bond and Gluma. Amer. J. Dent., v.4, n.2, p.736, Apr. 1991.

128 - TAY,F.R.; GWINNETT,A.J.; WEI,S.H.Y. The overwet phenomenon: an optical, micromorphological study of surface moisture in the acidconditioned, resin-dentin interface. Amer. J. Dent., v.9, n.1, p.43-8, Feb. 1996.

129 - TAY,F.R.; GWINNETT,A.J.; WEI,S.H.Y. The overwet phenomenon: a scanning electron microscopic study of surface moisture in the acidconditioned, resin-dentin interface. Amer. J. Dent., v.9, n.3, p.10913, June 1996.

130 - TAY,F.R.; GWINNETT,A.J.; WEI,S.H.Y. Micromorphological spectrum from overdrying to overwetting acid-conditioned dentin in water-free, acetone-based, single-bottle primer/adhesives. Dent. Mat., v.12, n.4 , p.236-44, July 1996.

131 - TAY;F.R.; GWINNETT,A.J.; WEI,S.H.Y. The overwet phenomenon: a transmission electron microscopic study of surface moisture in the acid-conditioned, resin-dentin interface. Amer. J. Dent., v.9, n.4, p.161-6, Aug. 1996.

132 - TAY,F.R.; GWINNETT,A.J.; WEI,S.H.Y. Ultrastructure of the resindentin interface following reversible and irreversible rewetting. Amer. J. Dent., v.10, n.2, p.77-82, Apr. 1997.

133 - TAY,F.R.; GWINNETT,A.J.; WEI,S.H.Y. Micromorphological sepctrum of acid-conditioned dentin following the application of a water-based adhesive. Dent. Mat., v.14, n.7, p.329-38, Sept. 1998. 
134 - TAY,F.R. et al. Structural evidence of a sealed tissue interface with total-etch wet-bonding technique, in vivo. J. dent. Res., v.73, n.3, p.629-36, Mar. 1994.

135 - TAY,F.R. et al. Micromorphologic relationship of the resin-dentin interface following a total etch technique in vivo using a dentinal bonding agent. Quintessence Int., v.26, n. 1, p.63-70, Jan. 1995.

136 - TAY,F.R. et al. Resin permeation into acid-conditioned, moist, and dry dentin: a paradigm using water-free adhesive primers. J. dent. Res., v.75, n.4, p.1034-44, Apr. 1996.

137 - TAY,F.R. et al. An ultrastructural study of the influence of acidity of selfetching primers and smear layer thickness on bonding to intact dentin. J. Adhes. Dent., 2000. /No prelo/

138 - TAY,F.R. et al. Effect of smear layers on the bonding of self-etching primer to dentin. J. Adhes. Dent., 2000. /No prelo/

139 - TITLEY,K. et al. Penetration of a dentin bonding agent into dentin. Amer. J. Dent., v.7, n.4, p.190-4, Aug. 1994.

140 - TITLEY,K. et al. The composition and ultrastructure of resin tags in etched dentin. Amer. J. Dent., v.8, n.5, p.224-30, Oct. 1995.

141 - UNO,S.; FINGER,W.J. Function of the hybrid zone as a stressabsorbing layer in resin-dentin bonding. Quintessence Int., v.26, n.10, p.733-8, Oct. 1995.

142 - VAN MEERBEEK,B. et al. Morphological aspects of the resin-dentin interdiffusion zone with different dentin adhesive systems. J. dent. Res., v.71, n.8, p.1530-40, Aug. 1992. 
143 - VAN MEERBEEK,B. et al. Assessment by nano-indentation of the hardness and elasticity of the resin-dentin bonding area. J. dent. Res., v.72, n.10, p.1434-42, Oct. 1993.

144 - VAN MEERBEEK,B. et al. The clinical performance of adhesives. J. Dent., v.26, n.1, p.1-20, Jan. 1998.

145 - VAN NOORT,R. Clinical relevance of laboratory studies on dental materials: strength determination - a personal view. J. Dent., v.22, p.4-8, 1994. Suppl. 1.

146 - VAN NOORT,R.; CARDEW,G.E.; HOWARD,I.C. A study of the interfacial shear and tensile stresses in a restored molar tooth. J. Dent., v.16, n.6, p.286-93, Dec. 1988.

147 - VAN NOORT,R. et

al. A critique of bond strength measurements. J. Dent., v.17, n.2, p.61-7, Apr. 1989.

148 - VAN NOORT,R. et al. The effect of local interfacial geometry on the measurement of the tensile bond strength to dentin. J. dent. Res., v.70, n.5, p.889-93, May 1991.

149 - VERSLUIS,A.; TANTBIROJN,D.; DOUGLAS,W.H. Why do shear bond tests pull out dentin? J. dent. Res., v.76, n.6, p.1298-307, June 1997.

150 - WAKABAYASHI,Y. et al. Effect of dissolution of collagen on adhesion to dentin. Int. J. Prosthodont., v.7, n.4, p.302-6, July/Aug. 1994.

151 - WALSHAW,P.R.; MCCOMB,D. SEM evaluation of the resin-dentin interface with proprietary bonding agents in human subjects. J. dent. Res., v.73, n.5, p.1079-87, May 1994. 
152 - WATANABE,L.G.; MARSHALL JR.,G.W.; MARSHALL,S.J. Dentin shear strength: effects of tubule orientation and intratooth location. Dent. Mat., v.12, n.2, p.109-15, Mar. 1996.

153 - WATANABE,I.; NAKABAYASHI,N.; PASHLEY,D.H. Bonding to ground dentin by a Phenyl-P self-etching primer. J. Dent. Res., v.73, n.6, p.1212-20, June 1994.

154 - YOSHIKAWA,T. et al. Effets of dentin depth and cavity configuration on bond strength. J. dent. Res., v.78, n.4, p.898-905, Apr. 1999.

155 - YOSHIYAMA,M. et al. Interfacial morphology and strength of bonds made to superficial versus deep dentin. Amer. J. Dent., v.8, n.6, p.297-302, Dec. 1995.

156 - YOSHIYAMA,M. et al. Regional strengths of bonding agents to cervical sclerotic root dentin. J. dent. Res., v.75, n.6, p.1404-13, June 1996.

157 - YOSHIYAMA,M. et al. Regional bond strengths of resins to human root dentine. J. Dent., v.24, n.6, p.435-42, Nov. 1996.

158 - YOSHIYAMA,M. et al. Regional bond strengths of self-etching/selfpriming adhesive systems. J. Dent., v.26, n.7, p.609-16, Sept. 1998.

159 - YOSHIYAMA,M. et al. Comparison of conventional vs self-etching adhesive bonds to caries-affected dentin. Oper. Dent., v.25, n.3, p.163-9, May/June 2000.

160 - ZHANG,Y. et al. Effects of acid-etching on the tensile properties of demineralized dentin matrix. Dent. Mat., v.14, n.3, p.222-8, June 1998. 
Anexos 
ANEXO 1 - Tabela do mapeamento: Clearfil Liner Bond 2V - Dente 1

\begin{tabular}{|c|c|c|c|c|c|}
\hline & $\begin{array}{l}\mathrm{N} 1 \\
\mathrm{C} \text { marron } \\
\text { A } 0,6560 \\
\mathrm{~F} 31,72 \mathrm{MPa} \\
\text { mista }\end{array}$ & $\begin{array}{l}\mathrm{N} 2 \\
\mathrm{C} \text { rosa } \\
\mathrm{A} 0,6966 \\
\mathrm{~F} 27,41 \mathrm{MPa} \\
\text { adesiva em dentina }\end{array}$ & $\begin{array}{l}\text { N } 3 \\
\text { C preto } \\
\text { A } 0,6800 \\
\text { F 29,92 MPa } \\
\text { mista }\end{array}$ & $\begin{array}{l}\text { N } 4 \\
\text { C verde } \\
\text { A 0,6640 } \\
\text { F 38,86 MPa } \\
\text { adesiva em dentina }\end{array}$ & \\
\hline & $\begin{array}{l}\text { N } 5 \\
\text { C cinza } \\
\text { A } 0,6080 \\
\text { F 23,56 MPa } \\
\text { adesiva em dentina }\end{array}$ & $\begin{array}{l}\text { N } 6 \\
\text { C polpa } \\
\text { A } 0,6960 \\
\text { F } 18,11 \mathrm{MPa} \\
\text { adesiva em dentina }\end{array}$ & $\begin{array}{l}\text { N } 7 \\
\text { C polpa } \\
\text { A } 0,6723 \\
\text { F 34,51 MPa } \\
\text { mista }\end{array}$ & $\begin{array}{l}\text { N } 8 \\
\text { C marron } \\
\text { A } 0,6557 \\
\text { F } 38,47 \mathrm{MPa} \\
\text { adesiva em dentina }\end{array}$ & $\begin{array}{l}\mathrm{N} 9 \\
\mathrm{C} \text { rosa } \\
\mathrm{A} 0,7020 \\
\mathrm{~F} 30,19 \mathrm{MPa} \\
\text { adesiva em dentina }\end{array}$ \\
\hline $\begin{array}{l}\mathrm{N} 16 \\
\mathrm{C} \text { rosa } \\
\text { A } 0,6237 \\
\mathrm{~F} 8,41 \mathrm{MPa} \\
\text { adesiva em dentina }\end{array}$ & $\begin{array}{l}\mathrm{N} 17 \\
\mathrm{C} \text { marron } \\
\text { A } 0,6318 \\
\mathrm{~F} 11,89 \mathrm{MPa} \\
\text { adesiva em dentina }\end{array}$ & $\begin{array}{l}\text { N } 18 \\
\text { C polpa } \\
\text { A } 0,6880 \\
\text { F } 17,97 \mathrm{MPa} \\
\text { adesiva em dentina }\end{array}$ & $\begin{array}{l}\text { N } 19 \\
\text { C polpa } \\
\text { A } 0,6720 \\
\text { F } 14,56 \mathrm{MPa} \\
\text { adesiva em dentina }\end{array}$ & $\begin{array}{l}\mathrm{N} 20 \\
\mathrm{C} \text { rosa claro } \\
\mathrm{A} 0,6636 \\
\mathrm{~F} 17,11 \mathrm{MPa} \\
\text { adesiva em dentina }\end{array}$ & $\begin{array}{l}\text { N } 21 \\
\text { C verde } \\
\text { A } 0,6942 \\
\text { F } 42,17 \mathrm{MPa} \\
\text { mista }\end{array}$ \\
\hline & & $\begin{array}{l}\text { N } 28 \\
\text { C laranja } \\
\text { A } 0,6794 \\
\text { F } \\
\text { perdido }\end{array}$ & $\begin{array}{l}\text { N } 29 \\
\text { C marron } \\
\text { A } 0,6318 \\
\text { F } 21,50 \mathrm{MPa} \\
\text { adesiva em dentina }\end{array}$ & $\begin{array}{l}\text { N } 30 \\
\text { C cinza } \\
\text { A } 0,6237 \\
\text { F 18,25 MPa } \\
\text { adesiva em dentina }\end{array}$ & \\
\hline
\end{tabular}

$\mathrm{N}=$ número de identificação, $\mathrm{C}=\operatorname{cor}, \mathrm{A}=$ área em $\mathrm{mm}^{2}, \mathrm{~F}=$ força em $\mathrm{MPa}$, tipo de fratura 
ANEXO 2 - Tabela do mapeamento: Clearfil Liner Bond 2V - Dente 2

\begin{tabular}{|c|c|c|c|c|}
\hline $\begin{array}{l}\mathrm{N} 1 \\
\mathrm{C} \text { preto } \\
\text { A } 0,6806 \\
\mathrm{~F} 24,86 \mathrm{MPa} \\
\text { adesiva em dentina }\end{array}$ & $\begin{array}{l}\mathrm{N} 2 \\
\text { C rosa } \\
\text { A } 0,6636 \\
\text { F } 51,75 \mathrm{MPa} \\
\text { coesiva em resina }\end{array}$ & $\begin{array}{l}\text { N } 3 \\
\text { C verde } \\
\text { A 0,6480 } \\
\text { F 54,63 MPa } \\
\text { adesiva em dentina }\end{array}$ & $\begin{array}{l}\text { N } 4 \\
\text { C marron } \\
\text { A } 0,6545 \\
\text { F 39,00 Mpa } \\
\text { adesiva em dentina }\end{array}$ & $\begin{array}{l}\text { N } 5 \\
\text { C laranja } \\
\text { A } 0,6468 \\
\text { F } 45,56 \mathrm{MPa} \\
\text { adesiva em dentina }\end{array}$ \\
\hline $\begin{array}{l}\text { N } 16 \\
\text { C } \\
\text { A } 0,6640 \\
\text { F } 57,64 \mathrm{MPa} \\
\text { adesiva em resina }\end{array}$ & $\begin{array}{l}\mathrm{N} 17 \\
\mathrm{C} \text { preto } \\
\mathrm{A} \\
\mathrm{F} \\
\text { perdido }\end{array}$ & $\begin{array}{l}\mathrm{N} 18 \\
\text { C rosa } \\
\text { A } 0,6640 \\
\text { F } 51,59 \mathrm{MPa} \\
\text { adesiva em resina }\end{array}$ & $\begin{array}{l}\text { N } 19 \\
\text { C polpa } \\
\text { A } 0,6804 \\
\text { F 26,49 MPa } \\
\text { mista }\end{array}$ & $\begin{array}{l}\text { N } 20 \\
\text { C verde } \\
\text { A } 0,6474 \\
\text { F } 52,76 \mathrm{MPa} \\
\text { adesiva em resina }\end{array}$ \\
\hline
\end{tabular}

$\mathrm{N}=$ número de identificação, $\mathrm{C}=$ cor, $\mathrm{A}=$ área em $\mathrm{mm}^{2}, \mathrm{~F}=$ força em $\mathrm{MPa}$, tipo de fratura 
ANEXO 3 - Tabela do mapeamento: Clearfil Liner Bond 2V - Dente 3

\begin{tabular}{|c|c|c|c|}
\hline $\begin{array}{l}\text { N } 1 \\
\text { C laranja } \\
\text { A } 0,6794 \\
\text { F 40,63 MPa } \\
\text { adesiva em dentina }\end{array}$ & $\begin{array}{l}\mathrm{N} 2 \\
\mathrm{C} \text { marron } \\
\text { A } 0,7395 \\
\mathrm{~F} 42,58 \mathrm{MPa} \\
\text { mista }\end{array}$ & $\begin{array}{l}\text { N } 3 \\
\text { C rosa } \\
\text { A } 0,6960 \\
\text { F } 42,71 \mathrm{MPa} \\
\text { adesiva em resina }\end{array}$ & $\begin{array}{l}\text { N } 4 \\
\text { C prata } \\
\text { A } 0,7047 \\
\text { F 23,00 MPa } \\
\text { mista }\end{array}$ \\
\hline $\begin{array}{l}\mathrm{N} 13 \\
\text { C preto } \\
\text { A } 0,7134 \\
\mathrm{~F} 47,10 \mathrm{MPa} \\
\text { mista }\end{array}$ & $\begin{array}{l}\text { N } 14 \\
\text { C polpa - 2,52 } \\
\text { A } 0,7134 \\
\text { F } 40,08 \mathrm{MPa} \\
\text { mista }\end{array}$ & $\begin{array}{l}\text { N } 15 \\
\text { C polpa - 3,04 } \\
\text { A 0,6786 } \\
\text { F 43,44 MPa } \\
\text { mista }\end{array}$ & $\begin{array}{l}\text { N } 16 \\
\text { C laranja } \\
\text { A 0,6960 } \\
\text { F 43,61 MPa } \\
\text { mista }\end{array}$ \\
\hline $\begin{array}{l}\text { N } 21 \\
\text { C prata } \\
\text { A } 0,8100 \\
\text { F } 30,21 \mathrm{MPa} \\
\text { mista }\end{array}$ & $\begin{array}{l}\text { N } 22 \\
\text { C preto } \\
\text { A } 0,8300 \\
\text { F } 42,85 \mathrm{MPa} \\
\text { mista }\end{array}$ & $\begin{array}{l}\text { N } 23 \\
\text { C verde } \\
\text { A } 0,8000 \\
\text { F } 40,33 \mathrm{MPa} \\
\text { adesiva em resina }\end{array}$ & $\begin{array}{l}\text { N } 24 \\
\text { C laranja } \\
\text { A } 0,8100 \\
\text { F 61,96 MPa } \\
\text { mista }\end{array}$ \\
\hline
\end{tabular}

$\mathrm{N}=$ número de identificação, $\mathrm{C}=\mathrm{cor}, \mathrm{A}=$ área em $\mathrm{mm}^{2}, \mathrm{~F}=$ força em $\mathrm{MPa}$, tipo de fratura 
ANEXO 4 - Tabela do mapeamento: Clearfil Liner Bond 2V - Dente 4

\begin{tabular}{|c|c|c|c|c|}
\hline & & $\begin{array}{l}\text { N } 1 \\
\text { C preto } \\
\text { A } 0,7332 \\
\text { F } 29,60 \mathrm{MPa} \\
\text { mista }\end{array}$ & $\begin{array}{l}\text { N } 2 \\
\text { C verde } \\
\text { A } 0,7505 \\
\text { F } 19,05 \mathrm{MPa} \\
\text { mista }\end{array}$ & \\
\hline & $\begin{array}{l}\text { N } 3 \\
\text { C laranja } \\
\text { A } 0,7140 \\
\text { F } 40,17 \mathrm{MPa} \\
\text { mista }\end{array}$ & $\begin{array}{l}\text { N } 4 \\
\text { C marron } \\
\text { A } 0,6970 \\
\text { F } 35,25 \mathrm{MPa} \\
\text { mista }\end{array}$ & $\begin{array}{l}\text { N } 5 \\
\text { C prata } \\
\text { A } 0,6800 \\
\text { F } 19,94 \mathrm{MPa} \\
\text { mista }\end{array}$ & $\begin{array}{l}\text { N } 6 \\
\text { C rosa } \\
\text { A } 0,7052 \\
\text { F } 27,21 \mathrm{MPa} \\
\text { mista }\end{array}$ \\
\hline $\begin{array}{l}\text { N } 7 \\
\text { C preto } \\
\text { A } 0,7396 \\
\text { F } 30,67 \mathrm{MPa} \\
\text { mista }\end{array}$ & $\begin{array}{l}\text { N } 8 \\
\text { C verde } \\
\text { A } 0,7138 \\
\text { F } 17,10 \mathrm{MPa} \\
\text { adesiva em dentina }\end{array}$ & $\begin{array}{l}\text { N } 9 \\
\text { C polpa } \\
\text { A } 0,6885 \\
\text { F } 17,46 \mathrm{MPa} \\
\text { mista }\end{array}$ & $\begin{array}{l}\text { N } 10 \\
\text { C polpa } \\
\text { A } 0,7392 \\
\text { F 24,74 MPa } \\
\text { mista }\end{array}$ & $\begin{array}{l}\text { N 11 } \\
\text { C laranja } \\
\text { A } 0,6804 \\
\text { F 33,63 MPa } \\
\text { adesiva em dentina }\end{array}$ \\
\hline $\begin{array}{l}\text { N } 12 \\
\text { C marron } \\
\text { A } 0,7396 \\
\text { F } 26,47 \mathrm{MPa} \\
\text { adesiva em dentina }\end{array}$ & $\begin{array}{l}\text { N } 13 \\
\text { C prata } \\
\text { A } 0,7224 \\
\text { F 23,99 MPa } \\
\text { mista }\end{array}$ & $\begin{array}{l}\text { N } 14 \\
\text { C polpa } \\
\text { A } 0,6970 \\
\text { F 14,58 MPa } \\
\text { mista }\end{array}$ & $\begin{array}{l}\text { N } 15 \\
\text { C polpa } \\
\text { A } 0,7224 \\
\text { F } 30,48 \mathrm{MPa} \\
\text { mista }\end{array}$ & $\begin{array}{l}\text { N } 16 \\
\text { C rosa } \\
\text { A } 0,6880 \\
\text { F } 54,88 \mathrm{MPa} \\
\text { adesiva em resina }\end{array}$ \\
\hline \multirow[t]{2}{*}{$\begin{array}{l}\text { N } 17 \\
\text { C preto } \\
\text { A } 0,7396 \\
\text { F 24,57 MPa } \\
\text { mista }\end{array}$} & $\begin{array}{l}\text { N } 18 \\
\text { C verde } \\
\text { A } 0,7224 \\
\text { F } 37,74 \mathrm{MPa} \\
\text { adesiva em dentina }\end{array}$ & $\begin{array}{l}\text { N } 19 \\
\text { C polpa } \\
\text { A } 0,7138 \\
\text { F 29,55 MPa } \\
\text { mista }\end{array}$ & $\begin{array}{l}\text { N } 20 \\
\text { C polpa } \\
\text { A } 0,7221 \\
\text { F } 37,93 \mathrm{MPa} \\
\text { mista }\end{array}$ & $\begin{array}{l}\text { N } 21 \\
\text { C laranja } \\
\text { A } 0,6972 \\
\text { F } 38,61 \mathrm{MPa} \\
\text { mista }\end{array}$ \\
\hline & $\begin{array}{l}\text { N } 22 \\
\text { C marron } \\
\text { A } 0,7310 \\
\text { F 55,29 MPa } \\
\text { mista }\end{array}$ & $\begin{array}{l}\text { N } 23 \\
\text { C prata } \\
\text { A } 0,7052 \\
\text { F } 43,46 \mathrm{MPa} \\
\text { mista }\end{array}$ & $\begin{array}{l}\mathrm{N} 24 \\
\mathrm{C} \text { rosa } \\
\text { A } 0,6970 \\
\mathrm{~F} 44,93 \mathrm{MPa} \\
\text { mista }\end{array}$ & $\begin{array}{l}\text { N } 25 \\
\text { C preto } \\
\text { A } 0,6885 \\
\text { F } 32,92 \mathrm{MPa} \\
\text { adesiva em dentina }\end{array}$ \\
\hline
\end{tabular}

$\mathrm{N}=$ número de identificação, $\mathrm{C}=$ cor, $\mathrm{A}=$ área em $\mathrm{mm}^{2}, \mathrm{~F}=$ força em $\mathrm{MPa}$, tipo de fratura 
ANEXO 5 - Tabela do mapeamento: Clearfil Liner Bond 2V - Dente 5

\begin{tabular}{|c|c|c|c|c|}
\hline $\begin{array}{l}\text { N } 1 \\
\text { C branco } \\
\text { A } 0,6715 \\
\text { F 29,65 MPa } \\
\text { mista }\end{array}$ & $\begin{array}{l}\text { N } 2 \\
\text { C marron } \\
\text { A } 0,6794 \\
\text { F 29,10 MPa } \\
\text { mista }\end{array}$ & $\begin{array}{l}\text { N } 3 \\
\text { C rosa } \\
\text { A } 0,6636 \\
\text { F 19,61 MPa } \\
\text { mista }\end{array}$ & $\begin{array}{l}\text { N } 4 \\
\text { C laranja } \\
\text { A } 0,6873 \\
\text { F 21,77 MPa } \\
\text { adesiva em dentina }\end{array}$ & $\begin{array}{l}\text { N } 5 \\
\text { C verde } \\
\text { A } 0,6794 \\
\text { F } 30,05 \mathrm{MPa} \\
\text { adesiva em dentina }\end{array}$ \\
\hline $\begin{array}{l}\text { N } 6 \\
\text { C amarelo } \\
\text { A } 0,6468 \\
\text { F 22,62 MPa } \\
\text { mista }\end{array}$ & $\begin{array}{l}\text { N } 7 \\
\text { C polpa } \\
\text { A } 0,6800 \\
\text { F } 18,27 \mathrm{MPa} \\
\text { mista }\end{array}$ & $\begin{array}{l}\text { N } 8 \\
\text { C polpa } \\
\text { A } 0,6720 \\
\text { F 24,81 MPa } \\
\text { mista }\end{array}$ & $\begin{array}{l}\text { N } 9 \\
\text { C polpa } \\
\text { A } 0,6800 \\
\text { F } 24,60 \mathrm{MPa} \\
\text { mista }\end{array}$ & $\begin{array}{l}\text { N } 10 \\
\text { C marron } \\
\text { A } 0,6636 \\
\text { F } 14,44 \mathrm{MPa} \\
\text { adesiva em dentina }\end{array}$ \\
\hline $\begin{array}{l}\text { N } 11 \\
\text { C laranja } \\
\text { A } 0,6800 \\
\text { F } 18,07 \mathrm{MPa} \\
\text { coesiva em resina }\end{array}$ & $\begin{array}{l}\text { N } 12 \\
\text { C polpa } \\
\text { A } 0,6873 \\
\text { F 22,20 MPa } \\
\text { mista }\end{array}$ & $\begin{array}{l}\text { N } 13 \\
\text { C polpa } \\
\text { A } \\
\text { F } \\
\text { perdido }\end{array}$ & $\begin{array}{l}\text { N } 14 \\
\text { C polpa } \\
\text { A } 0,6800 \\
\text { F 33,26 MPa } \\
\text { mista }\end{array}$ & $\begin{array}{l}\text { N } 15 \\
\text { C verde } \\
\text { A } 0,6966 \\
\text { F 27,59 MPa } \\
\text { mista }\end{array}$ \\
\hline $\begin{array}{l}\mathrm{N} 16 \\
\mathrm{C} \text { amarelo } \\
\mathrm{A} 0,6720 \\
\mathrm{~F} 17,73 \mathrm{MPa} \\
\text { mista }\end{array}$ & $\begin{array}{l}\text { N } 17 \\
\text { C polpa } \\
\text { A } 0,6557 \\
\text { F 23,41 MPa } \\
\text { mista }\end{array}$ & $\begin{array}{l}\text { N } 18 \\
\text { C polpa } \\
\text { A } \\
\text { F } \\
\text { perdido }\end{array}$ & $\begin{array}{l}\text { N } 19 \\
\text { C polpa } \\
\text { A } 0,7140 \\
\text { F } 14,23 \mathrm{MPa} \\
\text { mista }\end{array}$ & $\begin{array}{l}\text { N } 20 \\
\text { C marron } \\
\text { A } 0,7052 \\
\text { F } 18,86 \mathrm{MPa} \\
\text { mista }\end{array}$ \\
\hline \multirow[t]{2}{*}{$\begin{array}{l}\text { N } 21 \\
\text { C laranja } \\
\text { A } 0,6970 \\
\text { F } 11,33 \mathrm{MPa} \\
\text { adesiva em dentina }\end{array}$} & $\begin{array}{l}\text { N } 22 \\
\text { C verde } \\
\text { A } 0,7052 \\
\text { F } 30,40 \mathrm{MPa} \\
\text { mista }\end{array}$ & $\begin{array}{l}\text { N } 23 \\
\text { C preto } \\
\text { A } 0,7224 \\
\text { F 28,58 MPa } \\
\text { mista }\end{array}$ & $\begin{array}{l}\text { N } 24 \\
\text { C amarelo } \\
\text { A } 0,672 \\
\text { F 26,59 MPa } \\
\text { mista }\end{array}$ & $\begin{array}{l}\text { N } 25 \\
\text { C branco } \\
\text { A } 0,6970 \\
\text { F } 32,15 \mathrm{MPa} \\
\text { mista }\end{array}$ \\
\hline & $\begin{array}{l}\text { N } 26 \\
\text { C rosa } \\
\text { A } 0,6715 \\
\text { F } 23,98 \mathrm{MPa} \\
\text { mista }\end{array}$ & $\begin{array}{l}\text { N } 27 \\
\text { C laranja } \\
\text { A } 0,7138 \\
\text { F 40,43 MPa } \\
\text { mista }\end{array}$ & $\begin{array}{l}\text { N } 28 \\
\text { C verde } \\
\text { A } 0,7052 \\
\text { F 24,38 MPa } \\
\text { mista }\end{array}$ & \\
\hline
\end{tabular}

$\mathrm{N}=$ número de identificação, $\mathrm{C}=\operatorname{cor}, \mathrm{A}=$ área em $\mathrm{mm}^{2}, \mathrm{~F}=$ força em $\mathrm{MPa}$, tipo de fratura 
ANEXO 6 - Tabela do mapeamento: Clearfil Liner Bond 2V - Dente 6

\begin{tabular}{|c|c|c|c|c|c|}
\hline & $\begin{array}{l}\text { N } 1 \\
\text { C rosa } \\
\text { A } 0,7128 \\
\text { F } 20,47 \mathrm{MPa} \\
\text { mista }\end{array}$ & $\begin{array}{l}\text { N } 2 \\
\text { C verde } \\
\text { A 0,6794 } \\
\text { F 36,37 MPa } \\
\text { adesiva em dentina }\end{array}$ & $\begin{array}{l}\text { N } 3 \\
\text { C laranja } \\
\text { A 0,6885 } \\
\text { F 35,91 MPa } \\
\text { mista }\end{array}$ & $\begin{array}{l}\text { N } 4 \\
\text { C marron } \\
\text { A } 0,7052 \\
\text { F } 27,42 \mathrm{MPa} \\
\text { mista }\end{array}$ & $\begin{array}{l}\text { N } 5 \\
\text { C branco } \\
\text { A 0,7047 } \\
\text { F 31,05 MPa } \\
\text { mista }\end{array}$ \\
\hline $\begin{array}{l}\text { N } 6 \\
\text { C preto } \\
\text { A } 0,6764 \\
\text { F } 29,88 \mathrm{MPa} \\
\text { mista }\end{array}$ & $\begin{array}{l}\text { N } 7 \\
\text { C rosa } \\
\text { A } 0,6630 \\
\text { F } 40,63 \mathrm{MPa} \\
\text { mista }\end{array}$ & $\begin{array}{l}\text { N } 8 \\
\text { C polpa } \\
\text { A } 0,6880 \\
\text { F 40,35 MPa } \\
\text { mista }\end{array}$ & $\begin{array}{l}\text { N } 9 \\
\text { C polpa } \\
\text { A } 0,6715 \\
\text { F } 55,15 \mathrm{MPa} \\
\text { coesiva em dentina }\end{array}$ & $\begin{array}{l}\text { N } 10 \\
\text { C polpa } \\
\text { A } 0,7047 \\
\text { F 40,54 MPa } \\
\text { mista }\end{array}$ & $\begin{array}{l}\text { N } 11 \\
\text { C verde } \\
\text { A } 0,6880 \\
\text { F 29,15 MPa } \\
\text { mista }\end{array}$ \\
\hline $\begin{array}{l}\text { N } 17 \\
\text { C branco } \\
\text { A } 0,6952 \\
\text { F } 17,72 \mathrm{MPa} \\
\text { mista }\end{array}$ & $\begin{array}{l}\text { N } 18 \\
\text { C preto } \\
\text { A } 0,6880 \\
\text { F 28,27 MPa } \\
\text { mista }\end{array}$ & $\begin{array}{l}\text { N } 19 \\
\text { C polpa } \\
\text { A } 0,6885 \\
\text { F 20,15 MPa } \\
\text { mista }\end{array}$ & $\begin{array}{l}\text { N } 20 \\
\text { C rosa } \\
\text { A } 0,6966 \\
\text { F } 31,62 \mathrm{MPa} \\
\text { mista }\end{array}$ & $\begin{array}{l}\mathrm{N} 21 \\
\mathrm{C} \text { verde } \\
\text { A } 0,7055 \\
\mathrm{~F} 21,98 \mathrm{MPa} \\
\text { adesiva em dentina }\end{array}$ & \\
\hline
\end{tabular}

$\mathrm{N}=$ número de identificação, $\mathrm{C}=$ cor, $\mathrm{A}=$ área em $\mathrm{mm}^{2}, \mathrm{~F}=$ força em $\mathrm{MPa}$, tipo de fratura 
ANEXO 7 - Tabela do mapeamento: One Step - Dente 1

\begin{tabular}{|c|c|c|c|c|}
\hline & $\begin{array}{l}\text { N } 1 \\
\text { C rosa shock } \\
\text { A } 0,007395 \\
\text { F } 32,49 \mathrm{MPa} \\
\text { adesiva em dentina }\end{array}$ & $\begin{array}{l}\text { N } 2 \\
\text { C vermelho escuro } \\
\text { A } 0,007138 \\
\text { F 51,52 MPa } \\
\text { adesiva em dentina }\end{array}$ & $\begin{array}{l}\text { N } 3 \\
\text { C verde limão } \\
\text { A 0,007225 } \\
\text { F 73,30 MPa } \\
\text { adesiva em dentina }\end{array}$ & $\begin{array}{l}\text { N } 4 \\
\text { C azul claro } \\
\text { A 0,007225 } \\
\text { F 40,04 MPa } \\
\text { adesiva em dentina }\end{array}$ \\
\hline $\begin{array}{l}\text { N } 5 \\
\text { C marron } \\
\text { A } 0,007568 \\
\text { F } 71,92 \mathrm{MPa} \\
\text { adesiva em dentina }\end{array}$ & $\begin{array}{l}\text { N } 6 \\
\text { C azul escuro } \\
\text { A } 0,007744 \\
\text { F } 48,12 \mathrm{MPa} \\
\text { adesiva em dentina }\end{array}$ & $\begin{array}{l}\text { N } 7 \\
\text { C polpa }-2,75 \\
\text { A } 0,007387 \\
\text { F 52,44 MPa } \\
\text { coesiva em dentina }\end{array}$ & $\begin{array}{l}\text { N } 8 \\
\text { C verde } \\
\text { A } 0,00748 \\
\text { F 50,48 MPa } \\
\text { adesiva em dentina }\end{array}$ & $\begin{array}{l}\text { N } 9 \\
\text { C rosa claro } \\
\text { A } 0,007656 \\
\text { F } 62,13 \mathrm{MPa} \\
\text { adesiva em dentina }\end{array}$ \\
\hline $\begin{array}{l}\text { N } 15 \\
\text { C transparente } \\
\text { A } 0,007568 \\
\text { F 33,04 MPa } \\
\text { mista }\end{array}$ & $\begin{array}{l}\text { N } 16 \\
\text { C rosa } \\
\text { A } 0,007743 \\
\text { F 48,13 MPa } \\
\text { adesiva em dentina }\end{array}$ & $\begin{array}{l}\text { N } 17 \\
\text { C preto } \\
\text { A } 0,007392 \\
\text { F } 43,12 \mathrm{MPa} \\
\text { coesiva em dentina }\end{array}$ & $\begin{array}{l}\mathrm{N} 18 \\
\text { C rosa shock } \\
\text { A } 0,007568 \\
\text { F } 31,75 \mathrm{MPa} \\
\text { adesiva em dentina }\end{array}$ & $\begin{array}{l}\text { N } 19 \\
\text { C vermelho escuro } \\
\text { A } 0,007482 \\
\text { F } 66,85 \mathrm{MPa} \\
\text { adesiva em dentina }\end{array}$ \\
\hline
\end{tabular}

$\mathrm{N}$ = número de identificação, $\mathrm{C}=$ cor, $\mathrm{A}=$ área em $\mathrm{mm}^{2}, \mathrm{~F}=$ força em $\mathrm{MPa}$, tipo de fratura 
ANEXO 8 - Tabela do mapeamento: One Step - Dente 2

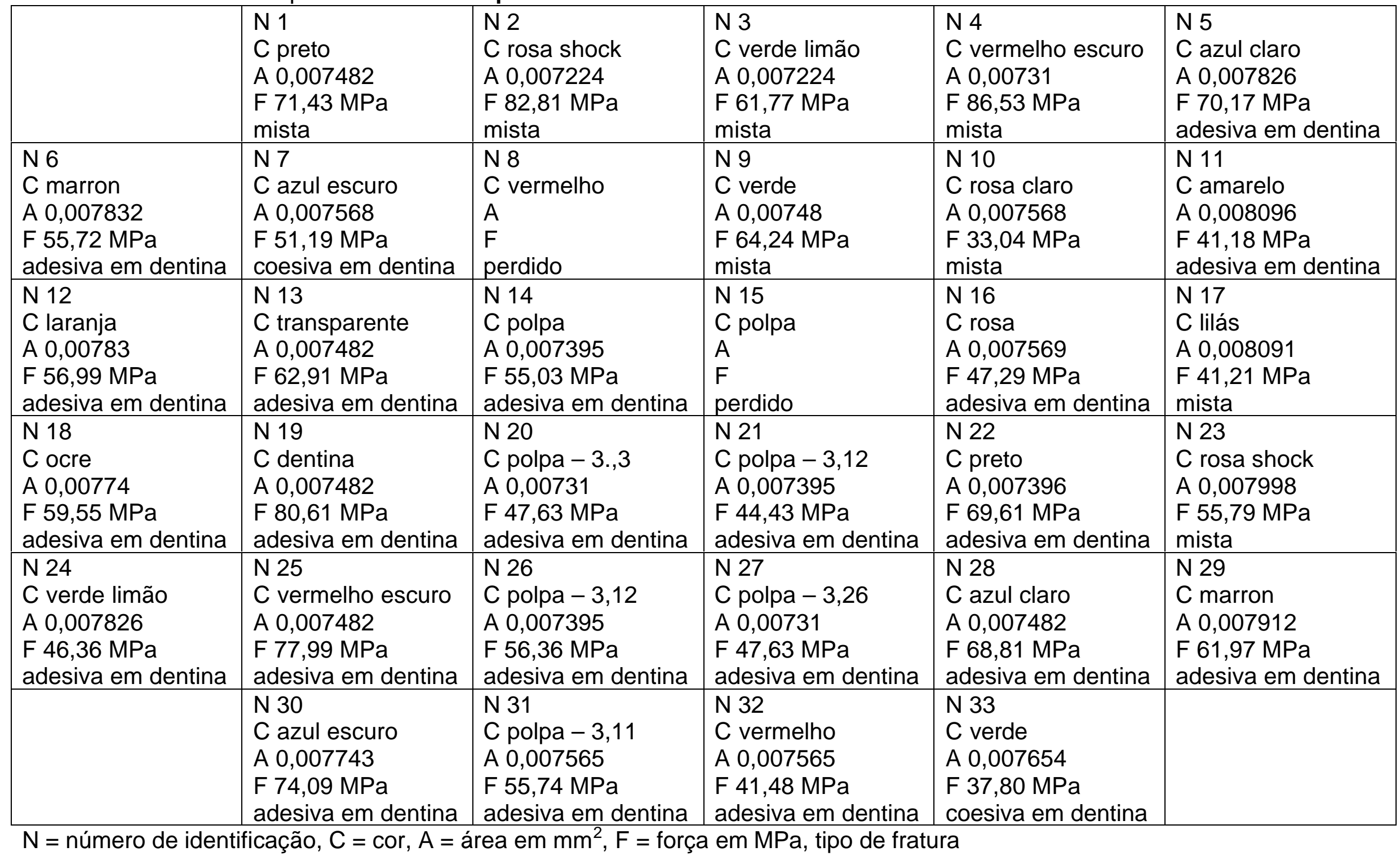


ANEXO 9 - Tabela do mapeamento: One Step - Dente 3

\begin{tabular}{|c|c|c|c|c|}
\hline & $\begin{array}{l}\mathrm{N} 1 \\
\mathrm{C} \text { marron } \\
\text { A } 0,007224 \\
\text { F } 38,69 \mathrm{MPa} \\
\text { adesiva em dentina }\end{array}$ & $\begin{array}{l}\mathrm{N} 2 \\
\mathrm{C} \text { azul esc./polpa/2,16 } \\
\text { A } 0,006972 \\
\text { F 35,87 MPa } \\
\text { adesiva em dentina }\end{array}$ & $\begin{array}{l}\text { N } 3 \\
\text { C vermelho claro } \\
\text { A } 0,007392 \\
\text { F 34,49 MPa } \\
\text { mista }\end{array}$ & $\begin{array}{l}\text { N } 4 \\
\text { C verde } \\
\text { A } 0,007392 \\
\text { F 63,02 MPa } \\
\text { adesiva em dentina }\end{array}$ \\
\hline & $\begin{array}{l}\text { N } 5 \\
\text { C amarelo } \\
\text { A } 0,007743 \\
\text { F } 41,16 \mathrm{MPa} \\
\text { adesiva em dentina }\end{array}$ & $\begin{array}{l}\text { N } 6 \\
\text { C laranja/polpa/2,63 } \\
\text { A 0,007476 } \\
\text { F 32,14 MPa } \\
\text { adesiva em dentina }\end{array}$ & $\begin{array}{l}\text { N } 7 \\
\text { C transparente } \\
\text { A } 0,007832 \\
\text { F 51,34 MPa } \\
\text { adesiva em dentina }\end{array}$ & $\begin{array}{l}\text { N } 8 \\
\text { C rosa } \\
\text { A } 0,007744 \\
\text { F 53,82 MPa } \\
\text { adesiva em dentina }\end{array}$ \\
\hline $\begin{array}{l}\text { N } 9 \\
\text { C lilás } \\
\text { A } 0,007392 \\
\text { F } 49,75 \mathrm{MPa} \\
\text { adesiva em dentina }\end{array}$ & $\begin{array}{l}\text { N } 10 \\
\text { C ocre } \\
\text { A } 0,007395 \\
\text { F } 71,61 \mathrm{MPa} \\
\text { coesiva em dentina }\end{array}$ & $\begin{array}{l}\text { N } 11 \\
\text { C preto/polpa/2,67 } \\
\text { A } 0,00714 \\
\text { F } 63,87 \mathrm{MPa} \\
\text { adesiva em dentina }\end{array}$ & $\begin{array}{l}\text { N } 12 \\
\text { C rosa shock } \\
\text { A } 0,007565 \\
\text { F } 55,74 \mathrm{MPa} \\
\text { adesiva em dentina }\end{array}$ & $\begin{array}{l}\text { N } 13 \\
\text { C vermelho escuro } \\
\text { A } 0,007392 \\
\text { F } 70,98 \mathrm{MPa} \\
\text { adesiva em dentina }\end{array}$ \\
\hline $\begin{array}{l}\text { N } 14 \\
\text { C verde limão } \\
\text { A } 0,007216 \\
\text { F 33,30 MPa } \\
\text { mista }\end{array}$ & $\begin{array}{l}\mathrm{N} 15 \\
\text { C azul claro } \\
\text { A } 0,007138 \\
\text { F } 64,57 \mathrm{MPa} \\
\text { adesiva em dentina }\end{array}$ & $\begin{array}{l}\text { N } 16 \\
\text { C marron/polpa/2,03 } \\
\text { A 0,006972 } \\
\text { F 64,70 MPa } \\
\text { adesiva em dentina }\end{array}$ & $\begin{array}{l}\text { N } 17 \\
\text { C azul escuro } \\
\text { A } 0,007304 \\
\text { F 59,75 MPa } \\
\text { adesiva em dentina }\end{array}$ & $\begin{array}{l}\text { N } 18 \\
\text { C vermelho claro } \\
\text { A } 0,007216 \\
\text { F 67,95 MPa } \\
\text { adesiva em dentina }\end{array}$ \\
\hline
\end{tabular}

$\mathrm{N}=$ número de identificação, $\mathrm{C}=$ cor, $\mathrm{A}=$ área em $\mathrm{mm}^{2}, \mathrm{~F}=$ força em $\mathrm{MPa}$, tipo de fratura 
ANEXO 10 - Tabela do mapeamento: Single Bond - Dente 1

\begin{tabular}{|c|c|c|c|c|}
\hline $\begin{array}{l}\text { N } 1 \\
\text { C vermelho } \\
\text { A 0,006806 } \\
\text { F 22,33 MPa } \\
\text { adesiva em dentina }\end{array}$ & $\begin{array}{l}\text { N } 2 \\
\text { C laranja } \\
\text { A 0,006972 } \\
\text { F } 37,22 \mathrm{MPa} \\
\text { adesiva em dentina }\end{array}$ & $\begin{array}{l}\text { N } 3 \\
\text { C azul escuro } \\
\text { A 0,006059 } \\
\text { F 62,31 MPa } \\
\text { adesiva em dentina }\end{array}$ & $\begin{array}{l}\mathrm{N} 4 \\
\mathrm{C} \text { rosa } \\
\text { A } 0,006142 \\
\mathrm{~F} 65,46 \mathrm{MPa} \\
\text { adesiva em dentina }\end{array}$ & $\begin{array}{l}\text { N } 5 \\
\text { C marron } \\
\text { A } 0,007216 \\
\text { F } 38,73 \mathrm{MPa} \\
\text { adesiva em dentina }\end{array}$ \\
\hline & $\begin{array}{l}\text { N } 16 \\
\text { C verde } \\
\text { A } 0,007396 \\
\text { F } 39,78 \mathrm{MPa} \\
\text { adesiva em dentina }\end{array}$ & $\begin{array}{l}\text { N } 17 \\
\text { C polpa }-3,13 \\
\text { A } 0,006536 \\
\text { F 44,26 MPa } \\
\text { adesiva em dentina }\end{array}$ & $\begin{array}{l}\text { N } 18 \\
\text { C azul escuro } \\
\text { A } 0,00629 \\
\text { F 55,35 MPa } \\
\text { mista }\end{array}$ & $\begin{array}{l}\text { N } 19 \\
\text { C vermelho } \\
\text { A } 0,00748 \\
\text { F 53,10 MPa } \\
\text { adesiva em dentina }\end{array}$ \\
\hline
\end{tabular}

$\mathrm{N}=$ número de identificação, $\mathrm{C}=$ cor, $\mathrm{A}=$ área em $\mathrm{mm}^{2}, \mathrm{~F}=$ força em $\mathrm{MPa}$, tipo de fratura 
ANEXO 11 - Tabela do mapeamento: Single Bond - Dente 2

\begin{tabular}{|c|c|c|c|c|}
\hline & $\begin{array}{l}\text { N } 1 \\
\text { C verde } \\
\text { A } 0,00731 \\
\text { F 60,37 MPa } \\
\text { adesiva em dentina }\end{array}$ & $\begin{array}{l}\mathrm{N} 2 \\
\text { C rosa claro } \\
\text { A } 0,007396 \\
\text { F } 39,78 \mathrm{MPa} \\
\text { adesiva em dentina }\end{array}$ & $\begin{array}{l}\text { N } 3 \\
\text { C vermelho escuro } \\
\text { A } 0,007396 \\
\text { F 46,41 MPa } \\
\text { adesiva em dentina }\end{array}$ & $\begin{array}{l}\text { N } 4 \\
\text { C azul escuro } \\
\text { A } 0,00731 \\
\text { F } 14,09 \mathrm{MPa} \\
\text { com bolha }\end{array}$ \\
\hline $\begin{array}{l}\text { N } 5 \\
\text { C laranja } \\
\text { A } 0,007644 \\
\text { F } 60,94 \mathrm{MPa} \\
\text { mista }\end{array}$ & $\begin{array}{l}\text { N } 6 \\
\text { C amarelo } \\
\text { A } 0,007224 \\
\text { F 38,69 MPa } \\
\text { adesiva em dentina }\end{array}$ & $\begin{array}{l}\text { N } 7 \\
\text { C polpa - 2,34 } \\
\text { A } 0,00748 \\
\text { F } 37,37 \mathrm{MPa} \\
\text { adesiva em dentina }\end{array}$ & $\begin{array}{l}\text { N } 8 \\
\text { C polpa }-2,52 \\
\text { A } 0,007568 \\
\text { F 38,23 MPa } \\
\text { adesiva em dentina }\end{array}$ & $\begin{array}{l}\text { N } 9 \\
\text { C azul claro } \\
\text { A } 0,007308 \\
\text { F 63,07 MPa } \\
\text { adesiva em dentina }\end{array}$ \\
\hline $\begin{array}{l}\text { N } 10 \\
\text { C lilás } \\
\text { A } 0,008008 \\
\text { F } 43,47 \mathrm{MPa} \\
\text { adesiva em dentina }\end{array}$ & $\begin{array}{l}\text { N } 11 \\
\text { C ocre } \\
\text { A } 0,007565 \\
\text { F 33,06 MPa } \\
\text { adesiva em dentina }\end{array}$ & $\begin{array}{l}\mathrm{N} 12 \\
\text { C polpa }-2,93 \\
\text { A } 0,007224 \\
\text { F } 52,94 \mathrm{MPa} \\
\text { adesiva em dentina }\end{array}$ & $\begin{array}{l}\mathrm{N} 13 \\
\mathrm{C} \text { polpa }-2,90 \\
\mathrm{~A} 0,007224 \\
\mathrm{~F} 43,44 \mathrm{MPa} \\
\text { adesiva em dentina }\end{array}$ & $\begin{array}{l}\text { N } 14 \\
\text { C preto } \\
\text { A } 0,007656 \\
\text { F 56,36 MPa } \\
\text { adesiva em dentina }\end{array}$ \\
\hline $\begin{array}{l}\text { N } 15 \\
\text { C verde limão } \\
\text { A } 0,007826 \\
\text { F 40,10 MPa } \\
\text { mista }\end{array}$ & $\begin{array}{l}\text { N 16 } \\
\text { C verde } \\
\text { A 0,007396 } \\
\text { F 25,19 MPa } \\
\text { adesiva em dentina }\end{array}$ & $\begin{array}{l}\mathrm{N} 17 \\
\mathrm{C} \text { rosa claro } \\
\mathrm{A} 0,007482 \\
\mathrm{~F} 45,22 \mathrm{MPa} \\
\text { adesiva em dentina }\end{array}$ & $\begin{array}{l}\text { N } 18 \\
\text { C vermelho escuro } \\
\text { A } 0,007482 \\
\text { F 53,74 MPa } \\
\text { adesiva em dentina }\end{array}$ & $\begin{array}{l}\text { N } 19 \\
\text { C azul escuro } \\
\text { A } 0,007482 \\
\text { F } 61,60 \mathrm{MPa} \\
\text { adesiva em dentina }\end{array}$ \\
\hline
\end{tabular}

$\mathrm{N}=$ número de identificação, $\mathrm{C}=\operatorname{cor}, \mathrm{A}=$ área em $\mathrm{mm}^{2}, \mathrm{~F}=$ força em $\mathrm{MPa}$, tipo de fratura 
ANEXO 12 - Tabela do mapeamento: Single Bond - Dente 3

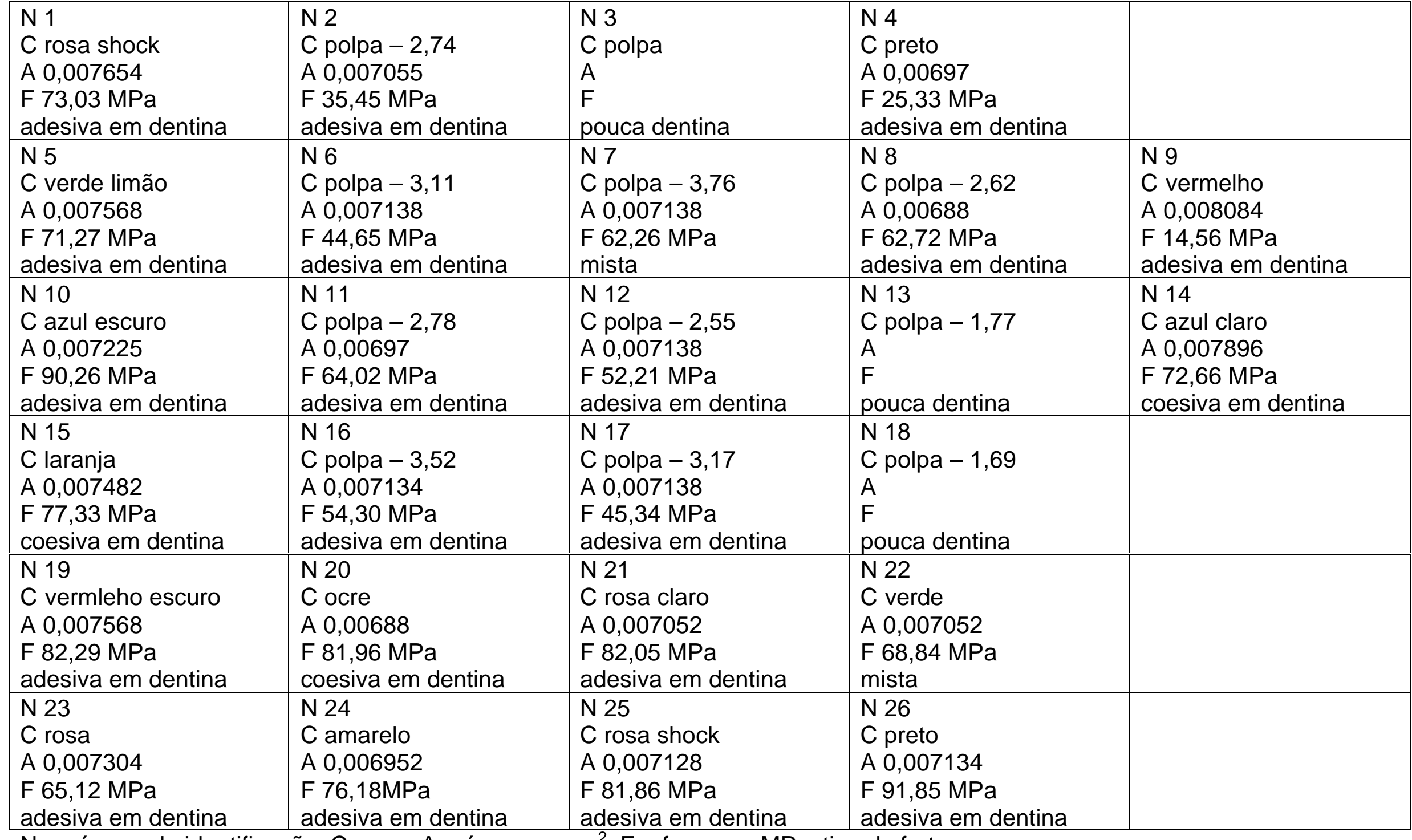

$\mathrm{N}=$ número de identificação, $\mathrm{C}=$ cor, $\mathrm{A}=$ área em $\mathrm{mm}^{2}, \mathrm{~F}=$ força em $\mathrm{MPa}$, tipo de fratura 
ANEXO 13 - Resultados originais dos valores de resistência adesiva (MPa), área adesiva $\left(\mathrm{mm}^{2}\right)$ e tipo de fratura dos testes de resistência de união à microtração de acordo com o sistema adesivo empregado - Clearfil Liner Bond 2V - e as amostras avaliadas - Dente 1.

\begin{tabular}{|c|c|c|c|}
\hline Número de Espécimes & Valor & Área & Tipo de Fratura \\
\hline 1 & 42,17 & 0,6942 & mista \\
\hline 2 & 38,86 & 0,6640 & adesiva em dentina \\
\hline 3 & 38,47 & 0,6557 & adesiva em dentina \\
\hline 4 & 34,51 & 0,6723 & mista \\
\hline 5 & 33,86 & 0,6888 & adesiva em dentina \\
\hline 6 & 31,72 & 0,6560 & mista \\
\hline 7 & 30,19 & 0,7020 & adesiva em dentina \\
\hline 8 & 29,92 & 0,6800 & mista \\
\hline 9 & 28,19 & 0,6474 & adesiva em dentina \\
\hline 10 & 27,41 & 0,6966 & adesiva em dentina \\
\hline 11 & 25,81 & 0,6840 & adesiva em dentina \\
\hline 12 & 25,40 & 0,7020 & adesiva em dentina \\
\hline 13 & 24,37 & 0,6552 & adesiva em dentina \\
\hline 14 & 23,56 & 0,6080 & adesiva em dentina \\
\hline 15 & 22,94 & 0,5913 & adesiva em dentina \\
\hline 16 & 21,79 & 0,6468 & adesiva em dentina \\
\hline 17 & 21,50 & 0,6318 & adesiva em dentina \\
\hline 18 & 20,93 & 0,6794 & adesiva em dentina \\
\hline 19 & 18,94 & 0,6396 & adesiva em dentina \\
\hline 20 & 18,25 & 0,6237 & adesiva em dentina \\
\hline 21 & 18,11 & 0,6960 & adesiva em dentina \\
\hline 22 & 17,97 & 0,6880 & adesiva em dentina \\
\hline 23 & 17,11 & 0,6636 & adesiva em dentina \\
\hline 24 & 15,97 & 0,6391 & adesiva em dentina \\
\hline 25 & 14,56 & 0,6720 & adesiva em dentina \\
\hline 26 & 11,89 & 0,6318 & adesiva em dentina \\
\hline 27 & 9,09 & 0,6314 & adesiva em dentina \\
\hline 28 & 8,41 & 0,6237 & adesiva em dentina \\
\hline
\end{tabular}


ANEXO 14 - Resultados originais dos valores de resistência adesiva (MPa), área adesiva $\left(\mathrm{mm}^{2}\right)$ e tipo de fratura dos testes de resistência de união à microtração de acordo com o sistema adesivo empregado - Clearfil Liner Bond 2V - e as amostras avaliadas - Dente 2.

\begin{tabular}{|c|c|c|c|}
\hline Número de Espécimes & Valor & Área & Tipo de Fratura \\
\hline 1 & 66,15 & 0,6806 & mista \\
\hline 2 & 57,64 & 0,6640 & adesiva em resina \\
\hline 3 & 54,89 & 0,6804 & coesiva em dentina \\
\hline 4 & 54,63 & 0,6480 & adesiva em dentina \\
\hline 5 & 53,97 & 0,6478 & mista \\
\hline 6 & 53,65 & 0,6804 & adesiva em dentina \\
\hline 7 & 52,76 & 0,6474 & adesiva em resina \\
\hline 8 & 51,75 & 0,6636 & coesiva em resina \\
\hline 9 & 51,59 & 0,6640 & adesiva em resina \\
\hline 10 & 50,81 & 0,6640 & mista \\
\hline 11 & 48,29 & 0,6552 & adesiva em resina \\
\hline 12 & 45,56 & 0,6468 & adesiva em dentina \\
\hline 13 & 39,00 & 0,6545 & adesiva em dentina \\
\hline 14 & 38,42 & 0,6560 & mista \\
\hline 15 & 36,31 & 0,6557 & mista \\
\hline 16 & 34,98 & 0,6889 & mista \\
\hline 17 & 27,98 & 0,6561 & mista \\
\hline 18 & 26,88 & 0,6640 & mista \\
\hline 19 & 26,49 & 0,6804 & mista \\
\hline 20 & 24,86 & 0,6806 & adesiva em dentina \\
\hline
\end{tabular}


ANEXO 15 - Resultados originais dos valores de resistência adesiva (MPa), área adesiva $\left(\mathrm{mm}^{2}\right)$ e tipo de fratura dos testes de resistência de união à microtração de acordo com o sistema adesivo empregado - Clearfil Liner Bond 2V - e as amostras avaliadas - Dente 3.

\begin{tabular}{|c|c|c|c|}
\hline Número de Espécimes & Valor & Área & Tipo de Fratura \\
\hline 1 & 61,96 & 0,8100 & mista \\
\hline 2 & 60,51 & 0,6478 & mista \\
\hline 3 & 59,74 & 0,7308 & adesiva em dentina \\
\hline 4 & 55,71 & 0,6399 & mista \\
\hline 5 & 55,31 & 0,6885 & mista \\
\hline 6 & 54,62 & 0,6880 & adesiva em resina \\
\hline 7 & 52,47 & 0,6396 & mista \\
\hline 8 & 51,07 & 0,6715 & mista \\
\hline 9 & 47,38 & 0,7052 & mista \\
\hline 10 & 47,33 & 0,7140 & mista \\
\hline 11 & 47,10 & 0,7134 & mista \\
\hline 12 & 43,61 & 0,6960 & mista \\
\hline 13 & 43,44 & 0,6786 & mista \\
\hline 14 & 42,85 & 0,8300 & mista \\
\hline 15 & 42,71 & 0,6960 & adesiva em resina \\
\hline 16 & 42,58 & 0,7395 & mista \\
\hline 17 & 40,63 & 0,6794 & adesiva em dentina \\
\hline 18 & 40,33 & 0,8000 & adesiva em resina \\
\hline 19 & 40,08 & 0,7134 & mista \\
\hline 20 & 35,48 & 0,6966 & adesiva em dentina \\
\hline 21 & 30,21 & 0,8100 & mista \\
\hline 22 & 26,44 & 0,6794 & mista \\
\hline 23 & 23,00 & 0,7047 & mista \\
\hline
\end{tabular}


ANEXO 16 - Resultados originais dos valores de resistência adesiva (MPa), área adesiva $\left(\mathrm{mm}^{2}\right)$ e tipo de fratura dos testes de resistência de união à microtração de acordo com o sistema adesivo empregado - Clearfil Liner Bond 2V - e as amostras avaliadas - Dente 4.

\begin{tabular}{|c|c|c|c|}
\hline Número de Espécimes & Valor & Área & Tipo de Fratura \\
\hline 1 & 55,29 & 0,7310 & mista \\
\hline 2 & 54,88 & 0,6880 & adesiva em resina \\
\hline 3 & 44,93 & 0,6970 & mista \\
\hline 4 & 43,46 & 0,7052 & mista \\
\hline 5 & 40,17 & 0,7140 & mista \\
\hline 6 & 38,61 & 0,6972 & mista \\
\hline 7 & 37,93 & 0,7221 & mista \\
\hline 8 & 37,74 & 0,7224 & adesiva em dentina \\
\hline 9 & 35,25 & 0,6970 & mista \\
\hline 10 & 33,63 & 0,6804 & adesiva em dentina \\
\hline 11 & 32,92 & 0,6885 & adesiva em dentina \\
\hline 12 & 30,67 & 0,7396 & mista \\
\hline 13 & 30,48 & 0,7224 & mista \\
\hline 14 & 29,60 & 0,7332 & mista \\
\hline 15 & 29,55 & 0,7138 & mista \\
\hline 16 & 27,21 & 0,7052 & mista \\
\hline 17 & 26,47 & 0,7396 & adesiva em dentina \\
\hline 18 & 24,74 & 0,7392 & mista \\
\hline 19 & 24,57 & 0,7396 & mista \\
\hline 20 & 23,99 & 0,7224 & mista \\
\hline 21 & 19,94 & 0,680 & mista \\
\hline 22 & 19,05 & 0,7505 & mista \\
\hline 23 & 17,46 & 0,6885 & mista \\
\hline 24 & 17,10 & 0,7138 & adesiva em dentina \\
\hline 25 & 14,58 & 0,6970 & mista \\
\hline
\end{tabular}


ANEXO 17 - Resultados originais dos valores de resistência adesiva (MPa), área adesiva $\left(\mathrm{mm}^{2}\right)$ e tipo de fratura dos testes de resistência de união à microtração de acordo com o sistema adesivo empregado - Clearfil Liner Bond 2V - e as amostras avaliadas - Dente 5.

\begin{tabular}{|c|c|c|c|}
\hline Número de Espécimes & Valor & Área & Tipo de Fratura \\
\hline 1 & 40,43 & 0,7138 & mista \\
\hline 2 & 33,26 & 0,6800 & mista \\
\hline 3 & 32,15 & 0,6970 & mista \\
\hline 4 & 30,40 & 0,7052 & mista \\
\hline 5 & 30,05 & 0,6794 & adesiva em dentina \\
\hline 6 & 29,65 & 0,6715 & mista \\
\hline 7 & 29,10 & 0,6794 & mista \\
\hline 8 & 28,58 & 0,7224 & mista \\
\hline 9 & 27,59 & 0,6966 & mista \\
\hline 10 & 26,59 & 0,6720 & mista \\
\hline 11 & 24,81 & 0,6720 & mista \\
\hline 12 & 24,60 & 0,6800 & mista \\
\hline 13 & 24,38 & 0,7052 & mista \\
\hline 14 & 23,98 & 0,6715 & mista \\
\hline 15 & 23,41 & 0,6557 & mista \\
\hline 16 & 22,62 & 0,6468 & mista \\
\hline 17 & 22,20 & 0,6873 & mista \\
\hline 18 & 21,77 & 0,6873 & adesiva em dentina \\
\hline 19 & 19,61 & 0,6636 & mista \\
\hline 20 & 18,86 & 0,7052 & mista \\
\hline 21 & 18,27 & 0,6800 & mista \\
\hline 22 & 18,07 & 0,6800 & coesiva em resina \\
\hline 23 & 17,73 & 0,6720 & mista \\
\hline 24 & 14,44 & 0,6636 & adesiva em dentina \\
\hline 25 & 14,23 & 0,7140 & mista \\
\hline 26 & 11,33 & 0,6970 & adesiva em dentina \\
\hline
\end{tabular}


ANEXO 18 - Resultados originais dos valores de resistência adesiva (MPa), área adesiva $\left(\mathrm{mm}^{2}\right)$ e tipo de fratura dos testes de resistência de união à microtração de acordo com o sistema adesivo empregado - Clearfil Liner Bond 2V - e as amostras avaliadas - Dente 6.

\begin{tabular}{|c|c|c|c|}
\hline Número de Espécimes & Valor & Área & Tipo de Fratura \\
\hline 1 & 55,15 & 0,6715 & coesiva em dentina \\
\hline 2 & 40,63 & 0,6630 & mista \\
\hline 3 & 40,54 & 0,7047 & mista \\
\hline 4 & 40,35 & 0,6880 & mista \\
\hline 5 & 37,14 & 0,7055 & mista \\
\hline 6 & 36,53 & 0,6970 & mista \\
\hline 7 & 36,37 & 0,6794 & adesiva em dentina \\
\hline 8 & 35,91 & 0,6885 & mista \\
\hline 9 & 35,17 & 0,7395 & mista \\
\hline 10 & 32,66 & 0,6885 & adesiva em dentina \\
\hline 11 & 32,11 & 0,6804 & mista \\
\hline 12 & 31,62 & 0.6966 & mista \\
\hline 13 & 31,55 & 0,7056 & mista \\
\hline 14 & 31,05 & 0,7047 & mista \\
\hline 15 & 30,58 & 0,7482 & mista \\
\hline 16 & 29,88 & 0,6764 & mista \\
\hline 17 & 29,15 & 0,6880 & mista \\
\hline 18 & 28,27 & 0,6880 & mista \\
\hline 19 & 27,45 & 0,7380 & mista \\
\hline 20 & 27,42 & 0,7052 & mista \\
\hline 21 & 22,29 & 0,7225 & - \\
\hline 22 & 21,98 & 0,7055 & adesiva em dentina \\
\hline 23 & 20,47 & 0,7128 & mista \\
\hline 24 & 20,15 & 0,6885 & mista \\
\hline 25 & 17,72 & 0,6952 & mista \\
\hline
\end{tabular}


ANEXO 19 - Resultados originais dos valores de resistência adesiva (MPa), área adesiva $\left(\mathrm{mm}^{2}\right)$ e tipo de fratura dos testes de resistência de união à microtração de acordo com o sistema adesivo empregado - One-Step - e as amostras avaliadas - Dente 1.

\begin{tabular}{|c|c|c|c|}
\hline Número de Espécimes & Valor & Área & Tipo de Fratura \\
\hline 1 & 73,30 & 0,7225 & adesiva em dentina \\
\hline 2 & 71,92 & 0,7568 & adesiva em dentina \\
\hline 3 & 66,85 & 0,7482 & adesiva em dentina \\
\hline 4 & 63,13 & 0,7224 & adesiva em dentina \\
\hline 5 & 62,13 & 0,7656 & adesiva em dentina \\
\hline 6 & 60,33 & 0,7396 & adesiva em dentina \\
\hline 7 & 57,68 & 0,7396 & adesiva em dentina \\
\hline 8 & 53,62 & 0,7224 & coesiva em dentina \\
\hline 9 & 52,99 & 0,7310 & adesiva em dentina \\
\hline 10 & 52,44 & 0,7387 & coesiva em dentina \\
\hline 11 & 51,52 & 0,7138 & adesiva em dentina \\
\hline 12 & 50,48 & 0,7480 & adesiva em dentina \\
\hline 13 & 48,13 & 0,7743 & adesiva em dentina \\
\hline 14 & 48,12 & 0,7744 & adesiva em dentina \\
\hline 15 & 47,73 & 0,7396 & adesiva em dentina \\
\hline 16 & 45,35 & 0,7568 & adesiva em dentina \\
\hline 17 & 44,06 & 0,7568 & mista \\
\hline 18 & 43,12 & 0,7392 & coesiva em dentina \\
\hline 19 & 41,10 & 0,7396 & adesiva em dentina \\
\hline 20 & 40,04 & 0,7225 & adesiva em dentina \\
\hline 21 & 33,04 & 0,7568 & mista \\
\hline 22 & 32,49 & 0,7395 & adesiva em dentina \\
\hline 23 & 31,75 & 0,7568 & adesiva em dentina \\
\hline
\end{tabular}


ANEXO 20 - Resultados originais dos valores de resistência adesiva (MPa), área adesiva $\left(\mathrm{mm}^{2}\right)$ e tipo de fratura dos testes de resistência de união à microtração de acordo com o sistema adesivo empregado - One-Step - e as amostras avaliadas - Dente 2.

\begin{tabular}{|c|c|c|c|}
\hline Número de Espécimes & Valor & Área & Tipo de Fratura \\
\hline 1 & 86,53 & 0,7310 & coesiva em adesivo \\
\hline 2 & 82,81 & 0,7224 & mista \\
\hline 3 & 80,61 & 0,7482 & adesiva em dentina \\
\hline 4 & 77,99 & 0,7482 & adesiva em dentina \\
\hline 5 & 74,09 & 0,7743 & adesiva em dentina \\
\hline 6 & 71,43 & 0,7482 & mista \\
\hline 7 & 70,17 & 0,7826 & adesiva em dentina \\
\hline 8 & 69,61 & 0,7396 & adesiva em dentina \\
\hline 9 & 68,81 & 0,7482 & adesiva em dentina \\
\hline 10 & 64,24 & 0,7480 & mista \\
\hline 11 & 62,91 & 0,7482 & adesiva em dentina \\
\hline 12 & 61,97 & 0,7912 & adesiva em dentina \\
\hline 13 & 61,77 & 0,7224 & mista \\
\hline 14 & 59,55 & 0,7740 & adesiva em dentina \\
\hline 15 & 56,99 & 0,7830 & adesiva em dentina \\
\hline 16 & 56,36 & 0,7395 & adesiva em dentina \\
\hline 17 & 55,79 & 0,7998 & mista \\
\hline 18 & 55,74 & 0,7565 & adesiva em dentina \\
\hline 19 & 55,72 & 0,7832 & adesiva em dentina \\
\hline 20 & 55,03 & 0,7395 & adesiva em dentina \\
\hline 21 & 51,19 & 0,7568 & coesiva em dentina \\
\hline 22 & 47,63 & 0,7310 & adesiva em dentina \\
\hline 23 & 47,63 & 0,7310 & adesiva em dentina \\
\hline 24 & 47,29 & 0,7569 & adesiva em dentina \\
\hline 25 & 46,36 & 0,7826 & adesiva em dentina \\
\hline 26 & 44,43 & 0,7395 & adesiva em dentina \\
\hline 27 & 41,48 & 0,7565 & adesiva em dentina \\
\hline 28 & 41,21 & 0,8091 & mista \\
\hline 29 & 41,18 & 0,8096 & adesiva em dentina \\
\hline 30 & 37,80 & 0,7654 & mista \\
\hline 31 & 33,04 & 0,7568 & mista \\
\hline
\end{tabular}


ANEXO 21 - Resultados originais dos valores de resistência adesiva (MPa), área adesiva $\left(\mathrm{mm}^{2}\right)$ e tipo de fratura dos testes de resistência de união à microtração de acordo com o sistema adesivo empregado - One-Step - e as amostras avaliadas - Dente 3.

\begin{tabular}{|c|c|c|c|}
\hline Número de Espécimes & Valor & Área & Tipo de Fratura \\
\hline 1 & 71,61 & 0,7395 & coesiva em dentina \\
\hline 2 & 70,98 & 0,7392 & adesiva em dentina \\
\hline 3 & 67,95 & 0,7216 & adesiva em dentina \\
\hline 4 & 66,61 & 0,7656 & adesiva em dentina \\
\hline 5 & 64,70 & 0,6972 & adesiva em dentina \\
\hline 6 & 64,57 & 0,7138 & adesiva em dentina \\
\hline 7 & 63,87 & 0,7140 & adesiva em dentina \\
\hline 8 & 63,02 & 0,7392 & adesiva em dentina \\
\hline 9 & 59,75 & 0,7304 & adesiva em dentina \\
\hline 10 & 57,02 & 0,7568 & adesiva em dentina \\
\hline 11 & 55,74 & 0,7565 & adesiva em dentina \\
\hline 12 & 53,82 & 0,7744 & adesiva em dentina \\
\hline 13 & 51,34 & 0,7832 & adesiva em dentina \\
\hline 14 & 49,75 & 0,7392 & adesiva em dentina \\
\hline 15 & 41,16 & 0,7743 & adesiva em dentina \\
\hline 16 & 38,69 & 0,7224 & adesiva em dentina \\
\hline 17 & 35,87 & 0,6972 & adesiva em dentina \\
\hline 18 & 34,49 & 0,7392 & mista \\
\hline 19 & 33,30 & 0,7216 & mista \\
\hline 20 & 32,14 & 0,7476 & adesiva em dentina \\
\hline
\end{tabular}


ANEXO 22 - Resultados originais dos valores de resistência adesiva (MPa), área adesiva $\left(\mathrm{mm}^{2}\right)$ e tipo de fratura dos testes de resistência de união à microtração de acordo com o sistema adesivo empregado - Single Bond - e as amostras avaliadas - Dente 1.

\begin{tabular}{|c|c|c|c|}
\hline Número de Espécimes & Valor & Área & Tipo de Fratura \\
\hline 1 & 65,46 & 0,6142 & adesiva em dentina \\
\hline 2 & 62,31 & 0,6059 & adesiva em dentina \\
\hline 3 & 55,66 & 0,7224 & adesiva em dentina \\
\hline 4 & 55,35 & 0,6290 & mista \\
\hline 5 & 53,36 & 0,6525 & adesiva em dentina \\
\hline 6 & 53,10 & 0,7480 & adesiva em dentina \\
\hline 7 & 46,97 & 0,7308 & mista \\
\hline 8 & 46,78 & 0,7128 & adesiva em dentina \\
\hline 9 & 44,26 & 0,6536 & adesiva em dentina \\
\hline 10 & 43,92 & 0,6364 & mista \\
\hline 11 & 41,16 & 0,7743 & mista \\
\hline 12 & 39,78 & 0,7396 & adesiva em dentina \\
\hline 13 & 38,73 & 0,7216 & adesiva em dentina \\
\hline 14 & 37,22 & 0,6972 & adesiva em dentina \\
\hline 15 & 36,52 & 0,7654 & adesiva em dentina \\
\hline 16 & 34,37 & 0,7134 & mista \\
\hline 17 & 32,26 & 0,6688 & adesiva em dentina \\
\hline 18 & 30,11 & 0,6351 & adesiva em dentina \\
\hline 19 & 22,33 & 0,6806 & adesiva em dentina \\
\hline
\end{tabular}


ANEXO 23 - Resultados originais dos valores de resistência adesiva (MPa), área adesiva $\left(\mathrm{mm}^{2}\right)$ e tipo de fratura dos testes de resistência de união à microtração de acordo com o sistema adesivo empregado - Single Bond - e as amostras avaliadas - Dente 2.

\begin{tabular}{|cccc|}
\hline Número de Espécimes & Valor & Área & Tipo de Fratura \\
\hline 1 & 63,07 & 0,7308 & adesiva em dentina \\
2 & 61,60 & 0,7482 & adesiva em dentina \\
3 & 60,94 & 0,7644 & mista \\
4 & 60,37 & 0,7310 & adesiva em dentina \\
5 & 56,36 & 0,7656 & adesiva em dentina \\
6 & 53,74 & 0,7482 & adesiva em dentina \\
7 & 52,94 & 0,7224 & adesiva em dentina \\
8 & 46,41 & 0,7396 & adesiva em dentina \\
9 & 45,22 & 0,7482 & adesiva em dentina \\
10 & 43,47 & 0,8008 & adesiva em dentina \\
11 & 43,44 & 0,7224 & adesiva em dentina \\
12 & 40,10 & 0,7826 & \\
13 & 39,78 & 0,7396 & adesiva em dentina \\
14 & 38,69 & 0,7224 & adesiva em dentina \\
15 & 38,23 & 0,7568 & adesiva em dentina \\
16 & 37,37 & 0,7480 & adesiva em dentina \\
17 & 33,06 & 0,7565 & adesiva em dentina \\
18 & 25,19 & 0,7396 & adesiva em dentina \\
\hline
\end{tabular}


ANEXO 24 - Resultados originais dos valores de resistência adesiva (MPa), área adesiva $\left(\mathrm{mm}^{2}\right)$ e tipo de fratura dos testes de resistência de união à microtração de acordo com o sistema adesivo empregado - Single Bond - e as amostras avaliadas - Dente 3.

\begin{tabular}{|cccc|}
\hline Número de Espécimes & Valor & Área & Tipo de Fratura \\
\hline 1 & 91,85 & 0,7134 & adesiva em dentina \\
2 & 90,26 & 0,7225 & adesiva em dentina \\
3 & 82,29 & 0,7568 & adesiva em dentina \\
4 & 82,05 & 0,7052 & adesiva em dentina \\
5 & 81,96 & 0,6880 & coesiva em dentina \\
6 & 81,86 & 0,7128 & adesiva em dentina \\
7 & 77,33 & 0,7482 & coesiva em dentina \\
8 & 76,18 & 0,6952 & adesiva em dentina \\
9 & 73,03 & 0,7654 & adesiva em dentina \\
10 & 72,66 & 0,7896 & coesiva em dentina \\
11 & 71,27 & 0,7568 & adesiva em dentina \\
12 & 68,84 & 0,7052 & mista \\
13 & 65,12 & 0,7304 & adesiva em dentina \\
14 & 64,02 & 0,6970 & adesiva em dentina \\
15 & 62,72 & 0,6880 & adesiva em dentina \\
16 & 62,26 & 0,7138 & mista \\
17 & 54,30 & 0,7134 & adesiva em dentina \\
18 & 52,21 & 0,7138 & adesiva em dentina \\
19 & 45,34 & 0,7138 & adesiva em dentina \\
20 & 44,65 & 0,7138 & adesiva em dentina \\
21 & 35,45 & 0,7055 & adesiva em dentina \\
22 & 25,33 & 0,6970 & adesiva em dentina \\
23 & 14,56 & 0,8084 & adesiva em dentina \\
\hline
\end{tabular}


Abstract 


\section{ABSTRACT}

The present work evaluated the influence of morphological variations of the dentinal substrate in the microtensile adhesive strength of three adhesive systems: Clearfil Liner Bond 2V, One-Step and Single Bond, using flat dentin surfaces. For the preparation and exposure of the dentin surface, the occlusal enamel was ground with 320 and 600 - grit SiC paper. The teeth were treated with one of the adhesive systems and a $1 \mathrm{~cm}$ thick layer of $Z 100$ resin composite was built up on the surface. After storage in distilled water at $37^{\circ} \mathrm{C}$ for 24 hours, the specimens were prepared to be subjected to the microtensile test. With the aid of a micrometer the teeth were serially sectioned in both " $\mathrm{x}$ " and " $y$ " directions to result in several bonded sticks of approximately $0.7 \mathrm{~mm}^{2}$ of cross-sectional area. Approximately twenty-three specimens per tooth were obtained. Each specimen was identified by a color code and the flat dentin surface was mapped. For the reading of the adhesive strength, each bonded stick was individually gluded to a Bencor Multi-T microtensile device with the adhesive area perpendicularly oriented to the long axis of the device. After testing, the mode of fracture of the adhesive interface was evaluated. The conclusions of this study were: there is a regional variance in the adhesive strenght on a flat dentin surface; regardless of the adhesive system used, the variation of the adhesive strength found on flat dentin surfaces was determined by variations in the dentinal substrate; when comparing the adhesive strength among the materials, One-Step $(53,97 \mathrm{MPa} \pm 12,58)$ and Single Bond $(52,59 \mathrm{MPa} \pm 17,67)$ systems presented a adhesive strength similar and statistically higher than the Clearfi Liner Bond $2 \mathrm{~V}(32,90 \mathrm{MPa} \pm 12,43)$ system; when comparing the adhesive strength to both central and peripheral dentin, the three materials did not present any statistically significant differences. 